\title{
Centriole growth is not limited by a finite pool of components, but is limited by the Cdk1/Cyclin-dependent phosphorylation of Ana2/STIL
}

\author{
Thomas L. Steinacker ${ }^{1,2, \$}$, Siu-Shing Wong ${ }^{1, \$}$, Zsofia A. Novak $^{1}$, Saroj Saurya ${ }^{1}$, Lisa \\ Gartenmann ${ }^{1}$, Eline J.H. van Houtum ${ }^{1}$, Judith R. Sayers ${ }^{1,3}$, B. Christoffer Lagerholm ${ }^{4}$, \\ Jordan W. Raff ${ }^{1^{*}}$
}

\section{Affiliation:}

${ }^{1}$ Sir William Dunn School of Pathology, University of Oxford, Oxford, UK

2Present address: Institute of Molecular Biotechnology of the Austrian Academy of Sciences (IMBA), Vienna Biocenter (VBC), Vienna, Austria

${ }^{3}$ Present address: Department of Physiology, Anatomy and Genetics (DPAG), University of Oxford, Oxford, UK

${ }^{4}$ Kennedy Institute of Rheumatology, University of Oxford, Oxford, UK.

\$These authors contributed equally to this work

* Correspondence: jordan.raff@path.ox.ac.uk

Key Words: centriole, centrosome, Ana2/STIL, organelle growth, cell cycle, fluorescence correlation spectroscopy 


\section{Abstract}

Centrioles duplicate once per cell cycle but it is unclear how daughter centrioles assemble at the right time and place and grow to the right size. Here we show that in early Drosophila embryos the cytoplasmic concentrations of the key centriole assembly proteins Asl, Plk4, Ana2, Sas- 6 and Sas- 4 are low, but remain constant throughout the assembly processindicating that none of them are limiting for centriole assembly. The cytoplasmic diffusion rate of Ana2/STIL, however, increased significantly towards the end of S-phase as Cdk/Cyclin activity in the embryo increased. A mutant form of Ana2 that cannot be phosphorylated by Cdk/Cyclins did not exhibit the diffusion rate change, and allowed daughter centrioles to grow for an extended period. Thus, the Cdk1/Cyclin-dependent phosphorylation of cytoplasmic Ana2 seems to reduce the efficiency of daughter centriole assembly towards the end of Sphase. This helps to ensure that daughter centrioles stop growing at the correct time, and presumably also helps to explain why centrioles cannot duplicate during mitosis. 


\section{Introduction}

Centrioles form cilia and centrosomes, two organelles that are important organisers of the cell (Nigg and Raff, 2009; Conduit et al., 2015; Loncarek and Bettencourt-Dias, 2018; Breslow and Holland, 2019; Bornens, 2021; Vasquez-Limeta and Loncarek, 2021). Most new-born cells inherit a single pair of centrioles and, in cycling cells, these centrioles separate and then duplicate when a new daughter centriole grows from the side of each existing mother centriole. It is well established that centrioles normally duplicate in S-phase and that mitosis appears to be refractory for duplication (Lacey et al., 1999; Hinchcliffe et al., 1999; Hinchcliffe and Sluder, 2001). The mechanisms that enforce this strict cell cycle regulation remain largely obscure.

Recent studies have identified a conserved pathway of centriole duplication (Nigg and Holland, 2018; Gönczy and Hatzopoulos, 2019). Plk4 is the key enzyme that promotes centriole assembly (Bettencourt-Dias et al., 2005; Habedanck et al., 2005), and it is recruited to centrioles by Asl in flies (Dzhindzhev et al., 2010) and SPD-2 in worms (Kemp et al., 2004; Shimanovskaya et al., 2014), and a combination of the two (CEP152 and CEP192, respectively) in humans (Sonnen et al., 2013; Kim et al., 2013). Plk4 is initially recruited in a ring around the mother centriole, but it rapidly becomes focused at a single site on the mother centriole that specifies where the daughter centriole will assemble (Arquint and Nigg, 2016; Leda et al., 2018; Takao et al., 2019; Yamamoto and Kitagawa, 2021). Plk4 phosphorylates Ana2/STIL (fly/human) to allow its efficient interaction with Sas-6 (Dzhindzhev et al., 2014, 2017; Ohta et al., 2014, 2018; Kratz et al., 2015; Moyer et al., 2015; Moyer and Holland, 2019), and these proteins cooperate to form the central cartwheel structure upon which the rest of the centriole is assembled (Kitagawa et al., 2011; van Breugel et al., 2011). 
It is unclear how daughter centrioles grow to the correct size. In flies and worms, the central cartwheel and centriole MTs grow to approximately the same size (Schwarz et al., 2018; Gonzalez et al., 1998), and in Drosophila syncytial embryos both structures appear to abruptly stop growing in mid-late S-phase (Aydogan et al., 2018). The centriolar levels of Plk4 oscillate during each round of centriole duplication in fly embryos and human cultured cells (Aydogan et al., 2020; Takao et al., 2019). In fly embryos, this oscillation is normally entrained by the Cdk/Cyclin cell cycle oscillator (CCO) that times the rapid nuclear cycles in these syncytial embryos, and this ensures that Plk4 is maximally recruited to the centrioles in early S-phase, when the centrioles are starting to grow. However, the rather abrupt cessation of centriole growth in fly embryos during mid-late-S-phase (Aydogan et al., 2018) may be hard to reconcile with the more gradual decline in centriolar Plk4 levels (Aydogan et al., 2020). We suspected, therefore, that other mechanisms must work together with the PIk4 oscillation to ensure that the centrioles in fly embryos co-ordinately stop growing in late S-phase.

Quantitative Mass Spectroscopy has revealed that several key centriole assembly proteins (e.g. CEP152/Asl, PLK4/Plk4, SAS6/Sas-6, STIL/Ana2 and CPAP/Sas-4) (human/fly nomenclature) are present at a very low levels in human cells (Bauer et al., 2016), raising the possibility that one or more of these proteins might become depleted from the cytoplasm as centriole assembly proceeds. In worm embryos, such a "limiting component" mechanism is thought to set centrosome size, as the amount of pericentriolar material (PCM) that assembles around the centrioles appears to be set by a limiting pool of the key PCM-building block SPD-2 (Decker et al., 2011)-a protein that in worms is also essential for centriole duplication (Kemp et al., 2004). Alternatively, in human cells Cdk1/Cyclin B has been shown 
to inhibit centriole duplication by directly competing with Plk4 for binding to the central coiled-coil domain (CC) of STIL/Ana2 (Zitouni et al., 2016), a mechanism that should lead to the gradual inhibition of centriole duplication as Cdk1/Cyclin B levels rise during S-phase in the early fly embryo (Deneke et al., 2016). However, there is some question as to whether the interaction between Plk4 and the STIL/Ana2 CC is essential, as the CC is also required for STIL multimerization - which is essential for STIL/Ana2 function (Cottee et al., 2015; David et al., 2016) -and structural studies suggest that multimerization is incompatible with binding to PLK4 (Cottee et al., 2017). Moreover, Ana2/STIL proteins can also bind Plk4 through their C-terminal regions, independently of the CC (Ohta et al., 2018; McLamarrah et al., 2018). Thus, a direct competition between PIk4 and Cdk1/Cyclin B for binding to the CC of STIL/Ana2 seems unlikely to be a universal mechanism that suppresses centriole duplication when Cdk1/Cyclin B levels are high.

Here we have used Fluorescence Correlation Spectroscopy (FCS) (Kim et al., 2007) and Peak Counting Spectroscopy (PeCoS) (Aydogan et al., 2020) to monitor how the cytoplasmic concentration and/or biophysical characteristics of the core centriole duplication proteins in Drosophila (Asl, Plk4, Sas-6, Ana2 and Sas-4) change during the nuclear cycle in living early embryos. We find that although the cytoplasmic concentration of all these proteins is low (likely 1-40nM range), their concentration remains constant as the centrioles assemble. This suggests that none of these proteins act as limiting components that slow centriole growth because they become depleted from the cytoplasm. Strikingly, however, we noticed that the cytoplasmic diffusion rate of Ana2 increased significantly towards the end of S-phase, and this seemed to depend, at least in part, upon its phosphorylation by Cdk/Cyclins. This phosphorylation appears to inhibit Ana2's ability to promote centriole duplication in late S- 
bioRxiv preprint doi: https://doi.org/10.1101/2022.02.15.480489; this version posted February 16, 2022. The copyright holder for this

preprint (which was not certified by peer review) is the author/funder, who has granted bioRxiv a license to display the preprint in perpetuity. It is made available under aCC-BY-NC 4.0 International license.

phase, when Cdk/Cyclin levels are rising rapidly in preparation for mitosis. We propose that this novel mechanism helps to ensure that centrioles stop growing at the appropriate time, and likely also helps to ensure that centrioles cannot duplicate in mitosis when Cdk1/cyclin levels are high. 


\section{Results}

\section{Generating tools for FCS measurements}

To analyse the behaviour of the core duplication proteins under conditions as close to physiological as possible we fluorescently tagged Asl, Plk4, Sas-6, Ana2 and Sas-4 at their endogenous loci with monomeric-NeonGreen (mNG) using CRISPR/Cas9 (Port et al., 2014). The fusion proteins all localised to centrioles (Figure S1), and western blotting confirmed that they were expressed at similar levels to their endogenous proteins, except for mNG-Ana2 and Ana2-mNG, which appeared to be overexpressed by $\sim 2-4 X$ when compared to the endogenous untagged protein (Figure S2) - note that we could not examine Plk4 in this way, as it cannot be detected by western blotting. We failed to generate a Plk4-mNG knock-in, and an mNG-Plk4 knock-in line laid embryos that exhibited consistent centriole overduplication, suggesting that the fusion was overexpressed (yellow arrows, Figure S1). We therefore chose to further analyse Plk4 behaviour using a transgenic line (ePlk4-mNG) (Aydogan et al., 2020) in which the centrioles do not overduplicate (red box, Figure S1). We also examined transgenic lines expressing either monomeric-NeonGreen ( $\mathrm{mNG}$ ) or dimeric-NeonGreen ( $\mathrm{dNG}$ ) expressed from the Sas-6 promoter that were not fused to any target protein; these serve as inert controls that should not interact meaningfully with other proteins in the cytoplasm.

The cytoplasmic concentration of the Drosophila core centriole duplication proteins remains $\underline{\text { relatively constant as daughter centrioles assemble in S-phase }}$

Centrioles and centrosomes grow to a consistent size, and in worm embryos a limiting pool of SPD-2 is thought to set this size as it becomes sequestered at the growing centrosomes and depleted from the cytoplasm (Decker et al., 2011). To test whether a similar mechanism might help to limit centriole growth in the early Drosophila embryo, we used FCS to monitor the 
cytoplasmic concentration of the core duplication proteins as the centrioles assembled during S-phase of nuclear cycle 12. Control experiments in which we altered the genetic dosage of fluorescent fusion proteins confirmed that FCS can be used to measure cytoplasmic concentration changes in the early Drosophila embryo (Figure S3).

As a control, we first examined the behaviour of untagged $\mathrm{mNG}$ and $\mathrm{dNG}$ expressed from the Sas-6 promoter (Figure 1A). In both cases, the concentration of mNG or dNG remained relatively constant throughout nuclear cycle 12 , although there was a tendency for their concentration to dip slightly during early S-phase, to rise slightly as the embryos entered mitosis, and then dip again as the embryos entered the next cycle. These proteins are biologically inert, so we suspect that these minor fluctuations occur because the biophysical properties of the cytoplasm change slightly as the embryos progress through the nuclear cycle. In support of this possibility, we observed a broadly similar pattern when we examined the concentration of Asl-mNG, mNG-Sas-6, Sas-6-mNG, Sas-4-mNG, mNG-Ana2 or Ana2-mNG (Figure 1B). The average cytoplasmic concentration of all these proteins was low: $7-15 \mathrm{nM}$ for the Asl, Sas-6 and Sas-4 knock-in lines and 18-42nM for the Ana2 knock-in lines. As the mNG-knock-ins at the Ana2 locus appear to be $2-4 \mathrm{X}$ overexpressed, we conclude that these core centriole duplication proteins are likely present in the $\sim 5-20 \mathrm{nM}$ concentration range, which seems surprisingly low but is in agreement with previous estimates from human cells (Bauer et al., 2016) (see Discussion). Importantly, the concentration of all these proteins remained relatively constant over the entire nuclear cycle, while exhibiting the same general tendency as the mNG and dNG controls to fluctuate slightly. 
We showed previously that the concentration of a PIk4-mNG fusion driven transgenically from its own promoter (ePIk4-mNG) was too low to be measured by FCS (Aydogan et al., 2020), and this was also true of our mNG-PIk4 CRISPR/Cas9 knock-in line, even though this protein appeared to be overexpressed, leading to centriole overduplication (Figure S1). Interestingly, a previous study using a similar microscopy set-up but a different mNG-Plk4 knock-in line used FCS to estimate a concentration of $\sim 7-8 \mathrm{nM}$ (Nabais et al., 2021). As we could not use FCS, we used Peak-Counting Spectroscopy (PeCoS) (Aydogan et al., 2020) to monitor how the cytoplasmic concentration of the transgenically expressed ePlk4-mNG fusion protein varied during nuclear cycle 12 (as the centrioles do not overduplicate in this line). This data was noisy, but we detected no significant change in the cytoplasmic concentration of ePIk4-mNG during nuclear cycle 12 (Figure 1C). Taken together, these data suggest that the cytoplasmic concentration of all the core centriole duplication proteins remains relatively constant during nuclear cycle 12 , meaning that none of them are likely to act as limiting components for centriole growth.

The cytoplasmic diffusion rate of Ana2 increases as embryos exit S-phase and enter mitosis To test whether any of the core duplication proteins might change their biophysical properties as centrioles assembled we used FCS to see if their diffusion rates changed during nuclear cycle 12 (Figure 2) (note that PeCoS does not allow us to extract this information for Plk4). The diffusion rate of the inert $\mathrm{mNG}$ and $\mathrm{dNG}$ controls did not change significantly over the cycle (Figure 2A), but for Asl, Sas-6 and Sas-4 it tended to increase slightly as S-phase progressed, and then decrease slightly during mitosis and into the next nuclear cycle (Figure 2Bi-iv). This tendency was not, or was only just, statistically significant, but it was consistent, and no similar trend was observed with the mNG and dNG controls. This suggests that the 
average cytoplasmic diffusion rate of these three core duplication proteins may increase subtly as S-phase progresses-perhaps indicating that their ability to interact with other cytoplasmic proteins gradually decreases during the assembly process.

Strikingly, and in contrast to the other core duplication proteins, the diffusion rate of both the mNG-Ana2 and Ana2-mNG fusions remained relatively constant in early-mid S-phase, but then increased sharply in late S-phase as the embryos prepared to enter mitosis, before falling sharply again at the start of the next cycle (pink boxes, Figure 2Bv+vi).

The change in Ana2 diffusion rate during the nuclear cycle does not appear to depend on

\section{Ana2's ability to multimerise or to bind to Sas- 6}

Ana2/STIL proteins can homo-oligomerise (Arquint et al., 2015; Cottee et al., 2015; Rogala et al., 2015; David et al., 2016). To test if Ana2's homo-oligomerisation state changed during nuclear cycle 12, we used FCS to monitor Ana2's "photon-count rate per molecule" (CPM). This is the average number of photons generated by each fluorescently tagged molecule that passes through the FCS observation volume-so the CPM of a fluorescent dimer should be nearly twice that of a fluorescent monomer (the photochemistry means the fluorescence will not precisely double) (Dunsing et al., 2018). As a control, dNG exhibited a CPM that was 1.7fold higher than mNG (Figure S4A). Interestingly, Ana2-mNG fusions had an average CPM that was slightly higher than that of dNG (Figure S4A), suggesting that cytoplasmic Ana2 exists in a homo-oligomeric state that is, on average, slightly larger than a dimer. However, Ana2's CPM did not change significantly during nuclear cycle 12 , and neither did the CPM of the controls or other core duplication proteins (Figure S4B,C). Thus, the change in Ana2's diffusion rate during the nuclear cycle is not due to a change in its homo-oligomerisation state. 
We wanted to test if Ana2's ability to multimerise or to interact with Sas-6 was required for the change in Ana2's diffusion rate during the nuclear cycle. The central coiled-coil (CC) region of Ana2/STIL proteins is essential for their homo-oligomerisation (Arquint et al., 2015; Cottee et al., 2015; Rogala et al., 2015), while the conserved STAN domain is required for Ana2's interaction with Sas-6 (Dzhindzhev et al., 2014; Ohta et al., 2014; Kratz et al., 2015; Moyer et al., 2015). We generated flies transgenically expressing forms of Ana2 in which either the CC (eAna2( $\triangle C C)-m N G)$ or STAN domain (eAna2( $\triangle S T A N)-m N G)$ was deleted (Figure $3 A$ ).

As Ana2 is essential for centriole duplication, ana $2^{-/-}$mutant females lack centrioles and are uncoordinated due to the lack of cilia in their sensory neurons-so they cannot mate or lay embryos (Stevens et al., 2010a; Basto et al., 2006). As the CC and STAN domains are essential for Ana2 function (Cottee et al., 2015), the mutant transgenes did not rescue this uncoordinated phenotype, so to analyse the behaviour of these proteins we generated heterozygous fly lines expressing one copy of the mNG-tagged WT or mutant Ana2 protein together with one copy of the WT untagged ana2 gene. All the fusion proteins were expressed at similar levels to the endogenous protein (Figure S5). The average diffusion rate of both truncated proteins at the start of S-phase was elevated compared to WT eAna2-mNG - from $\sim 2.5 \mu \mathrm{m}^{2} / \mathrm{s}$ (WT) to $\sim 9 \mu \mathrm{m}^{2} / \mathrm{s}(\Delta C C)$ and $\sim 3.5 \mu \mathrm{m}^{2} / \mathrm{s}(\Delta S T A N)$ - but the significant increase in diffusion rate in late-S-phase/early-mitosis was still detectable, although this was somewhat suppressed for the $\triangle C C$ mutant (Figure $3 B$ ). Thus, the change in Ana2's cytoplasmic diffusion rate may be slightly enhanced if the protein can homo-oligomerise, but it does not depend on its interaction with Sas-6. A caveat to this conclusion is that these experiments are performed in the presence of WT protein that may oligomerise with the mutant proteins- 
although the rapid diffusion of Ana2- $\triangle C C$ suggests that it cannot form homo-oligomers, consistent with previous structural studies (Cottee et al., 2015).

The change in Ana2 diffusion during the nuclear cycle appears to depend, at least in part, on phosphorylation by Cdk/Cyclins

We wondered whether the diffusion rate increase of Ana2 might be caused by its cell-cycle specific phosphorylation. CDK1-Cyclin B is a potential candidate kinase, as it can phosphorylate vertebrate STIL (Zitouni et al., 2016) and, in the early Drosophila embryo, Cdk/Cyclin activity gradually increases as S-phase progresses (Deneke et al., 2016). To test the potential role of Cdk1/Cyclin-dependent phosphorylation, we generated fly lines transgenically expressing a mutant form of Ana2 in which all 12 potential Cdk phosphorylation sites (S/T-P motifs) were mutated to non-phosphorylatable alanine (A-P) (eAna2(12A)-mNG) (Figure 3A). Mass Spectroscopy studies have identified peptides phosphorylated at 10 of these 12 sites in extracts from S2 cells or embryos (McLamarrah et al., 2018; Dzhindzhev et al., 2017), indicating that many of these sites can be phosphorylated in vivo, and we found that short peptides containing two of the most conserved sites ( 284 and T301) can be specifically and efficiently phosphorylated by recombinant Cdk1/Cyclin B in vitro (Figure S6).

The eAna2(12A)-mNG transgene fully rescued the defects in ana $2^{-/}$flies caused by the lack of centrioles: rescued flies were as coordinated as WT controls and laid embryos that hatched at similar rates (Figure S7A,B). Moreover, we detected no centriole defects in EM studies of ana $2^{-/}$mutant wing disc cells rescued by transgenically expressing an untagged version of eAna2(12A) (Figure S7C). We conclude that the Ana2(12A) protein is largely functional. 
We next used FCS to compare the cytoplasmic diffusion behaviour of the WT and mutant eAna2-mNG fusions throughout nuclear cycle 12. Transgenic WT eAna2-mNG was expressed at similar levels to Ana2-mNG in the CRISPR knock-in line (Figure S8A), and it exhibited the same dramatic rise and fall in diffusion rate (Figure 3Bi and $3 \mathrm{Ci}$ ) that we observed previously with the Ana2-mNG CRISPR knock-in lines (Figure 2Bvi). The transgenic eAna2(12A)-mNG protein was expressed at similar levels (Figure S8B), but the rise and fall in its diffusion rate during nuclear cycle 12 was much less obvious and was not statistically significant (Figure 3Cii). We conclude that phosphorylation of Ana2 by Cdk1/cyclins could play a part in Ana2's cell cycle-specific diffusion change.

\section{Ana2(12A) continues to accumulate at centrioles until the entry into mitosis}

To test whether the $12 \mathrm{~A}$ mutations influence Ana2's interaction with centrioles, we compared the dynamics of Ana2-mNG and eAna2(12A)-mNG centriolar recruitment during nuclear cycle 12 (Figure 4A). Similar to the other core centriole cartwheel protein Sas-6 (Aydogan et al., 2018), WT Ana2-mNG initially accumulated at centrioles in a near-linear fashion during early S-phase, but whereas eSas-6-GFP incorporation usually plateaued by mid-S-phase (Aydogan et al., 2018), Ana2 continued to accumulate at the centrioles until 1-2 minutes before NEB, when its levels peaked and then started to decline rapidly (black line, Figure $4 \mathrm{~A}$ ). There was a strong correlation $(r>0.98 ; p<0.0001)$ between the period of Ana2 accumulation at the centriole and S-phase length over nuclear cycles 11-13 (Figure 4C). This suggests that the core Cdk/Cyclin cell cycle oscillator (CCO) - that drives the nuclear cycles in these embryos and sets S-phase length (Farrell and O'Farrell, 2014)-influences the timing of Ana2 recruitment to the centrioles, supporting our hypothesis that Ana2 may be a direct target of Cdk/Cyclins. 
Surprisingly, eAna2(12A)-mNG was present at higher levels on centrioles than WT Ana2-mNG (red line, Figure 4A), even though eAna2(12A)-mNG was expressed at similar, or if anything slightly lower, levels than Ana2-mNG (Figure S8B). Moreover, whereas centriolar levels of WT Ana2-mNG peaked well before NEB, eAna2(12A)-mNG levels kept increasing until approximately the onset of mitosis (Figure 4A,B). This behaviour is consistent with the possibility that Cdk1 normally phosphorylates Ana2 towards the end of S-phase to inhibit Ana2's recruitment to centrioles. Importantly, centriolar Ana2(12A)-mNG levels still started to decline once the embryos had actually entered mitosis (Figure $4 \mathrm{~A}$ ), so there was still a strong correlation $(r>0.91, p<0.0001)$ between the period of Ana2(12A) growth and S-phase length (Figure 4C). This indicates that other mechanisms must normally help to inhibit Ana2's accumulation at centrioles during mitosis, potentially explaining why centriole duplication is only subtly perturbed in the presence of Ana2(12A).

\section{Centrioles grow for a longer period, but at a slower rate, in eAna2(12A) embryos}

To assess how Ana2(12A) might influence the assembly of the centriole cartwheel we analysed the incorporation of the core centriole cartwheel protein Sas-6-mNG in embryos laid by females transgenically expressing two copies of untagged eAna2(12A) in the ana $2^{-/}$mutant background (Figure 5). In WT embryos, we observed a similar Sas-6-mNG incorporation profile as we previously described for eSas-6-GFP (Aydogan et al., 2018), and regression analysis confirmed that this was best-fit by a linear increase during early-mid-S-phase followed by a plateau (presumably when the daughter centrioles reach their final size) (Figure 5A). Sas-6mNG growth kinetics were significantly altered in embryos expressing Ana2(12A) (Figure 5A). Strikingly, the centrioles continued to incorporate Sas- 6 for a significantly longer period 
(Figure $5 \mathrm{Bi}, \mathrm{ii}$ ), consistent with our hypothesis that if Ana2 cannot be phosphorylated by Cdk1/cyclin its ability to promote centriole growth is not inhibited efficiently in late S-phase.

Unexpectedly, however, significantly less Sas-6-mNG was recruited to centrioles in embryos expressing Ana2(12A) (Figure 5A,Biv-vi), and this was not due to any change in the total levels of Sas-6-mNG in the Ana2(12A) embryos (Figure 5C). Moreover, and potentially as a result of the decreased Sas-6 recruitment, the centrioles grew at a significantly slower rate in the presence of Ana2(12A) (Figure 5A,Biii). We currently do not understand why the expression of Ana2(12A) inhibits the recruitment of Sas- 6 to centrioles (see Discussion), but this reduced recruitment of Sas-6-mNG seems unlikely to explain why the period of Sas-6-mNG incorporation is prolonged in these embryos.

\section{Ana2(12A) does not appear to influence the behaviour of the Plk4 oscillation at centrioles}

We have previously shown that centriole growth kinetics are influenced by an oscillation in Plk4 levels at the centriole (Aydogan et al., 2020) and that, as in the Ana2(12A) embryos, the centrioles grow slowly but for a longer period when the genetic dose of Plk4 is halved. We therefore tested whether the centriolar Plk4 oscillation was altered in the Ana2(12A) embryos. Unfortunately, embryos laid by females expressing ePIk4-mNG and eAna2(12A) in the absence of any endogenous WT Ana2 failed to develop, so we had to perform this experiment in embryos laid by heterozygous females expressing one copy of eAna2(12A) in the presence of one copy of the endogenous WT ana2 gene. The centriolar Plk4 oscillation in both sets of embryos was very similar, indicating that the expression of eAna2(12A) does not dramatically influence the Plk4 oscillation, at least under these conditions (Figure 6). 


\section{Ana2(12D/E) is not recruited efficiently to centrioles}

Finally, we tested whether mutating the $12 \mathrm{~S} / \mathrm{T}-\mathrm{P}$ motifs in Ana2 to potentially phosphomimicking D/E-P motifs influenced Ana2's behaviour. The transgenic eAna2(12D/E)-mNG fusion was expressed at similar levels to WT Ana2-mNG and eAna2(12A)-mNG (Figure S8B), and it rescued the uncoordinated phenotype of ana2\% mutant flies, indicating that the mutant protein can support centriole duplication and cilia assembly (Figure S7A). However, mutant females 'rescued' by eAna2(12D/E)-mNG were sterile and laid embryos that failed to develop (Figure S7B). We have observed this phenotype several times previously with mutations in core centriole duplication proteins that inhibit the efficiency of centriole or centrosome assembly, but do not entirely prevent it (Cottee et al., 2015; Novak et al., 2016; Alvarez Rodrigo et al., 2019; Alvarez-Rodrigo et al., 2021). This seems to be because reducing the efficiency of centriole or centrosome assembly is lethal to the early embryo (where centrioles and centrosomes have to assemble in only a few minutes), but not to somatic cells (where centrioles and centrosomes can assemble over a much longer period-presumably allowing these cells to better compensate for any inefficiency in the assembly process).

To probe eAna2(12D/E)-mNG centriole kinetics we therefore examined embryos laid by females expressing one copy of this transgene together with one copy of the endogenous untagged WT ana2 gene. These embryos developed normally, but eAna2(12D/E)-mNG was recruited to centrioles very poorly (Figure 7). This is consistent with our hypothesis that phosphorylation at one or more of these S/T-P sites inhibits, but does not completely block, Ana2 recruitment to and/or maintenance at centrioles. 


\section{Discussion}

\section{Core centriole duplication proteins are present at low concentrations in the embryo}

Several studies have attempted to estimate the cytoplasmic levels of the core centriole duplication proteins in human cells. Keller et al., used FCS to estimate a Sas-6 cytoplasmic concentration of $\sim 80-360 \mathrm{nM}$, depending on cell cycle stage (Keller et al., 2014), while Bauer et al. used quantitative MS to estimate that the total number of Plk4, Sas-6, CEP152/Asl, and STIL/Ana2 molecules in human cultured cells was $\sim 2000-20,000-$ which was $\sim 10-15 X$ lower than the number of $\gamma$-tubulin molecules (Bauer et al., 2016). If the volume of a HeLa cell is $\sim 4000 \mu \mathrm{m}^{3}$ (Zhao et al., 2008), these numbers equate to a concentration of $\sim 1-10 \mathrm{nM}$. This seems low, but might reflect that somatic cells only have to assemble two tiny daughter centrioles during a cell cycle that often lasts many hours.

Given that the early Drosophila embryo assembles 6000 centrioles in less than two hours (Foe and Alberts, 1983), we anticipated that centriole assembly proteins would be stored at higher concentrations, but this does not appear to be the case. We estimate that Asl, Sas-6, Ana2 and Sas-4 are present in the $\sim 5-20 n M$ range (note that $20 \mathrm{nM}$ would be the concentration of the Ana2 oligomer), while the cytoplasmic concentration of Plk4 is so low that we cannot measure it by FCS. These concentrations are similar to the MS estimates in human cell lines (Bauer et al., 2016), suggesting that the early embryo does not store a large surplus of any of these proteins. As many of these building blocks have a tendency to selfassemble into larger structures (Stevens et al., 2010b; Montenegro Gouveia et al., 2018; Kim et al., 2019; Gartenmann et al., 2020) this low cytoplasmic concentration presumably helps to ensure that these proteins only assemble into macromolecular structures at the kinetically 
favourable site defined by Plk4 on the side of the mother centriole (Lopes et al., 2015; Banterle et al., 2021).

The concentration of the core centriole duplication proteins does not change significantly during the centriole assembly process

How cellular structures grow to the correct size is a topic of great interest (Marshall, 2015; Reber and Goehring, 2015). In C. elegans embryos mitotic centrosome size appears to be set by a limiting cytoplasmic pool of the centrosome building block SPD-2 (Decker et al., 2011)although this does not appear to be the case for Spd-2 in early Drosophila embryos (Wong et al., 2021). The concept of setting organelle size with a limiting pool of building blocks is attractive, as it allows size to be controlled without the need for a specific mechanism to measure it (Goehring and Hyman, 2012). Our data, however, suggests that such a mechanism does not regulate centriole size in Drosophila embryos. This is perhaps surprising, as the cytoplasmic concentration of all these proteins appears to be low. We conclude that either the amount of these proteins sequestered at centrioles is insignificant compared to the amount in the cytoplasm (a plausible scenario given the large volume of the embryo and small volume of the centriole), and/or that the rate of protein sequestration and degradation in the embryo is finely balanced by the rate of new protein synthesis so that a constant cytoplasmic concentration is maintained.

Cdk/Cyclin phosphorylates Ana2 to modulate its ability to promote centriole duplication In vertebrates, STIL binds and is phosphorylated by CDK1/Cyclin B kinase (Zitouni et al., 2016). The function of this phosphorylation is unclear, but it is thought that binding to (rather than phosphorylation by) CDK1/Cyclin B keeps STIL in an inactive state because Cdk1/Cyclin B binds 
to the same central coiled-coil (CC) region of STIL that binds PLK4 (Arquint et al., 2015). Our data suggests that in fly embryos Cdk1/Cyclin activity inhibits the growth of the daughter centriole by phosphorylating, rather than binding to, Ana2. Ana2's diffusion rate increases as Cdk/Cyclin activity increases towards the end of S-phase, and this increase is abrogated if Ana2 cannot be phosphorylated by Cdk1/Cyclin (due to mutation of all $12 \mathrm{~S} / \mathrm{T}-\mathrm{P}$ motifs). This Ana2(12A) mutant protein can support centriole duplication, but it continues to be recruited to the duplicating centrioles for an unusually long period of time, allowing the protein to accumulate at centrioles to abnormally high levels. Mutating these 12 motifs to phosphomimicking $\mathrm{D} / \mathrm{E}$ motifs has the opposite effect: Ana2(12D/E) is recruited poorly to centrioles and it can no longer support the rapid cycles of centriole duplication in the early embryo. While we cannot rule out that the $12 \mathrm{~A}$ and 12D/E mutations influence some other aspect of Ana2 function, their opposing effects suggests that they largely perturb Ana2 function by preventing or mimicking protein phosphorylation, respectively.

We do not know how the phosphorylation of Ana2 by Cdk1/Cyclins influences centriole duplication, but we speculate that it decreases Ana2's affinity for one or more of the other core centriole duplication proteins to which it binds (e.g. Sas-6, Plk4 or Sas-4). This scenario would explain why Ana2's average cytoplasmic diffusion rate normally increases towards the end of S-phase, and why this increase is abrogated in the $12 \mathrm{~A}$ mutant. Our FCS analysis suggests that the average cytoplasmic diffusion rate of all the core duplication proteins we analysed here increases slightly as S-phase progresses, hinting that their cytoplasmic interactions might be generally suppressed by increasing Cdk/Cyclin activity. In embryos expressing Ana2(12A), a failure to efficiently inhibit Ana2's interactions with one or more other duplication proteins towards the end of S-phase would allow Ana2(12A) and Sas-6 to 
continue to incorporate into centrioles for an extended period. Such a mechanism could also explain previous observations that inhibiting Cdk1 activity can lead to centriole or spindlepole-body overduplication (Haase et al., 2001; Vidwans et al., 2003).

Unexpectedly, expressing Ana2(12A) significantly decreased the amount of Sas-6 recruited to centrioles. This is surprising because Ana2 is thought to help recruit Sas- 6 to centrioles, and centriolar Ana2(12A) levels are abnormally high. An intriguing interpretation of this finding is that while the phosphorylation of Ana2 by Cdk/Cyclins in late S-phase helps to inhibit centriole duplication, Cdk/Cyclin-dependent phosphorylation of Ana2 in early S-phase (presumably on different sites) might help promote centriole duplication by increasing the efficiency with which Ana2 interacts with Sas-6 to recruit it to centrioles. The S-phaseinitiating CDK2/Cyclin kinase is required for centriole duplication (Hinchcliffe et al., 1999; Lacey et al., 1999; Meraldi et al., 1999), but it's relevant substrate(s) are largely unknown. Perhaps CDK2/Cyclins phosphorylate Ana2 in early S-phase to promote centriole duplication, while CDK1/Cyclins phosphorylate Ana2 from late-S-phase onwards to inhibit centriole duplication. Alternatively, the differential phosphorylation of different Cdk/Cyclin targets by different levels of Cdk/Cyclin activity plays an important part in ordering cell cycle events (Swaffer et al., 2016). Perhaps low (early-S-phase-like) levels of Cdk/Cyclin activity phosphorylate Ana2 on certain sites to promote centriole assembly, while higher levels phosphorylate Ana2 at additional sites to inhibit centriole assembly. In either scenario, Ana2 would act as a 'rheostat', responding to global changes in Cdk/Cyclin activity to coordinate centriole duplication with cell cycle progression. Plk4 phosphorylates Ana2 in an ordered fashion at multiple sites to elicit sequential changes in Ana2 behaviour (McLamarrah et al., 2018, 2020; Dzhindzhev et al., 2017), so perhaps Cdk/Cyclins do the same. 
In summary, our studies indicate that at least two mechanisms cooperate to help ensure that centrioles duplicate at the right time and place and then grow to the right size in Drosophila embryos: (1) the periodic recruitment of Plk4 to centrioles ensures that a single burst of Plk4 activity in late-mitosis/early S-phase drives a single round of daughter centriole assembly during each nuclear cycle (Aydogan et al., 2020); (2) The increase in global Cdk1/Cyclin activity during S-phase gradually inhibits the ability of Ana2 to promote centriole assembly, helping to switch off centriole growth in late S-phase, and likely helping to ensure that the centrioles cannot duplicate in mitosis. We note, however, that the potential regulation of Ana2 by Cdk/Cyclin-dependent phosphorylation cannot be essential for coordinating efficient centriole duplication in flies, as flies expressing only Ana2(12A) can duplicate centrioles quite normally. Thus, the Cdk1/Cyclin-dependent phosphorylation of Ana2 appears to influence the efficiency of centriole duplication, but it is not essential for maintaining the normal timing of centriole duplication. This is presumably because multiple additional regulatory mechanisms - such as the oscillation in centriolar Plk4 levels-work together to ensure that daughter centriole assembly still occurs at the right place and time even when Ana2 cannot be phosphorylated by Cdk/Cyclins. 


\section{Acknowledgements:}

We are grateful to Alan Wainman for help with microscopy as part of the Micron Oxford Advanced Bioimaging Unit-partly funded by a Strategic Award from the Wellcome Trust (107457). We thank members of the Raff Laboratory for advice, discussion and for critically reading the manuscript. The research was funded by a Wellcome Trust Senior Investigator Award (215523) to J.W.R., a CRUK Oxford Centre Prize DPhil Studentship (C5255/A23225), a Balliol Jason Hu Scholarship and a Clarendon Scholarship (to S.S.W.)., and an MRC 4-year studentship (MR/N013468/1) to J.L.S.

\section{Author contributions:}

This study was conceptualised by T.L.S., S.S.W., and J.W.R. Investigation was done by T.L.S., S.S.W., S.S., Z.A.N., L.G., E. v-H., and J.S. Computational analysis pipelines were developed by S.S.W. and B.C.L. Data was analysed by all authors. The project was supervised and administered by J.W.R. The manuscript was initially drafted by T.L.S., S.S.W., and J.W.R. and all authors contributed to the editing of the manuscript.

\section{Declaration of interests:}

The authors declare no competing interests. 


\section{References}

Alvarez Rodrigo, I., T.L. Steinacker, S. Saurya, P.T. Conduit, J. Baumbach, Z.A. Novak, M.G. Aydogan, A. Wainman, and J.W. Raff. 2019. Evidence that a positive feedback loop drives centrosome maturation in fly embryos. Elife. 8. doi:10.7554/eLife.50130.

Alvarez-Rodrigo, I., A. Wainman, S. Saurya, and J.W. Raff. 2021. Ana1 helps recruit Polo to centrioles to promote mitotic PCM assembly and centriole elongation. Journal of Cell Science. 134. doi:10.1242/jcs.258987.

Arquint, C., A.-M. Gabryjonczyk, S. Imseng, R. Böhm, E. Sauer, S. Hiller, E.A. Nigg, and T. Maier. 2015. STIL binding to Polo-box 3 of PLK4 regulates centriole duplication. Elife. 4:1948. doi:10.7554/eLife.07888.

Arquint, C., and E.A. Nigg. 2016. The PLK4-STIL-SAS-6 module at the core of centriole duplication. Biochem. Soc. Trans. 44:1253-1263. doi:10.1042/BST20160116.

Aydogan, M.G., T.L. Steinacker, M. Mofatteh, Z.M. Wilmott, F.Y. Zhou, L. Gartenmann, A. Wainman, S. Saurya, Z.A. Novak, S.-S. Wong, A. Goriely, M.A. Boemo, and J.W. Raff. 2020. An Autonomous Oscillation Times and Executes Centriole Biogenesis. Cell. 181:1566-1581.e27. doi:10.1016/j.cell.2020.05.018.

Aydogan, M.G., A. Wainman, S. Saurya, T.L. Steinacker, A. Caballe, Z.A. Novak, J. Baumbach, N. Muschalik, and J.W. Raff. 2018. A homeostatic clock sets daughter centriole size in flies. J Cell Biol. 217:1233-1248. doi:10.1083/jcb.201801014.

Banterle, N., A.P. Nievergelt, S. de Buhr, G.N. Hatzopoulos, C. Brillard, S. Andany, T. Hübscher, F.A. Sorgenfrei, U.S. Schwarz, F. Gräter, G.E. Fantner, and P. Gönczy. 2021. Kinetic and structural roles for the surface in guiding SAS- 6 self-assembly to direct centriole architecture. Nat Commun. 12:6180. doi:10.1038/s41467-021-26329-1.

Basto, R., J. Lau, T. Vinogradova, A. Gardiol, C.G. Woods, A. Khodjakov, and J.W. Raff. 2006. Flies without centrioles. Cell. 125:1375-1386. doi:10.1016/j.cell.2006.05.025.

Bauer, M., F. Cubizolles, A. Schmidt, and E.A. Nigg. 2016. Quantitative analysis of human centrosome architecture by targeted proteomics and fluorescence imaging. EMBO J. 35:2152-2166. doi:10.15252/embj.201694462.

Bettencourt-Dias, M., A. Rodrigues-Martins, L. Carpenter, M. Riparbelli, L. Lehmann, M.K. Gatt, N. Carmo, F. Balloux, G. Callaini, and D.M. Glover. 2005. SAK/PLK4 is required for centriole duplication and flagella development. Current Biology. 15:2199-2207. doi:10.1016/j.cub.2005.11.042.

Bornens, M. 2021. Centrosome organization and functions. Curr Opin Struct Biol. 66:199206. doi:10.1016/j.sbi.2020.11.002.

Breslow, D.K., and A.J. Holland. 2019. Mechanism and Regulation of Centriole and Cilium Biogenesis. Annu. Rev. Biochem. 88:annurev-biochem-013118-111153. doi:10.1146/annurev-biochem-013118-111153. 
van Breugel, M., M. Hirono, A. Andreeva, H.-A. Yanagisawa, S. Yamaguchi, Y. Nakazawa, N. Morgner, M. Petrovich, I.-O. Ebong, C.V. Robinson, C.M. Johnson, D. Veprintsev, and B. Zuber. 2011. Structures of SAS-6 suggest its organization in centrioles. Science. 331:1196-1199. doi:10.1126/science.1199325.

Conduit, P.T., A. Wainman, and J.W. Raff. 2015. Centrosome function and assembly in animal cells. Nat Rev Mol Cell Biol. 16:611-624. doi:10.1038/nrm4062.

Cottee, M.A., S. Johnson, J.W. Raff, and S.M. Lea. 2017. A key centriole assembly interaction interface between human PLK4 and STIL appears to not be conserved in flies. Biology Open. 6:381-389. doi:10.1242/bio.024661.

Cottee, M.A., N. Muschalik, S. Johnson, J. Leveson, J.W. Raff, and S.M. Lea. 2015. The homooligomerisation of both Sas- 6 and Ana2 is required for efficient centriole assembly in flies. Elife. 4:e07236. doi:10.7554/eLife.07236.

David, A., H. Amartely, N. Rabinowicz, M. Shamir, A. Friedler, and S. Izraeli. 2016. Molecular basis of the STIL coiled coil oligomerization explains its requirement for de-novo formation of centrosomes in mammalian cells. Sci Rep. 6:24296. doi:10.1038/srep24296.

Decker, M., S. Jaensch, A. Pozniakovsky, A. Zinke, K.F. O'Connell, W. Zachariae, E. Myers, and A.A. Hyman. 2011. Limiting amounts of centrosome material set centrosome size in C. elegans embryos. Curr. Biol. 21:1259-1267. doi:10.1016/j.cub.2011.06.002.

Deneke, V.E., A. Melbinger, M. Vergassola, and S. Di Talia. 2016. Waves of Cdk1 Activity in S Phase Synchronize the Cell Cycle in Drosophila Embryos. Dev Cell. 38:399-412. doi:10.1016/j.devcel.2016.07.023.

Dunsing, V., M. Luckner, B. Zühlke, R.A. Petazzi, A. Herrmann, and S. Chiantia. 2018. Optimal fluorescent protein tags for quantifying protein oligomerization in living cells. Sci Rep. 8:10634. doi:10.1038/s41598-018-28858-0.

Dzhindzhev, N.S., G. Tzolovsky, Z. Lipinszki, M. Abdelaziz, J. Debski, M. Dadlez, and D.M. Glover. 2017. Two-step phosphorylation of Ana2 by Plk4 is required for the sequential loading of Ana 2 and Sas6 to initiate procentriole formation. Open Biol. 7:170247-11. doi:10.1098/rsob.170247.

Dzhindzhev, N.S., G. Tzolovsky, Z. Lipinszki, S. Schneider, R. Lattao, J. Fu, J. Debski, M. Dadlez, and D.M. Glover. 2014. Plk4 phosphorylates Ana2 to trigger Sas6 recruitment and procentriole formation. Curr. Biol. 24:2526-2532. doi:10.1016/j.cub.2014.08.061.

Dzhindzhev, N.S., Q.D. Yu, K. Weiskopf, G. Tzolovsky, I. Cunha-Ferreira, M. Riparbelli, A. Rodrigues-Martins, M. Bettencourt-Dias, G. Callaini, and D.M. Glover. 2010. Asterless is a scaffold for the onset of centriole assembly. Nature. 467:714-718. doi:10.1038/nature09445. 
Farrell, J.A., and P.H. O'Farrell. 2014. From egg to gastrula: how the cell cycle is remodeled during the Drosophila mid-blastula transition. Annu Rev Genet. 48:269-294. doi:10.1146/annurev-genet-111212-133531.

Foe, V.E., and B.M. Alberts. 1983. Studies of nuclear and cytoplasmic behaviour during the five mitotic cycles that precede gastrulation in Drosophila embryogenesis. J Cell Sci. 61:31-70.

Gartenmann, L., C.C. Vicente, A. Wainman, Z.A. Novak, B. Sieber, J.H. Richens, and J.W. Raff. 2020. Drosophila Sas-6, Ana2 and Sas-4 self-organise into macromolecular structures that can be used to probe centriole and centrosome assembly. J Cell Sci. 133:jcs244574. doi:10.1242/jcs.244574.

Goehring, N.W., and A.A. Hyman. 2012. Organelle Growth Control through Limiting Pools of Cytoplasmic Components. Current Biology. 22:R330-9. doi:10.1016/j.cub.2012.03.046.

Gönczy, P., and G.N. Hatzopoulos. 2019. Centriole assembly at a glance. Journal of cell science. 132:jcs228833. doi:10.1242/jcs.228833.

Gonzalez, C., G. Tavosanis, and C. Mollinari. 1998. Centrosomes and microtubule organisation during Drosophila development. J Cell Sci. 111 ( Pt 18):2697-2706.

Haase, S.B., M. Winey, and S.I. Reed. 2001. Multi-step control of spindle pole body duplication by cyclin-dependent kinase. Nat Cell Biol. 3:38-42. doi:10.1038/35050543.

Habedanck, R., Y.-D. Stierhof, C.J. Wilkinson, and E.A. Nigg. 2005. The Polo kinase Plk4 functions in centriole duplication. Nat Cell Biol. 7:1140-1146. doi:10.1038/ncb1320.

Hinchcliffe, E.H., C. Li, E.A. Thompson, J.L. Maller, and G. Sluder. 1999. Requirement of Cdk2Cyclin E Activity for Repeated Centrosome Reproduction in Xenopus Egg Extracts. Science. 283:851-854. doi:10.1126/science.283.5403.851.

Hinchcliffe, E.H., and G. Sluder. 2001. "It Takes Two to Tango": understanding how centrosome duplication is regulated throughout the cell cycle. Genes Dev. 15:11671181. doi:10.1101/gad.894001.

Keller, D., M. Orpinell, N. Olivier, M. Wachsmuth, R. Mahen, R. Wyss, V. Hachet, J. Ellenberg, S. Manley, and P. Gönczy. 2014. Mechanisms of HsSAS-6 assembly promoting centriole formation in human cells. J Cell Biol. 204:697-712. doi:10.1083/jcb.201307049.

Kemp, C.A., K.R. Kopish, P. Zipperlen, J. Ahringer, and K.F. O'Connell. 2004. Centrosome maturation and duplication in C. elegans require the coiled-coil protein SPD-2. Dev Cell. 6:511-523.

Kim, S.A., K.G. Heinze, and P. Schwille. 2007. Fluorescence correlation spectroscopy in living cells. Nat Methods. 4:963-973. doi:10.1038/nmeth1104. 
Kim, T.-S., J.-E. Park, A. Shukla, S. Choi, R.N. Murugan, J.H. Lee, M. Ahn, K. Rhee, J.K. Bang, B.Y. Kim, J. Loncarek, R.L. Erikson, and K.S. Lee. 2013. Hierarchical recruitment of Plk4 and regulation of centriole biogenesis by two centrosomal scaffolds, Cep192 and Cep152. Proc Natl Acad Sci USA. 110:E4849-57. doi:10.1073/pnas.1319656110.

Kim, T.-S., L. Zhang, J. II Ahn, L. Meng, Y. Chen, E. Lee, J.K. Bang, J.M. Lim, R. Ghirlando, L. Fan, Y.-X. Wang, B.Y. Kim, J.-E. Park, and K.S. Lee. 2019. Molecular architecture of a cylindrical self-assembly at human centrosomes. Nat Commun. 10:1151. doi:10.1038/s41467-019-08838-2.

Kitagawa, D., I. Vakonakis, N. Olieric, M. Hilbert, D. Keller, V. Olieric, M. Bortfeld, M.C. Erat, I. Flückiger, P. Gönczy, and M.O. Steinmetz. 2011. Structural basis of the 9-fold symmetry of centrioles. Cell. 144:364-375. doi:10.1016/j.cell.2011.01.008.

Kratz, A.-S., F. Bärenz, K.T. Richter, and I. Hoffmann. 2015. Plk4-dependent phosphorylation of STIL is required for centriole duplication. Biology Open. 4:370-377. doi:10.1242/bio.201411023.

Lacey, K.R., P.K. Jackson, and T. Stearns. 1999. Cyclin-dependent kinase control of centrosome duplication. PNAS. 96:2817-2822. doi:10.1073/pnas.96.6.2817.

Leda, M., A.J. Holland, and A.B. Goryachev. 2018. Autoamplification and Competition Drive Symmetry Breaking: Initiation of Centriole Duplication by the PLK4-STIL Network. iScience. 8:222-235. doi:10.1016/j.isci.2018.10.003.

Loncarek, J., and M. Bettencourt-Dias. 2018. Building the right centriole for each cell type. J Cell Biol. 217:823-835. doi:10.1083/jcb.201704093.

Lopes, C.A.M., S.C. Jana, I. Cunha-Ferreira, S. Zitouni, I. Bento, P. Duarte, S. Gilberto, F. Freixo, A. Guerrero, M. Francia, M. Lince-Faria, J. Carneiro, and M. Bettencourt-Dias. 2015. PLK4 trans-Autoactivation Controls Centriole Biogenesis in Space. Dev Cell. 35:222-235. doi:10.1016/j.devcel.2015.09.020.

Marshall, W.F. 2015. Subcellular size. Cold Spring Harb Perspect Biol. 7:a019059. doi:10.1101/cshperspect.a019059.

McLamarrah, T.A., D.W. Buster, B.J. Galletta, C.J. Boese, J.M. Ryniawec, N.A. Hollingsworth, A.E. Byrnes, C.W. Brownlee, K.C. Slep, N.M. Rusan, and G.C. Rogers. 2018. An ordered pattern of Ana2 phosphorylation by Plk4 is required for centriole assembly. $J$ Cell Biol. 217:1217-1231. doi:10.1083/jcb.201605106.

McLamarrah, T.A., S.K. Speed, J.M. Ryniawec, D.W. Buster, C.J. Fagerstrom, B.J. Galletta, N.M. Rusan, and G.C. Rogers. 2020. A molecular mechanism for the procentriole recruitment of Ana2. J Cell Biol. 219:1156. doi:10.1083/jcb.201905172.

Meraldi, P., J. Lukas, A.M. Fry, J. Bartek, and E.A. Nigg. 1999. Centrosome duplication in mammalian somatic cells requires E2F and Cdk2-Cyclin A. Nat Cell Biol. 1:88-93. doi:10.1038/10054. 
Montenegro Gouveia, S., S. Zitouni, D. Kong, P. Duarte, B. Ferreira Gomes, A.L. Sousa, E.M. Tranfield, A. Hyman, J. Loncarek, and M. Bettencourt-Dias. 2018. PLK4 is a microtubule-associated protein that self-assembles promoting de novo MTOC formation. J Cell Sci. 132:jcs219501. doi:10.1242/jcs.219501.

Moyer, T.C., K.M. Clutario, B.G. Lambrus, V. Daggubati, and A.J. Holland. 2015. Binding of STIL to Plk4 activates kinase activity to promote centriole assembly. J Cell Biol. 209:863-878. doi:10.1083/jcb.201502088.

Moyer, T.C., and A.J. Holland. 2019. PLK4 promotes centriole duplication by phosphorylating STIL to link the procentriole cartwheel to the microtubule wall. eLife. 8:570. doi:10.7554/eLife.46054.

Nabais, C., D. Pessoa, J. de-Carvalho, T. van Zanten, P. Duarte, S. Mayor, J. Carneiro, I.A. Telley, and M. Bettencourt-Dias. 2021. Plk4 triggers autonomous de novo centriole biogenesis and maturation. J Cell Biol. 220. doi:10.1083/jcb.202008090.

Nigg, E.A., and A.J. Holland. 2018. Once and only once: mechanisms of centriole duplication and their deregulation in disease. Nat Rev Mol Cell Biol. 19:297-312. doi:10.1038/nrm.2017.127.

Nigg, E.A., and J.W. Raff. 2009. Centrioles, centrosomes, and cilia in health and disease. Cell. 139:663-678. doi:10.1016/j.cell.2009.10.036.

Novak, Z.A., A. Wainman, L. Gartenmann, and J.W. Raff. 2016. Cdk1 Phosphorylates Drosophila Sas-4 to Recruit Polo to Daughter Centrioles and Convert Them to Centrosomes. Dev Cell. 37:545-557. doi:10.1016/j.devcel.2016.05.022.

Ohta, M., T. Ashikawa, Y. Nozaki, H. Kozuka-Hata, H. Goto, M. Inagaki, M. Oyama, and D. Kitagawa. 2014. Direct interaction of Plk4 with STIL ensures formation of a single procentriole per parental centriole. Nat Commun. 5:5267. doi:10.1038/ncomms6267.

Ohta, M., K. Watanabe, T. Ashikawa, Y. Nozaki, S. Yoshiba, A. Kimura, and D. Kitagawa. 2018. Bimodal Binding of STIL to Plk4 Controls Proper Centriole Copy Number. Cell Rep. 23:3160-3169.e4. doi:10.1016/j.celrep.2018.05.030.

Port, F., H.-M. Chen, T. Lee, and S.L. Bullock. 2014. Optimized CRISPR/Cas tools for efficient germline and somatic genome engineering in Drosophila. Proc Natl Acad Sci USA. 111:E2967-76. doi:10.1073/pnas.1405500111.

Reber, S., and N.W. Goehring. 2015. Intracellular Scaling Mechanisms. Cold Spring Harb Perspect Biol. 7:a019067. doi:10.1101/cshperspect.a019067.

Rogala, K.B., N.J. Dynes, G.N. Hatzopoulos, J. Yan, S.K. Pong, C.V. Robinson, C.M. Deane, P. Gönczy, and I. Vakonakis. 2015. The Caenorhabditis elegans protein SAS-5 forms large oligomeric assemblies critical for centriole formation. eLife. 4:e07410. doi:10.7554/eLife.07410. 
Schwarz, A., P. Sankaralingam, K.F. O’Connell, and T. Müller-Reichert. 2018. Revisiting Centrioles in Nematodes-Historic Findings and Current Topics. Cells. 7:101. doi:10.3390/cells7080101.

Shimanovskaya, E., V. Viscardi, J. Lesigang, M.M. Lettman, R. Qiao, D.I. Svergun, A. Round, K. Oegema, and G. Dong. 2014. Structure of the C. elegans ZYG-1 cryptic polo box suggests a conserved mechanism for centriolar docking of Plk4 kinases. Structure. 22:1090-1104. doi:10.1016/j.str.2014.05.009.

Sonnen, K.F., A.M. Gabryjonczyk, E. Anselm, Y.D. Stierhof, and E.A. Nigg. 2013. Human Cep192 and Cep152 cooperate in Plk4 recruitment and centriole duplication. J Cell Sci. 126:3223-3233. doi:10.1242/jcs.129502.

Stevens, N.R., J. Dobbelaere, K. Brunk, A. Franz, and J.W. Raff. 2010a. Drosophila Ana2 is a conserved centriole duplication factor. J Cell Biol. 188:313-323. doi:10.1083/jcb.200910016.

Stevens, N.R., H. Roque, and J.W. Raff. 2010b. DSas-6 and Ana2 coassemble into tubules to promote centriole duplication and engagement. Dev Cell. 19:913-919. doi:10.1016/j.devcel.2010.11.010.

Swaffer, M.P., A.W. Jones, H.R. Flynn, A.P. Snijders, and P. Nurse. 2016. CDK Substrate Phosphorylation and Ordering the Cell Cycle. Cell. 167:1750-1761.e16. doi:10.1016/j.cell.2016.11.034.

Takao, D., K. Watanabe, K. Kuroki, and D. Kitagawa. 2019. Feedback loops in the PIk4-STILHsSAS6 network coordinate site selection for procentriole formation. Biology Open. 8:bio047175. doi:10.1242/bio.047175.

Vasquez-Limeta, A., and J. Loncarek. 2021. Human centrosome organization and function in interphase and mitosis. Seminars in Cell \& Developmental Biology. 117:30-41. doi:10.1016/j.semcdb.2021.03.020.

Vidwans, S.J., M.L. Wong, and P.H. O'Farrell. 2003. Anomalous centriole configurations are detected in Drosophila wing disc cells upon Cdk1 inactivation. J Cell Sci. 116:137143.

Wong, S.-S., Z.M. Wilmott, S. Saurya, F.Y. Zhou, K.-Y. Chau, A. Goriely, and J.W. Raff. 2021. Mother centrioles generate a local pulse of Polo/PLK1 activity to initiate mitotic centrosome assembly. 2021.10.26.465695. doi:10.1101/2021.10.26.465695.

Yamamoto, S., and D. Kitagawa. 2021. Emerging insights into symmetry breaking in centriole duplication: updated view on centriole duplication theory. Current Opinion in Structural Biology. 66:8-14. doi:10.1016/j.sbi.2020.08.005.

Zhao, L., C.D. Kroenke, J. Song, D. Piwnica-Worms, J.J.H. Ackerman, and J.J. Neil. 2008. Intracellular water-specific MR of microbead-adherent cells: the HeLa cell intracellular water exchange lifetime. NMR Biomed. 21:159-164. doi:10.1002/nbm.1173. 
bioRxiv preprint doi: https://doi.org/10.1101/2022.02.15.480489; this version posted February 16, 2022. The copyright holder for this

preprint (which was not certified by peer review) is the author/funder, who has granted bioRxiv a license to display the preprint in perpetuity. It is made available under aCC-BY-NC 4.0 International license.

Zitouni, S., M.E. Francia, F. Leal, S.M. Gouveia, C. Nabais, P. Duarte, S. Gilberto, D. Brito, T. Moyer, S. Kandels-Lewis, M. Ohta, D. Kitagawa, A.J. Holland, E. Karsenti, T. Lorca, M. Lince-Faria, and M. Bettencourt-Dias. 2016. CDK1 Prevents Unscheduled PLK4-STIL Complex Assembly in Centriole Biogenesis. Current Biology. 26:1127-1137. doi:10.1016/j.cub.2016.03.055. 


\section{Figure 1}

A i)

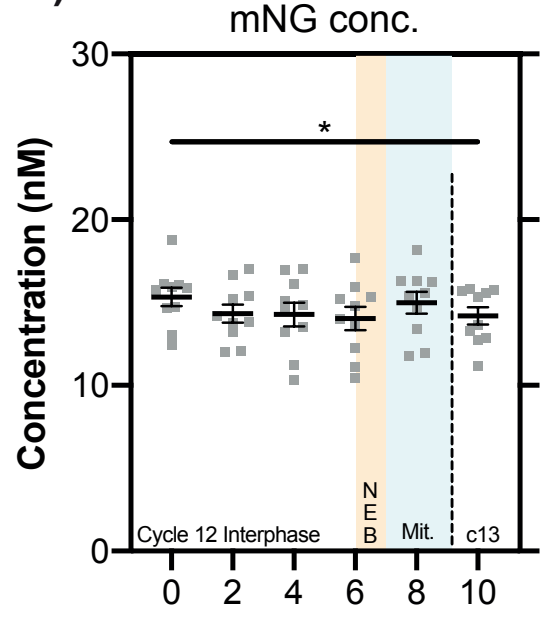

Time ( $\min )$

ii)

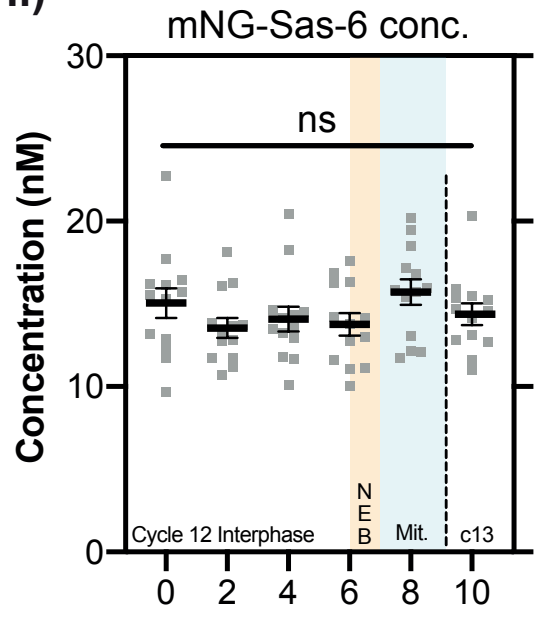

Time $(\min )$

v)

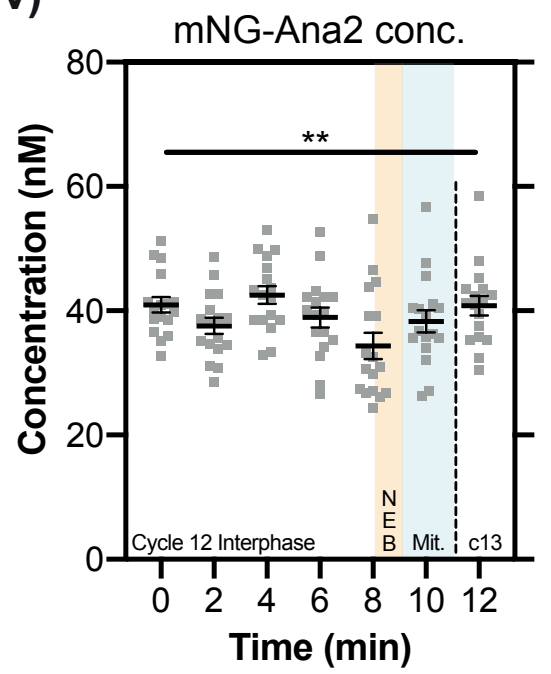

ii)

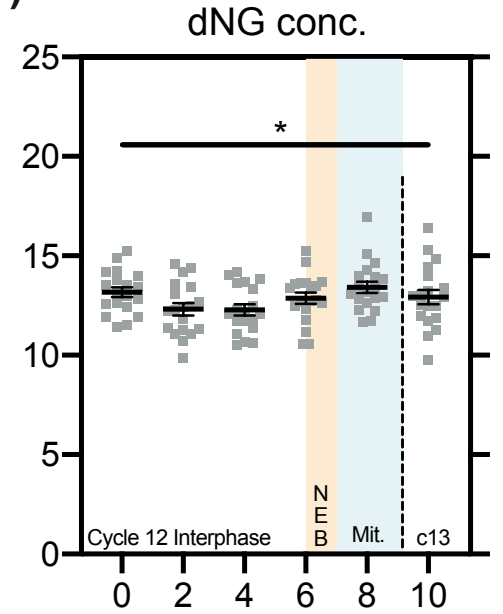

Time (min)

iii)

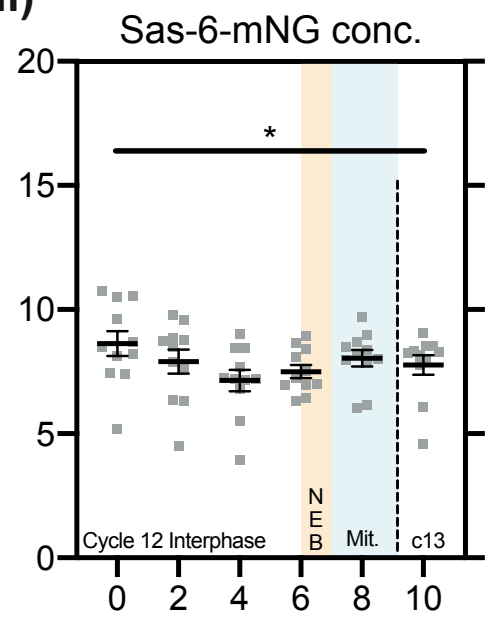

Time (min)

vi)

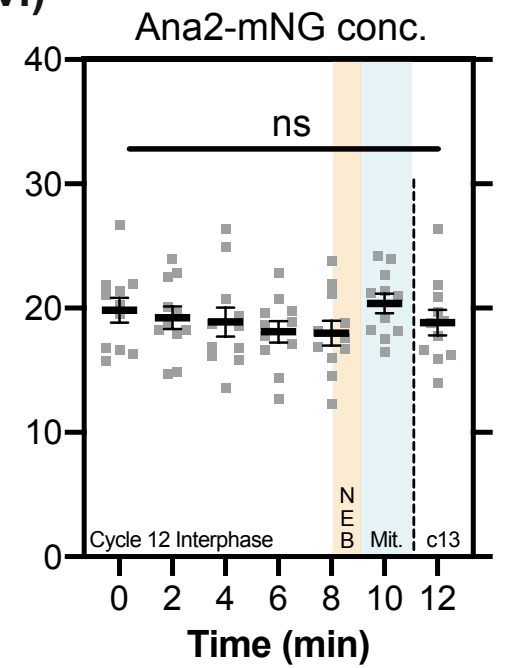

$\mathrm{B}$ i)

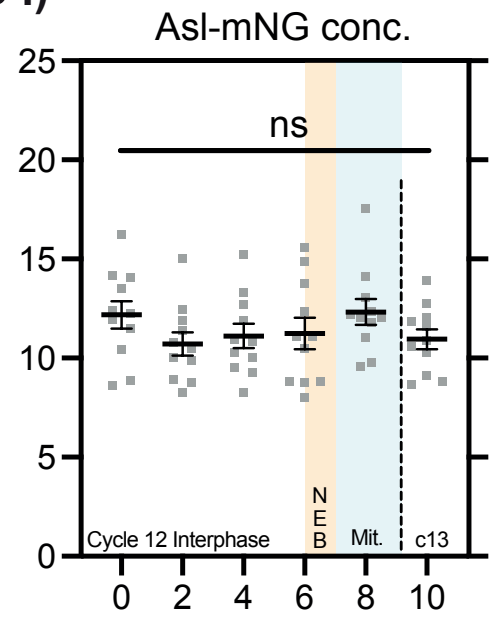

Time (min)

iv)

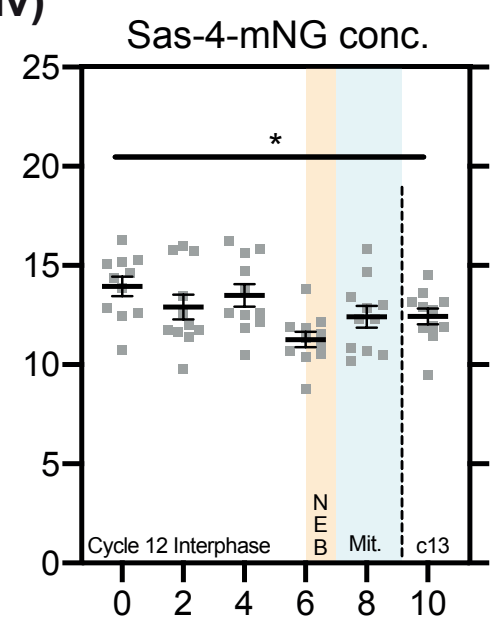

Time (min)

C

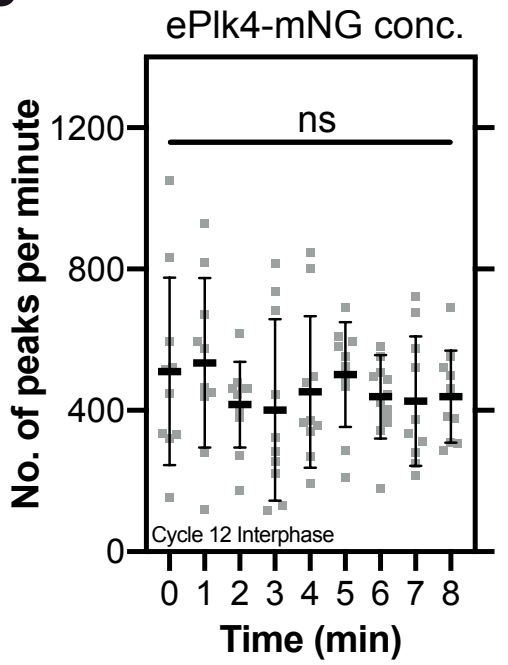

The cytoplasmic concentration of the core centriole duplication proteins does not change dramatically as daughter centrioles assemble during nuclear cycle 12. (A,B) Graphs show cytoplasmic FCS concentration measurements (Mean \pm SEM) of either $\mathrm{mNG}$ or $\mathrm{dNG}$ controls $(\mathrm{A})$ or $\mathrm{mNG}$-fusions to the core centriole duplication proteins (B). Measurements were taken every two minutes from the start of nuclear cycle 12. The timing window of NEB is depicted in Ilow, and of mitosis in green. Each data point represents the average of 4-6x 10sec recordings from an individual embryo. (C) Graph shows ePlk4-mNG PeCoS measurements (Mean \pm SD) taken at 60-second intervals from the start of nuclear cycle 12. Each data point represents an individual $60 \mathrm{sec}$ PeCoS measurement. Statistical significance was assessed using a paired one-way ANOVA test (for Gaussian-distributed data) or a Friedman test ( ${ }^{*}, \mathrm{P}<0.01$; ${ }^{*}, \mathrm{P}<0.05$; ns, not significant). 
Figure 2

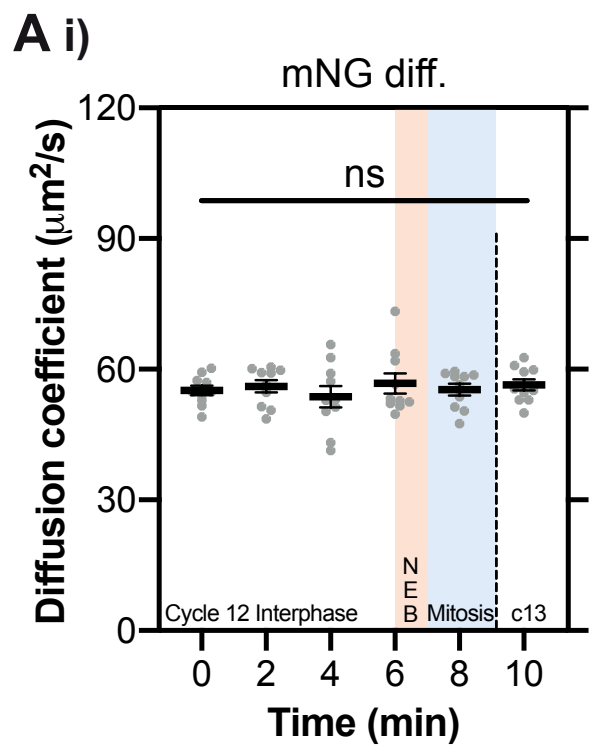

ii)

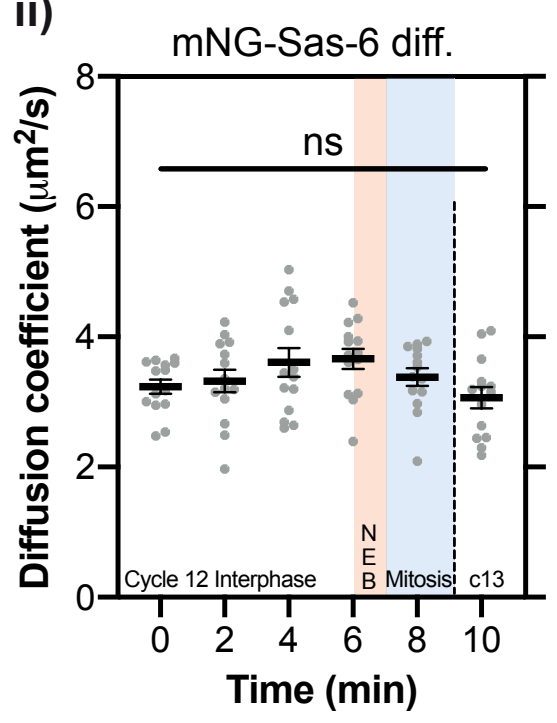

v)

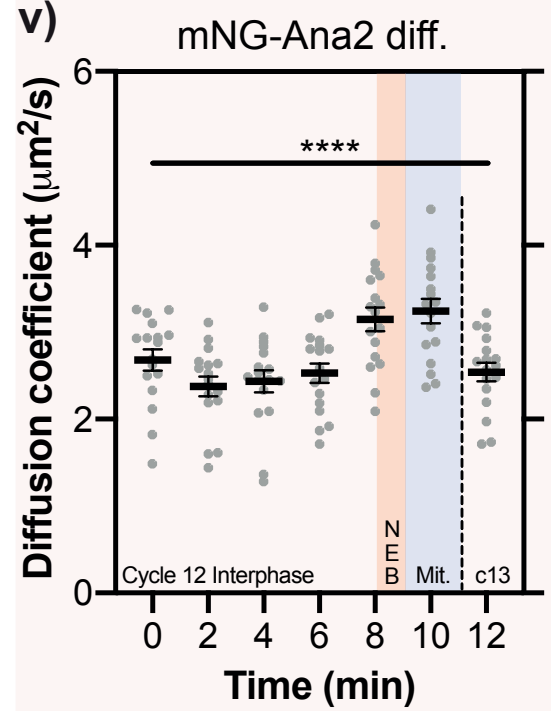

ii)

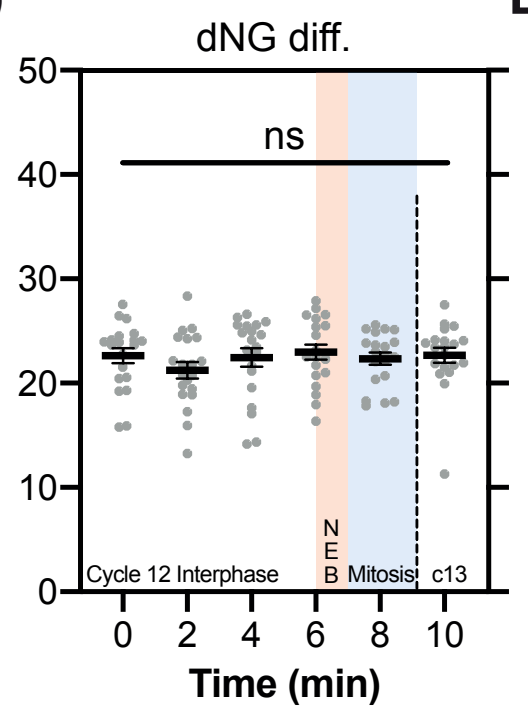

iii)

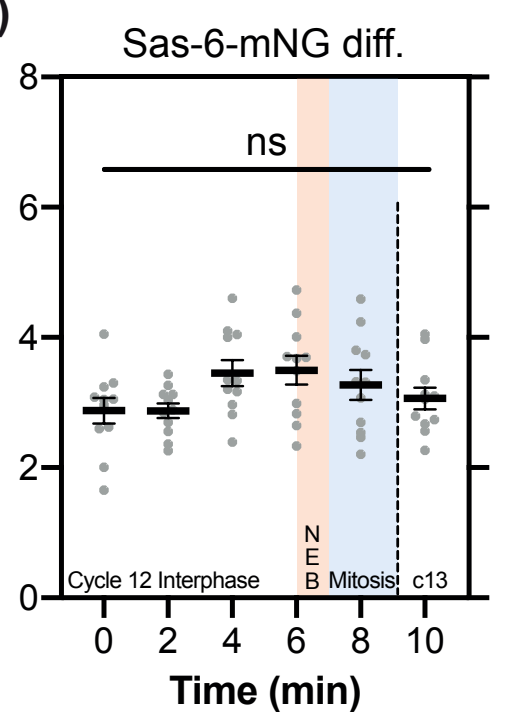

vi)

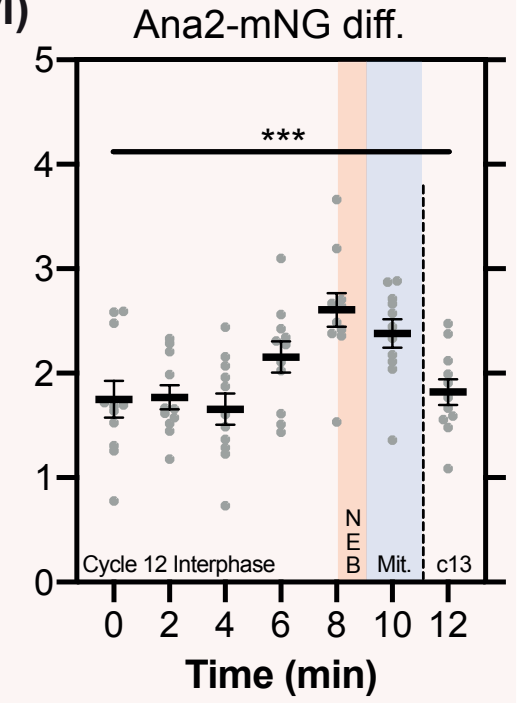

B i)

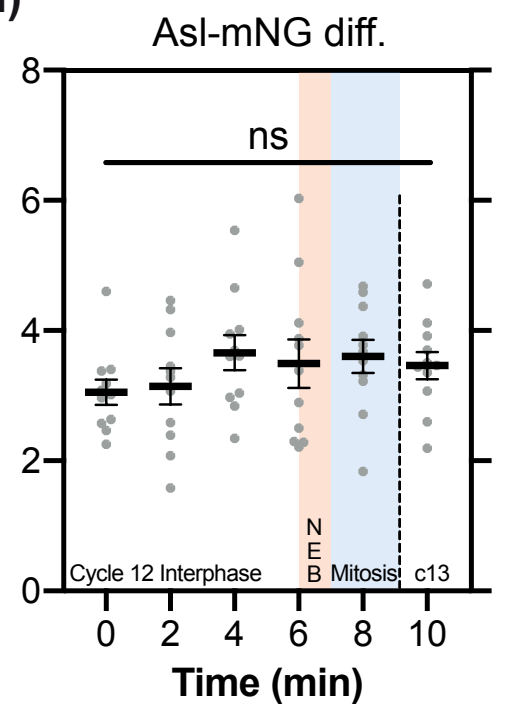

iv)

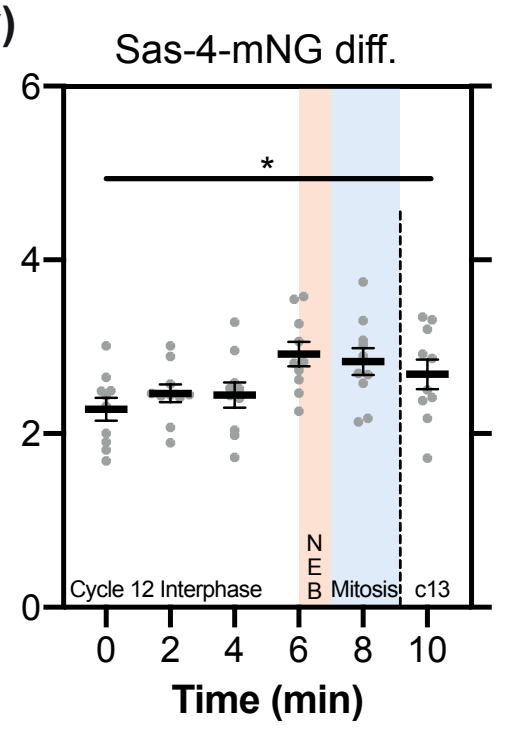

The cytoplasmic diffusion rate of Ana2 changes significantly as embryos exit S-phase. $(A, B)$ Graphs show cytoplasmic FCS diffusion rate measurements (Mean \pm SEM) of either $\mathrm{mNG}$ or dNG controls (A) or $\mathrm{mNG}$-fusions to the core centriole duplication proteins (B). Measurements were taken every two minutes from the start of nuclear cycle 12. The timing window of NEB is depicted in red, and of mitosis in blue. Each data point represents the average of 4-6x $10 \mathrm{sec}$ recordings from an individual embryo. The mNG-Ana2 and Ana2-mNG graphs are boxed in pink, as these proteins showed the most dramatic change in diffusion rates during the cycle. Statistical significance was assessed using a paired one-way ANOVA test (for Gaussian-distributed data) or a Friedman test $\left({ }^{* * *}, \mathrm{P}<0.0001 ;{ }^{* * *}, \mathrm{P}<0.001\right.$; ${ }^{*}, \mathrm{P}<0.05$; ns, not significant). 
A i)

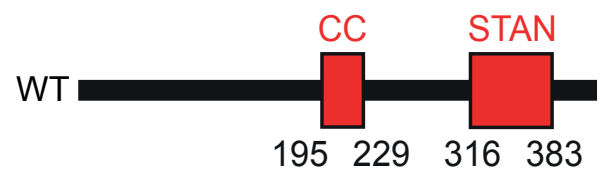

$\Delta \mathrm{CC}$

$\triangle$ STAN

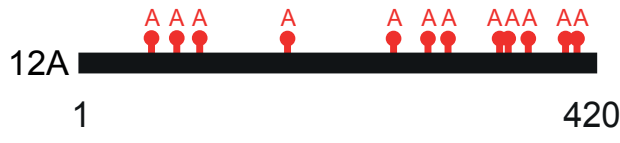

B i)

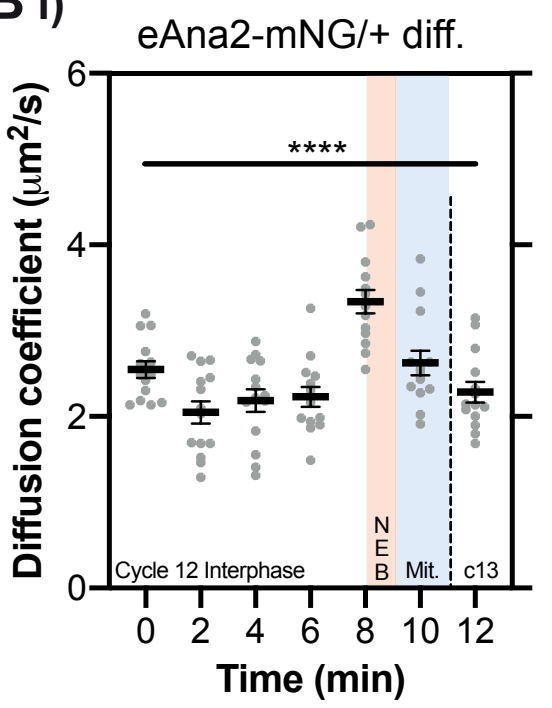

C i)

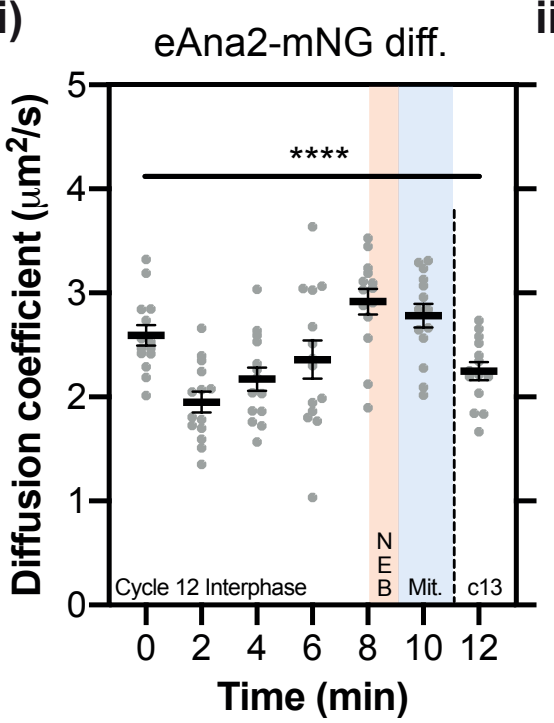

ii)

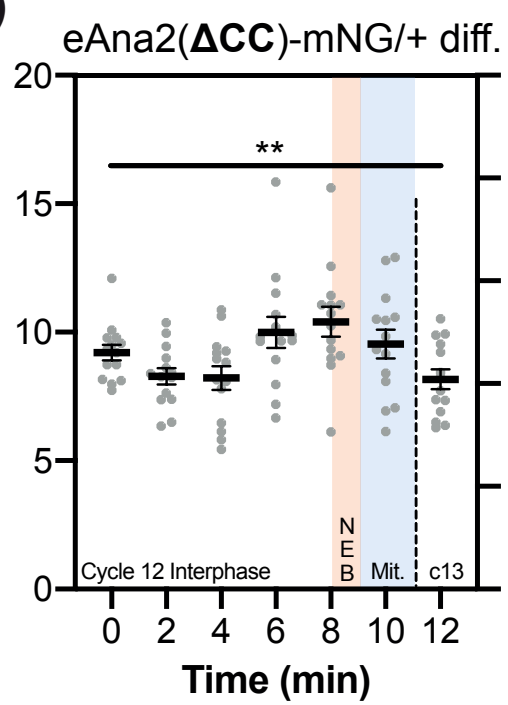

ii) eAna2(12A)-mNG diff

Ana2's change in diffusion rate is not dependent on the CC or STAN domain, but is perturbed if Ana2 cannot be phosphorylated by Cdk1/Cyclin. (A) Schematic illustration of the Ana2 protein and the deletion/mutant forms analysed in this study: central Coiled-Coil (CC) domain (aa195-230); STil/ANa2 (STAN) domain (aa316-383); the $12 \mathrm{~S} / \mathrm{T}$ residues in S/T-P motifs that were mutated to Alanine. (B,C) Graphs show cytoplasmic FCS diffusion measurements (Mean $\pm S E M$ ) in embryos laid by females of the following genotypes: $B($ (i) eAna2-mNG/+; B(ii) eAna2( $\Delta C \mathrm{CC}$ )-mNG/+; B(iii) eAna2( $\Delta$ STAN)-mNG; C(i) eAna2-mNG; C(ii) eAna2(12A)-mNG. Measurements were taken every two minutes from the start of nuclear cycle 12. The timing window of NEB is depicted in red, and of mitosis in blue. Each data point represents the average of 4-6x 10 sec recordings from an individual embryo. Statistical significance was assessed using a paired one-way ANOVA test (for Gaussian-distributed data) or a Friedman test ${ }^{* * * *}, \mathrm{P}<0.0001 ;{ }^{* *}, \mathrm{P}<0.01$; ns, not significant). 


\section{Figure 4}

A i)
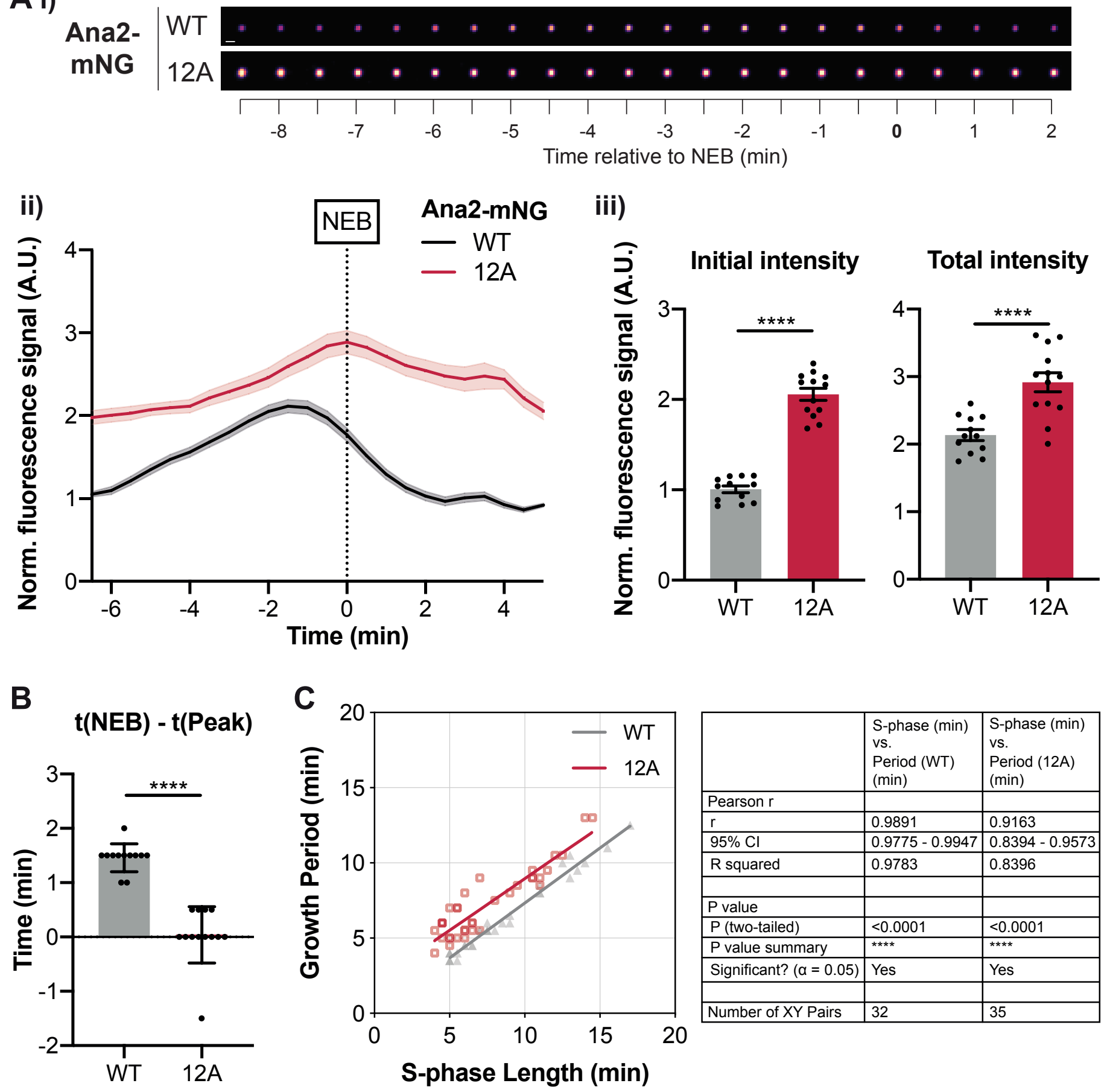

\begin{tabular}{|c|c|c|}
\hline & $\begin{array}{l}\text { S-phase (min) } \\
\text { vs. } \\
\text { Period (WT) } \\
\text { (min) }\end{array}$ & $\begin{array}{l}\text { S-phase (min) } \\
\text { vs. } \\
\text { Period }(12 A) \\
\text { (min) }\end{array}$ \\
\hline \multicolumn{3}{|l|}{ Pearson $r$} \\
\hline$r$ & 0.9891 & 0.9163 \\
\hline $95 \% \mathrm{Cl}$ & $0.9775-0.9947$ & $0.8394-0.9573$ \\
\hline R squared & 0.9783 & 0.8396 \\
\hline \multicolumn{3}{|l|}{$P$ value } \\
\hline $\mathrm{P}$ (two-tailed) & $<0.0001$ & $<0.0001$ \\
\hline$P$ value summary & 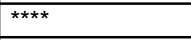 & $* * \star \star$ \\
\hline Significant? $(\alpha=0.05)$ & Yes & Yes \\
\hline Number of XY Pairs & 32 & 35 \\
\hline
\end{tabular}

eAna2(12A)-mNG exhibits an abnormal pattern of centriolar recruitment. (A) (i) Images show the typical centriolar recruitment dynamics of WT Ana2-mNG or eAna2(12A)-mNG in an embryo during nuclear cycle $12 a$ - ligned to nuclear envelope breakdown (NEB; $t=0)$. Images were obtained by superimposing all the centrioles at each time point and averaging their fluorescence (Scale Bar=1 $\mu \mathrm{m})$. (ii) Graph shows the normalised (Mean \pm SEM) centriolar fluorescence levels of WT Ana2-mNG (blak ) and eAna2(12A)-mNG (red) during nuclear cycle 12 aligned to nuclear envelope breakdown (NEB; $t=0$ ). $N>12$ embryos; $n \sim 100-150$ centriole pairs per embryo. (iii) Bar charts quantify the normalised initial and maximal centriolar intensity (Mean \pm SEM). Each data point represents the average value of all centrioles measured in an individual embryo. (B) Quantification of the time (Mean $\pm S D$ ) at which Ana2 levels start to decrease at the centriole relative to NEB/mitosis. Statistical significance was assessed using an unpaired t-test with Welch's correction (for Gaussian-distributed data) or a Mann-Whitney test (****, P<0.0001). (C) Scatterplot shows the correlation (obtained by linear regression of the data) between Ana2's growth period and S-phase length during nuclear cycles 11-13. $N \geq$ 10 embryos for each cycle, $n \sim 70-90$ (c11), n 100-150 (c12), and n 200-300 (c13) centriole pairs per embryo. Correlation strength was assessed using the Pearson's correlation coefficient. 


\section{Figure 5}

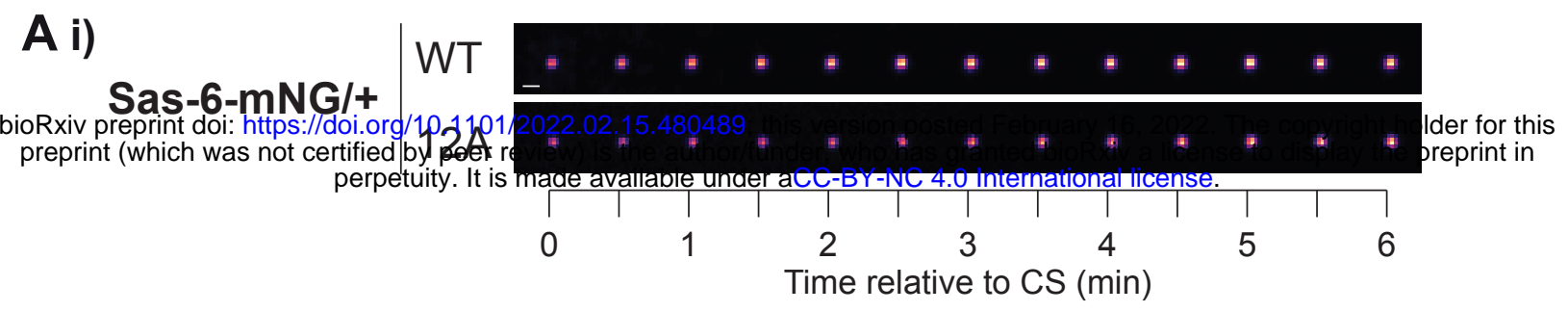

ii)
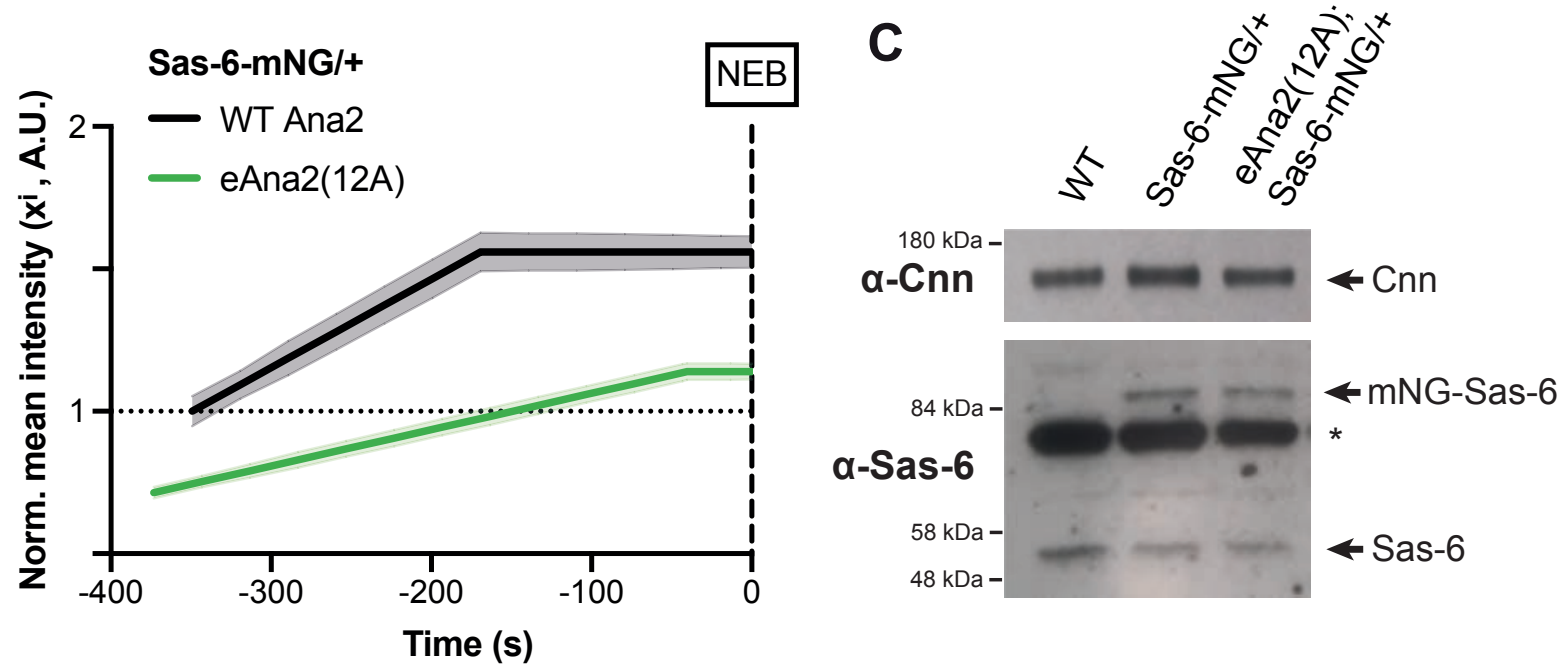

B i)

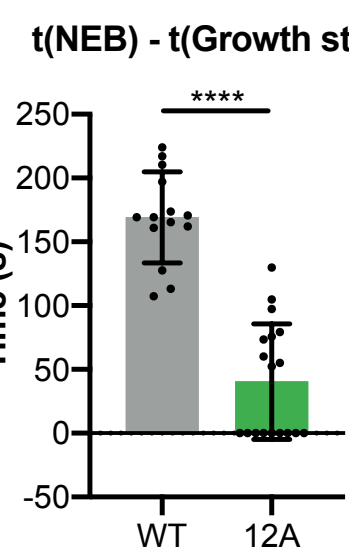

iv)

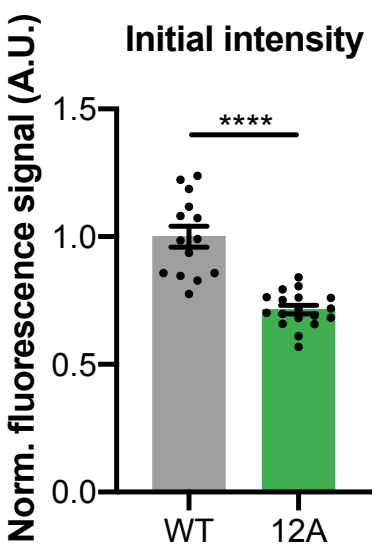

ii)

Growth period

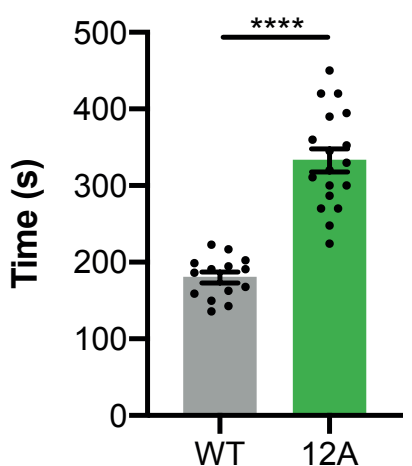

v)

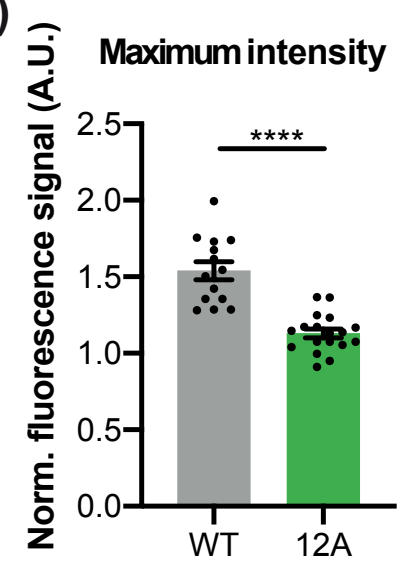

iii)

Growth rate

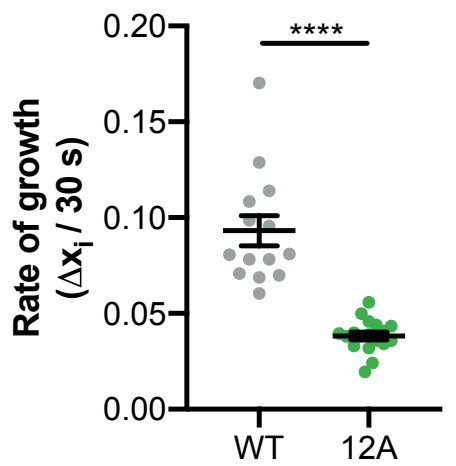

vi)

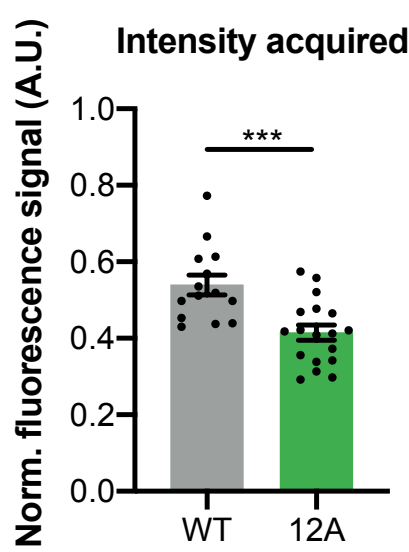

Centrioles grow more slowly, but for a longer period, in the presence of eAna2(12A). (A) (i) Images show the typical centriolar recruitment dynamics of Sas-6-mNG in a WT embryo or an embryo expressing eAna2(12A) during nuclear cycle 12a ligned to centriole separation at the start of S-phase (CS; $\mathrm{t}=0$ ). Images were obtained by superimposing all the centrioles at each time point and averaging their fluorescence (Scale Bar=1 $\mu \mathrm{m}$ ). (ii) Graph shows the normalised (Mean $\pm S E M)$ Sas-6-mNG centriole recruitment dynamics during nuclear cycle 12 in the presence of WT Ana2 (blak ) and eAna2(12A) (green) aligned to nuclear envelope breakdown (NEB; $t=0$ ). $N>14$ embryos, $n \sim 100-150$ centriole pairs per embryo. (B) Bar charts quantify and compare several centriole growth parameters (Mean \pm SEM) extracted from the data shown in (Aii). The values were derived from the fitted regression curve of the mean Sas-6-mNG intensity of each individual embryo. Each datapoint represents the average value of all the centriole pairs measured in each embryo. Statistical significance was assessed using an unpaired t-test with Welch's correction ${ }^{* * * *}$, $\mathrm{P}<0.0001$; $\left.{ }^{* * *}, \mathrm{P}<0.001\right)$. (C) Western blot shows Sas-6 levels in WT embryos and embryos expressing one copy of Sas-6-mNG in either a WT or eAna2(12A) background. A prominent non-specific band is highlighted $\left({ }^{*}\right)$; Cnn is shown as loading control. A representative blot is shown from two technical repeats. 


\section{Figure 6}

A i)

ii)
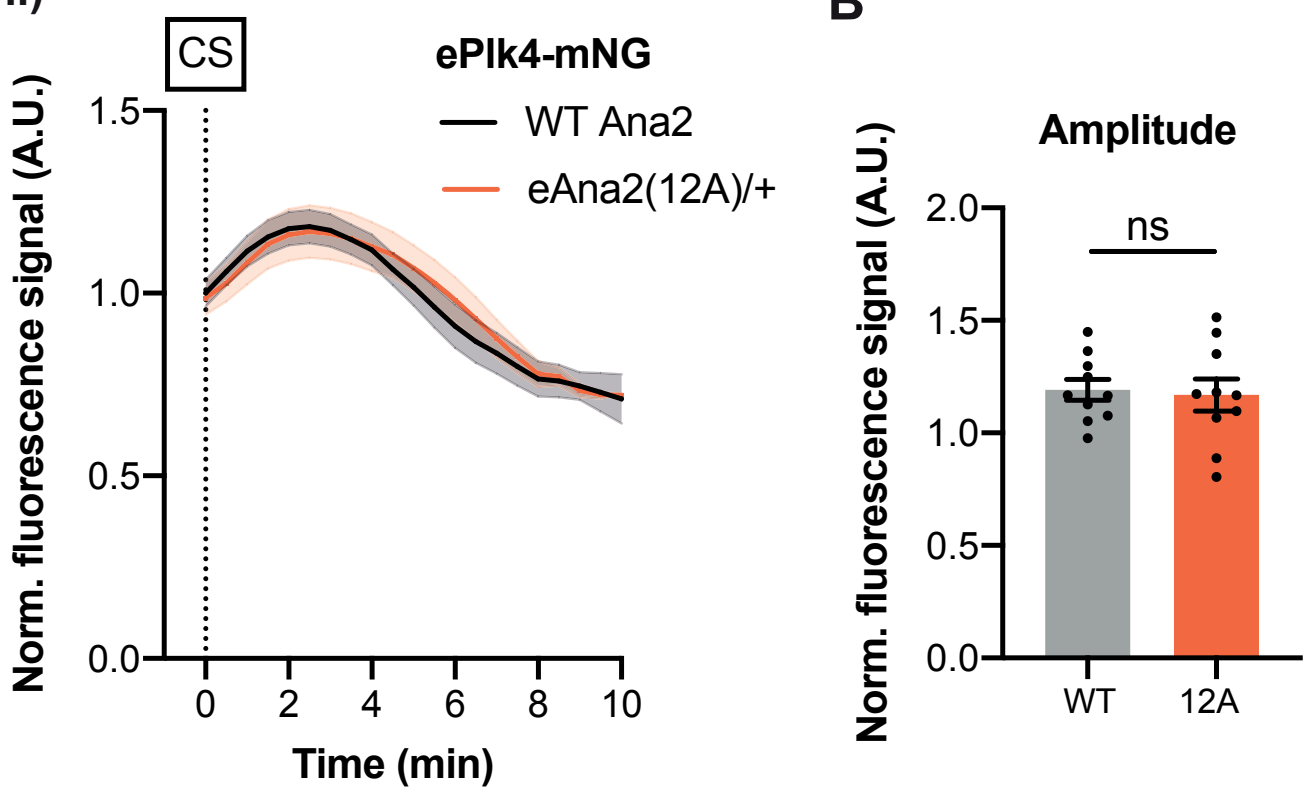

Width of half max

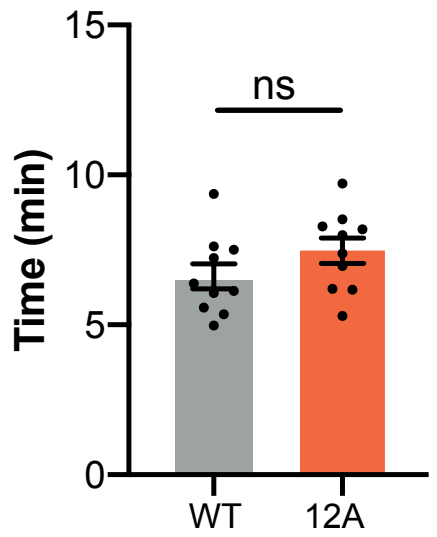

The centriolar PIk4 oscillation is not dramatically perturbed in the presence of eAna2(12A). (A) (i) Images show the typical centriolar recruitment dynamics of Plk4-mNG in a WT embryo or an embryo expressing one copy of untagged eAna2(12A) in the presence of one copy of the endogenous WT ana2 gene during nuclear cycle $12 \mathrm{z}$ - ligned to centriole separation at the start of $\mathrm{S}$-phase (CS; $\mathrm{t}=0$ ). Images were obtained by superimposing all the centrioles at each time point and averaging their fluorescence (Scale Bar=1 $\mu \mathrm{m}$ ). (ii) Graph shows the normalised (Mean \pm SEM) centriolar recruitment dynamics of ePlk4-mNG in the presence of either only untagged endogenous Ana2 (black) or one copy of untagged eAna2(12A) expressed in the presence of one copy of the endogenous WT ana2 gene (orange) during nuclear cycle 12. Data was aligned to centriole separation (CS) at the start of S-phase. $N=10$ embryos, $\mathrm{n} \sim 100$ centriole pairs per embryo. (B) Bar charts quantify the amplitude (maximal intensity) and period (full width at half maximum intensity) (Mean \pm SEM) of the Plk4-mNG oscillation. Each data point represents the average value of all the centrioles measured in an individual embryo. Statistical significance was assessed using an unpaired t-test with Welch's correction (ns, not significant). 


\section{Figure 7}

A i)

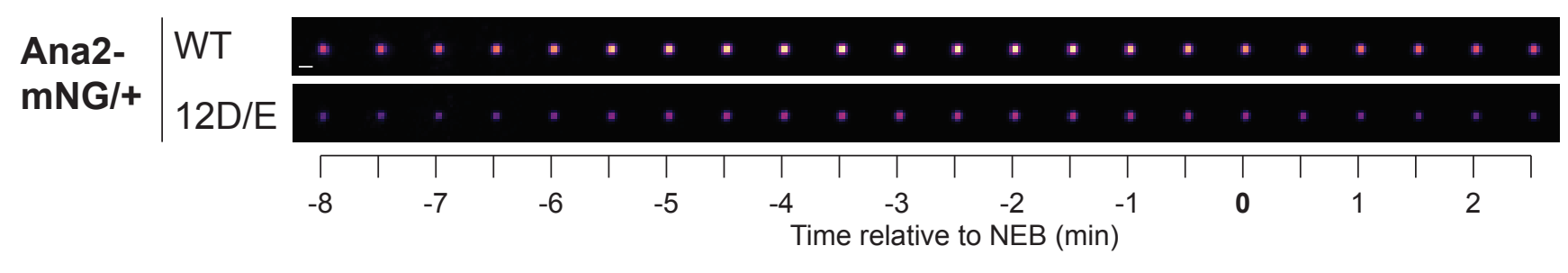

ii)

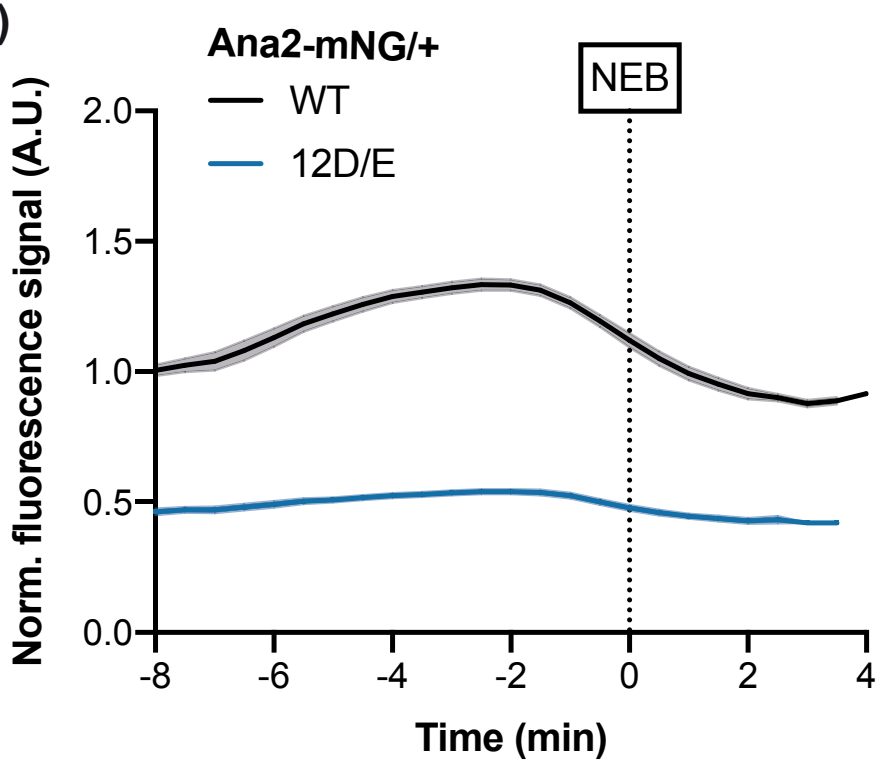

B
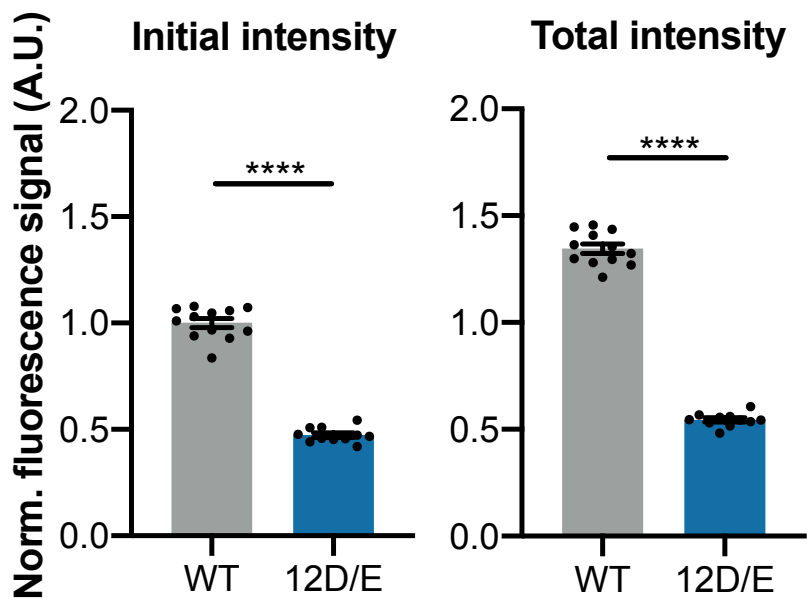

eAna2(12D/E)-mNG is not recruited to centrioles efficiently. (A) (i) Images show the typical centriolar recruitment dynamics of WT Ana2-mNG or eAna2(12D/E)-mNG in an embryo also expressing one copy of the endogenous untagged ana2 gene during nuclear cycle $12 a$ - ligned to nuclear envelope breakdown $(\mathrm{NEB} ; \mathrm{t}=0)$. Images were obtained by superimposing all the centrioles at each time point and averaging their fluorescence (Scale Bar=1 $\mu \mathrm{m})$. Note that the centrioles in the embryo expressing eAna2(12D/E)-mNG were very dim so their brightness has been enhanced by $2 X$ relative to the WT control. (ii) Graph shows the normalised (Mean \pm SEM) centriolar recruitment dynamics of either WT Ana2-mNG (blak ) or eAna2(12D/E)-mNG (blue) expressed in the presence of 1 copy of the endogenous untagged ana2 gene during nuclear cycle 12. Data was aligned to nuclear envelope breakdown (NEB; $t=0$ ). $N \geq 11$ embryos, $n \sim 100-150$ centriole pairs per embryo. (B) Bar charts quantify the normalised initial and maximal fluorescence intensity (Mean $\pm S E M)$. Each data point represents the average value of all centrioles measured in an individual embryo. Statistical significance was assessed using an unpaired t-test with Welch's correction (****, $\mathrm{P}<0.0001)$. 
bioRxiv preprint doi: https://doi.org/10.1101/2022.02.15.480489; this version posted February 16, 2022. The copyright holder for this preprint (which was not certified by peer review) is the author/funder, who has granted bioRxiv a license to display the preprint in perpetuity. It is made available under aCC-BY-NC 4.0 International license.

Figure S1

A

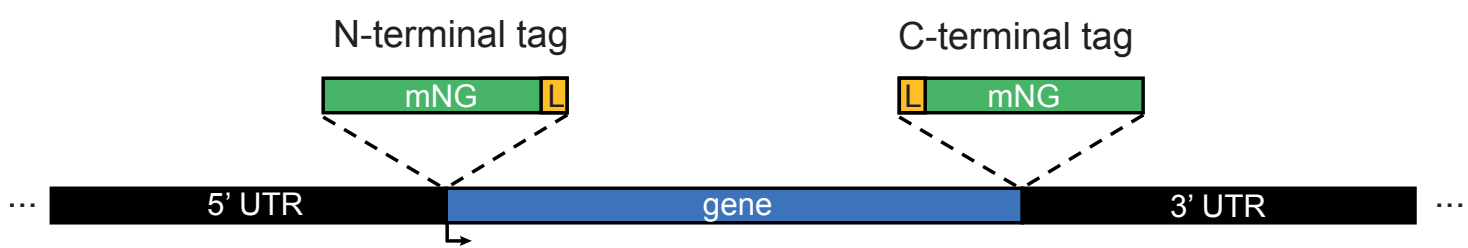

B
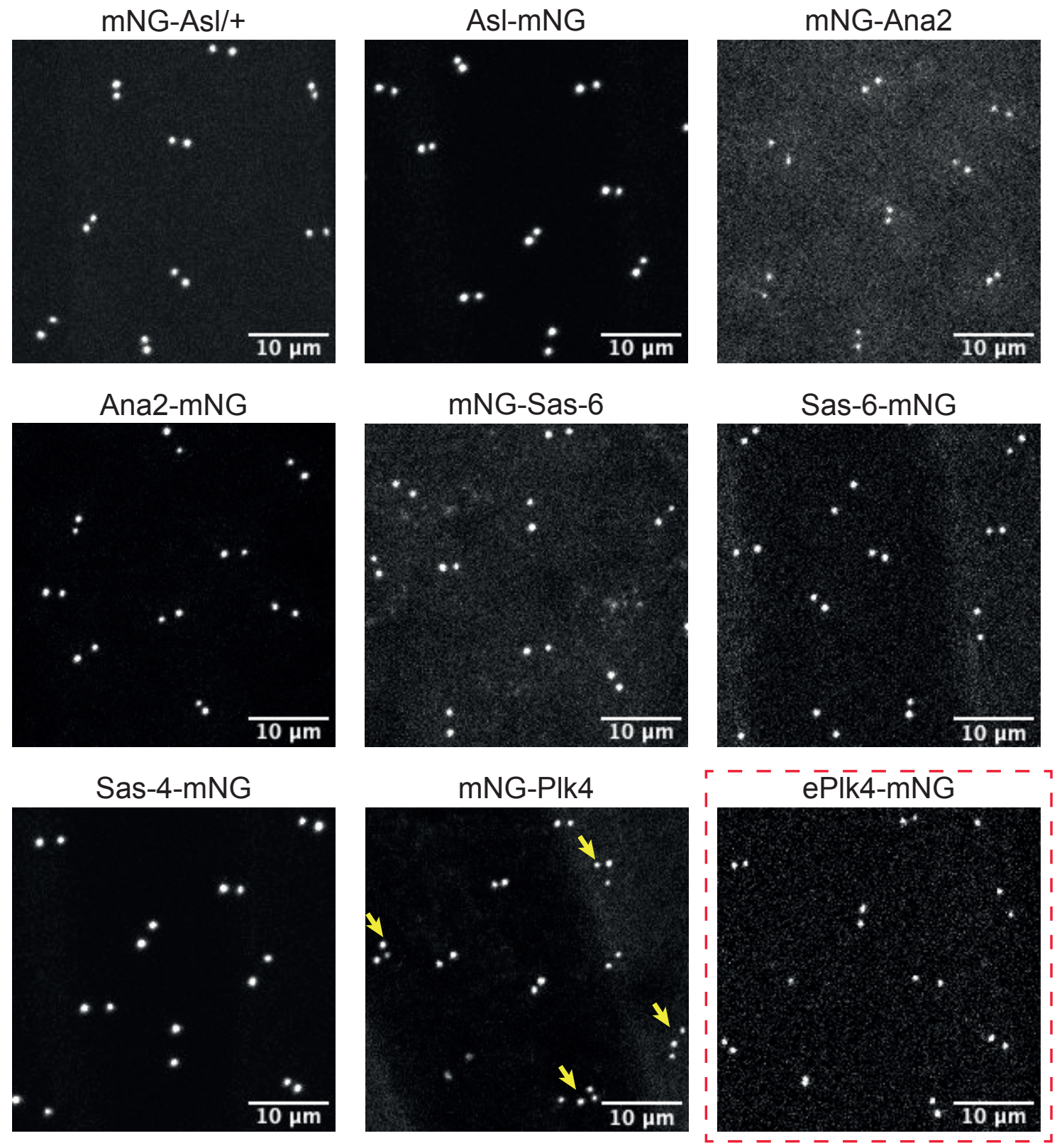

Generation of endogenously mNG-tagged centriolar proteins. (A) Schematic illustration of the strategy to "knock-in" mNG at either the N- or C-terminus of an endogenous locus. A short linker sequence (L) was introduced between the fluorescent tag and the gene of interest. (B) Images show the centriolar localisation of several mNG-tagged CRISPR/Cas9-mediated knock-in lines in living syncytial embryos (all images were acquired in early S-phase of nuclear cycle 12). N-terminally tagged mNG-Asl was not viable as a homozygous stock so it was expressed in a heterozygous ( $m N G-A s l /+)$ background. N-terminally tagged mNG-Plk4 consistently caused centriole overduplication in embryos (yellow arrows), so in subsequent experiments we used a P-element insertion line of Plk4-mNG expressed from its endogenous promoter in the Plk4 ${ }^{-/}$mutant background, which did not exhibit centriole overduplication (ePIk4-mNG, red dashed box). Note that the N-terminally tagged Ana2 and Sas-6 were present in the cytoplasm at higher levels than their C-terminally tagged counterparts (consistently exhibiting an increased cytoplasmic "background"). This difference was also detectable by FCS (Figure 1B (ii) vs (iii) and (v) vs (vi)). 


\section{Figure S2}
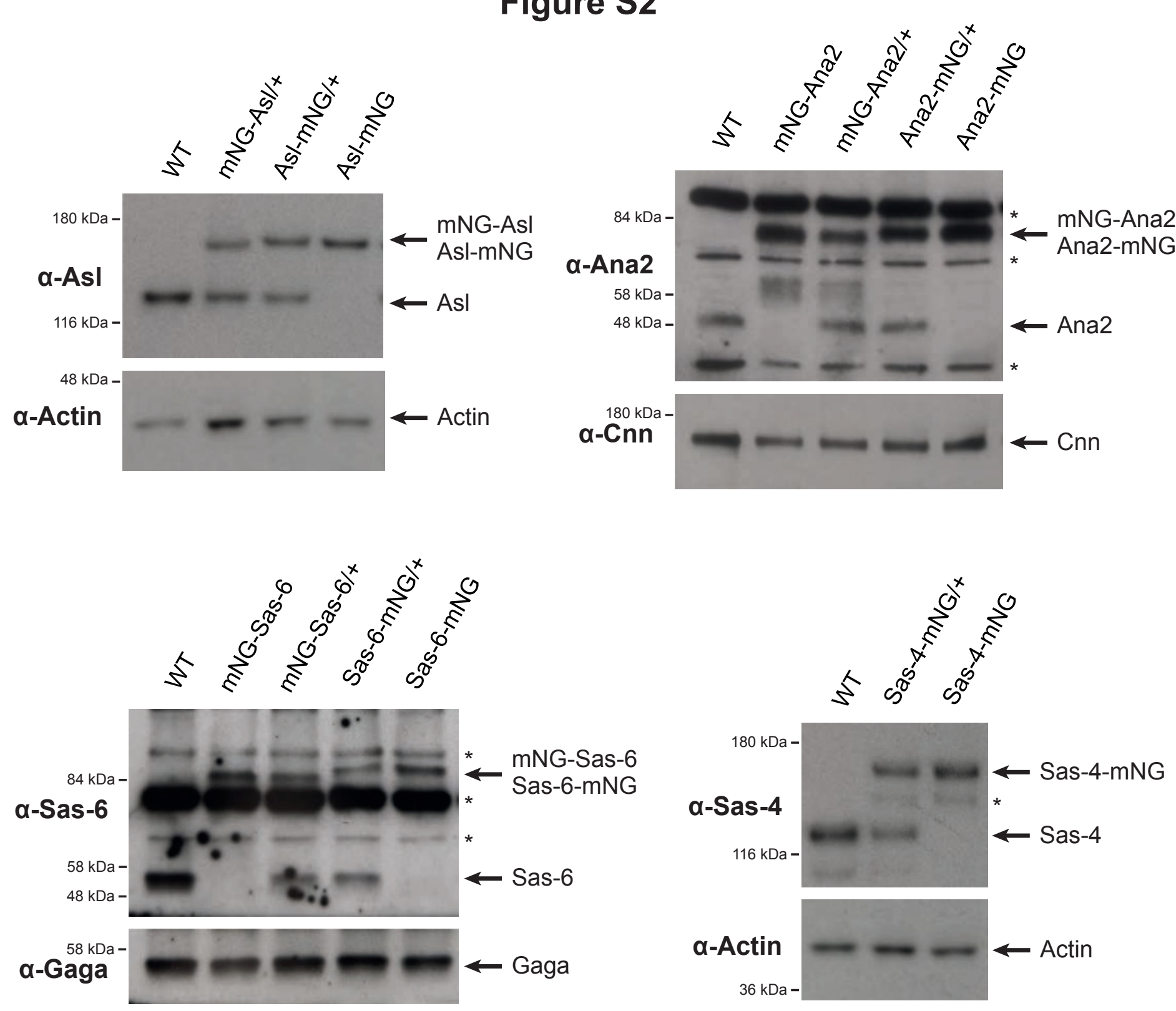

The mNG CRISPR/Cas9 knock-in lines are expressed at similar levels to the endogenous protein-except for Ana2 knock-ins, which are moderately overexpressed. Western blots show the expression levels of CRISPR/Cas9 knock-in lines and their cognate untagged endogenous proteins in 0-2hr old embryos. Prominent non-specific bands recognised by the centriolar protein-specific antibodies are highlighted (*); Actin, Cnn and Gaga transcription factor are shown as loading control. A representative blot is shown from at least two technical repeats. The Asl, Sas-4 and Sas-6 mNG-knock-in lines were expressed at similar levels to their endogenous proteins. In contrast, Ana2 mNG-knock-in lines were slightly overexpressed compared to the endogenous protein (we estimate by $\sim 2-4 X$ ). This overexpression seems to induce the mild overexpression of the endogenous protein in the heterozygous lines. This is consistent with experiments indicating that Ana2 multimerises in the cytoplasm, potentially allowing the overexpressed mNG-fusion to stabilise the untagged protein. Although imaging (Figure S1) and FCS experiments (Figure 1B) indicate that the N-terminally tagged Ana2 and Sas-6 proteins are present in the cytoplasm at higher levels than their C-terminally tagged counterparts, our western blotting experiments revealed no obvious difference in the total levels of these proteins in the embryo. Subsequent experiments demonstrated that, for Ana2 at least, this was due to the antibodies not recognising the $\mathrm{N}$-terminally tagged proteins as efficiently as the C-terminally tagged proteins in blotting experiments (data not shown). 


\section{Figure S3}

A i)

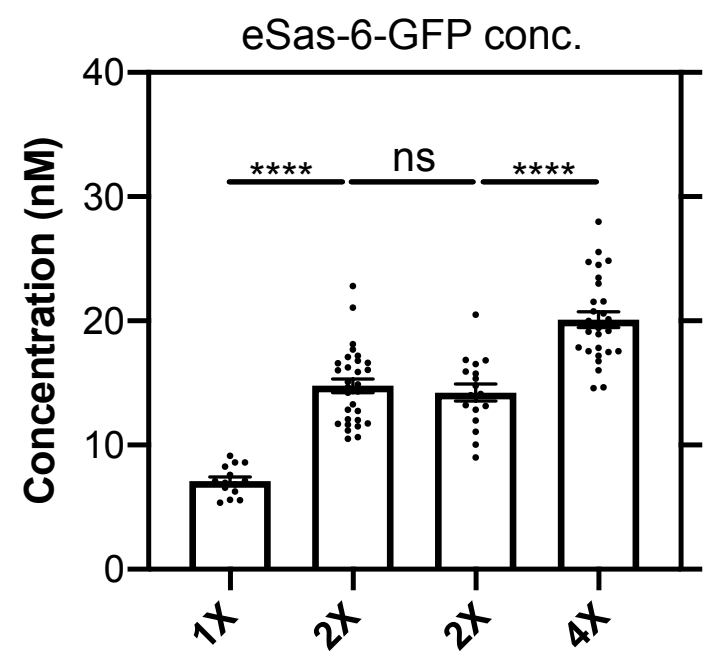

ii)

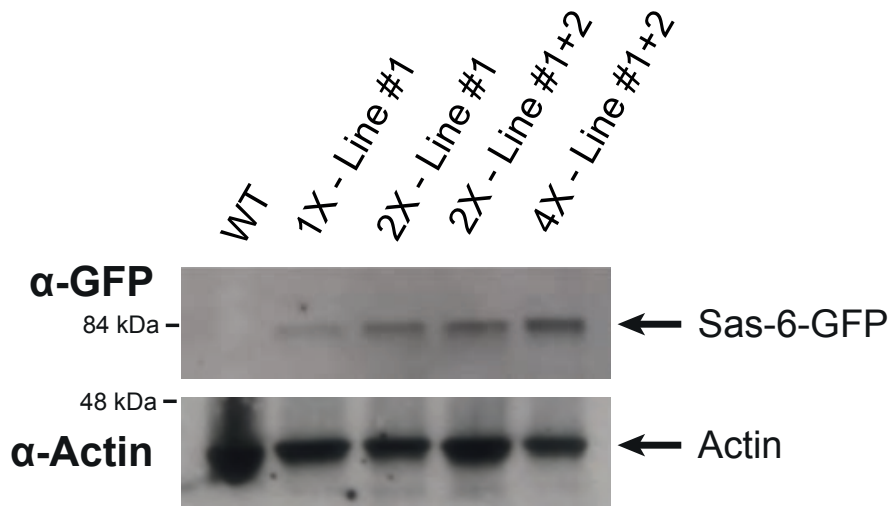

B i)

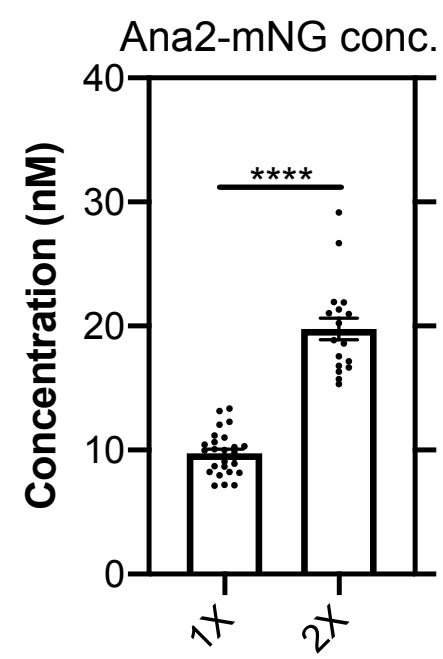

ii)

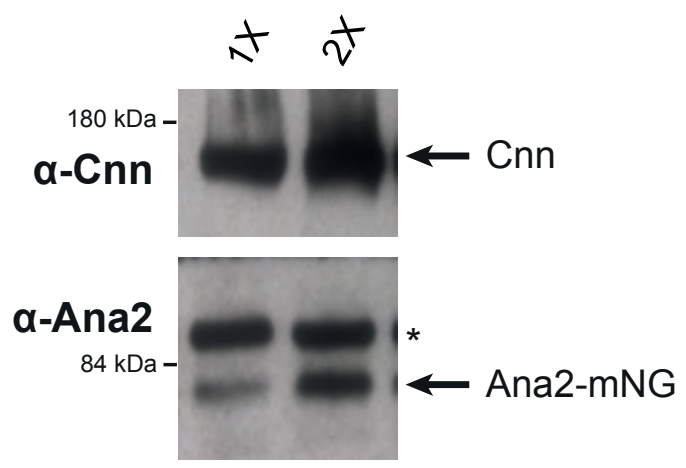

FCS can be used to measure cytoplasmic protein concentrations in the early Drosophila embryo. (A) (i) Graph shows the FCS-measured concentration (Mean \pm SEM) of Sas-6-GFP expressed transgenically from its endogenous promoter in embryos laid by females expressing either: 1 copy of the transgene (1Xf-rom transgenic Line \#1); 2 copies of the transgene (2Xe-ither from two copies of Line \#1 (bar 2) or 1 copy from both Line \#1 and transgenic Line \#2 (bar 3)) and four copies of the transgene (4Xf-rom 2 copies of both Lines \#1 and \#2 together). (ii) Western blots of 0-2hr old embryos laid by the females described in A(i). These blots confirm that these combinations of transgenes are expressed at approximately the expected levels. Actin is shown as a loading control. A representative blot is shown from at least two technical repeats. (B) (i) Graph shows the FCS-measured concentration (Mean \pm SEM) of Ana2-mNG expressed from a CRISPR/Cas9 knock-in line as either a heterogg ote ( $1 \mathrm{X}$ copy of the tagged gene) or homozg ote ( $2 \mathrm{X}$ copies of the tagged gene). (ii) Western blots of 0-2hr old embryos laid by the females described in B(i). These blots confirm that these combinations of transgenes are expressed at approximately the expected levels. Prominent non-specific bands recognised by the anti-Ana2 antibodies are highlighted (*), the centrosomal protein $\mathrm{Cnn}$ is shown as a loading control. A representative blot is shown from at least two technical repeats. 


\section{Figure S4}

A

C
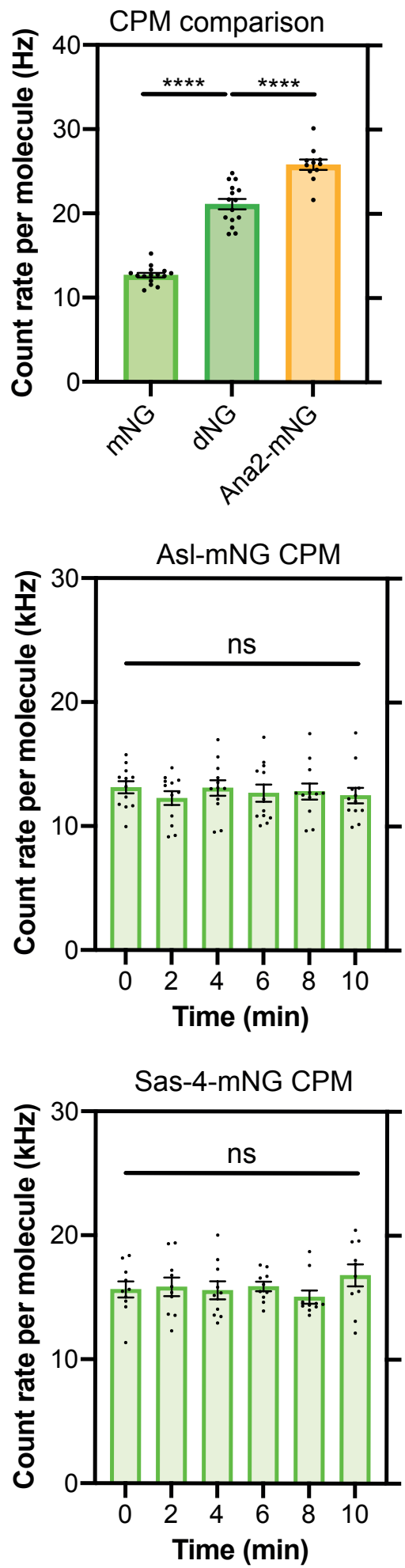

B
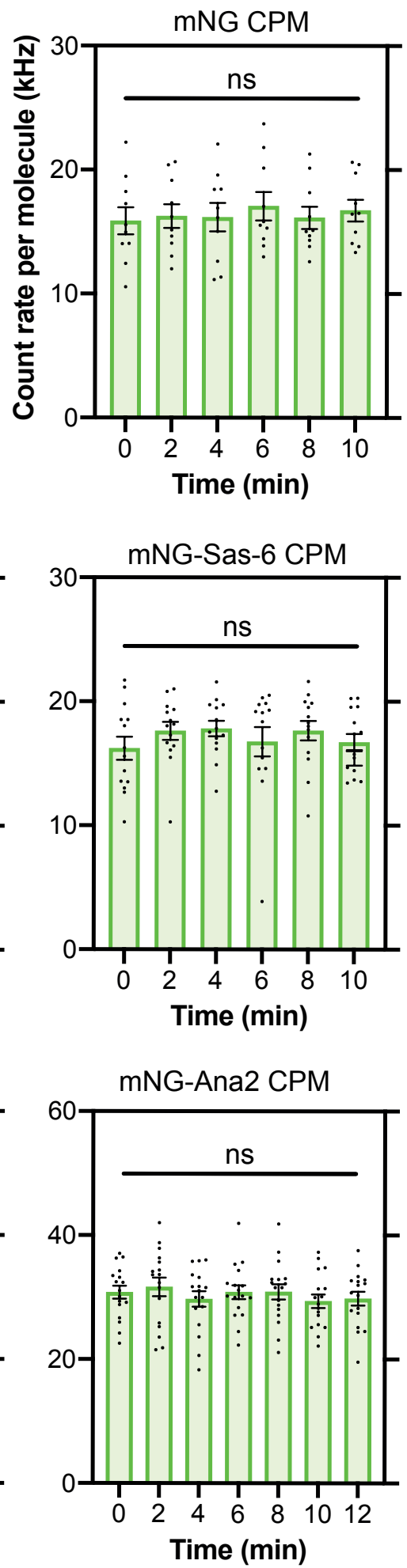
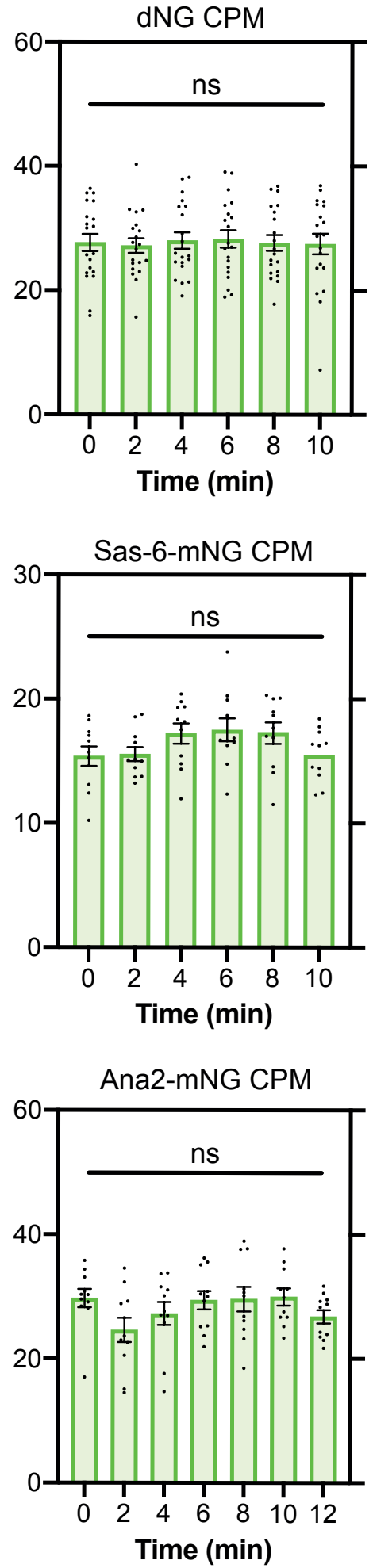

The homo-oligomeric state of Ana2 does not appear to change during the nuclear cycle. (A) Graph shows the average FCS-measured CPM values (Mean \pm SEM) for Ana2-mNG compared to monomeric and dimeric NeonGreen measured at the beginning of nuclear cycle 12. Statistical significance was assessed using an unpaired t-test with Welch's correction ( $\left.{ }^{* * * *}, \mathrm{P}<0.0001\right)$. (B,C) Graphs show cytoplasmic FCS-measured CPM values (Mean \pm SEM) of $\mathrm{mNG}, \mathrm{dNG}(\mathrm{B})$ and $\mathrm{mNG}$ fusions to the core centriole duplication proteins $(C)$ during nuclear cycle 12. Measurements were taken every two minutes from the start of nuclear cycle 12. Statistical significance was assessed using a paired one-way ANOVA test (for Gaussian-distributed data) or a Friedman test (ns, not significant). 


\section{Figure S5}

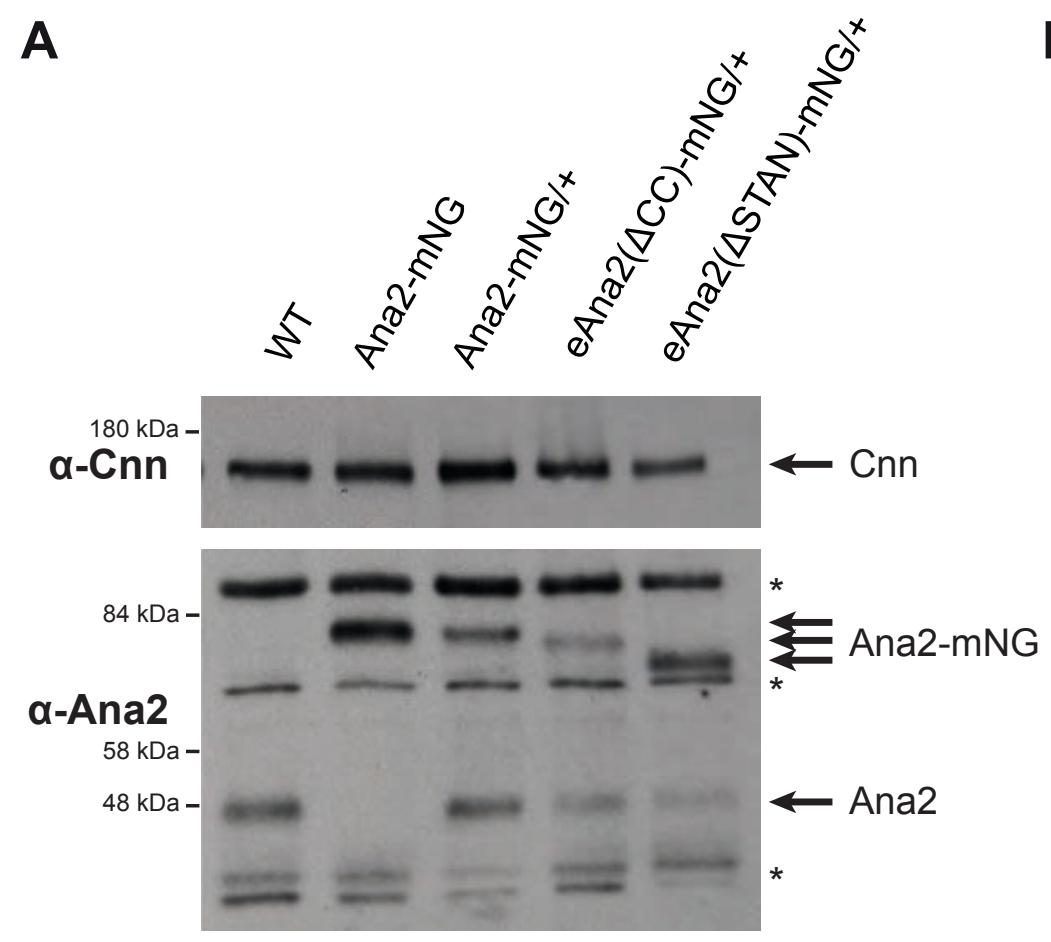

\section{B}

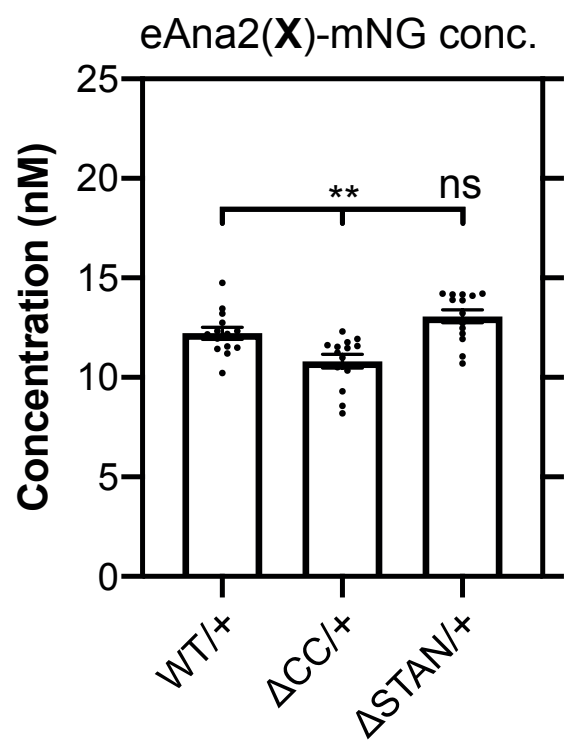

An analysis of the expression levels of WT and various mutant Ana2 transgenic and knock-in lines. (A) Western blots of 0-2hr embryos showing the expression levels of endogenous Ana2, a homogg ous WT Ana2-mNG knock-in line, and transgenic lines expressing either WT Ana2-mNG, eAna2( $\triangle \mathrm{CC}$ )-mNG and eAna2( $\triangle \mathrm{STAN}$ )-mNG (all in an ana2 ${ }^{+/}$heterołg ous background, i.e. in the presence of one copy of the endogenous, untagged ana2 gene). Prominent non-specific bands recognised by the anti-Ana2 antibodies are highlighted $\left({ }^{*}\right)$, and the centrosomal protein $\mathrm{Cnn}$ is shown as a loading control. A representative blot is shown from at least two technical repeats. (B) Graph shows FCS-measured cytoplasmic concentrations (Mean \pm SEM) of WT Ana2-mNG, eAna2( $\triangle \mathrm{CC}$ )-mNG and eAna2( $\triangle \mathrm{STAN}$ )-mNG (all in an ana2 ${ }^{+/}$heterozg ous background). Statistical significance was assessed using an unpaired t-test with Welch's correction (for Gaussian-distributed data) or a Mann-Whitney test (**, $\mathrm{P}<0.01$; ns, not significant). 


\section{Figure S6}

A

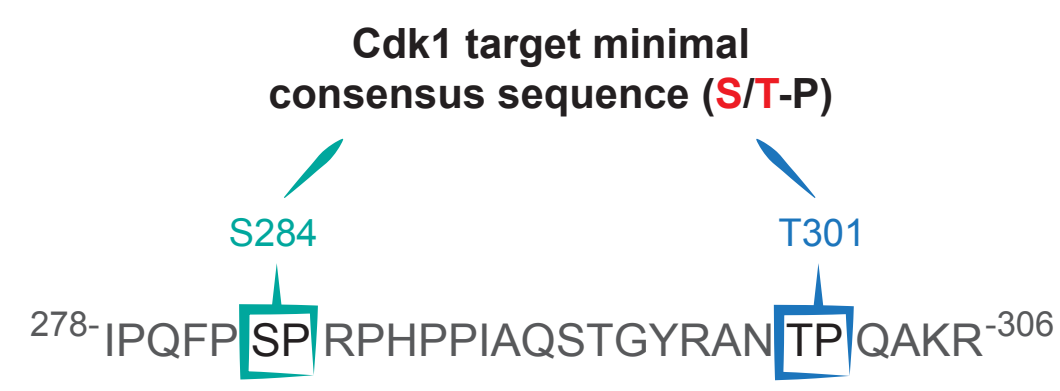

B

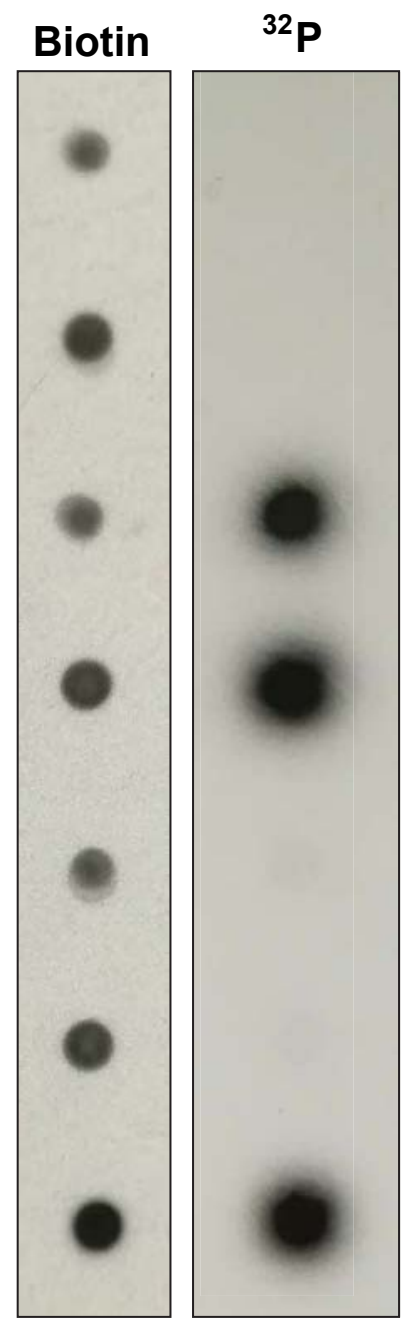

\author{
Biotinylated peptide \\ ${ }^{278-}$ IPQFPSPRPHP-289 \\ 295- GYRANTPQAKR ${ }^{-306}$ \\ 278-IPQFP $\underline{\text { SPRPHP }}{ }^{-289}$
}

295- GYRANTPQAKR ${ }^{-306}$

${ }^{278-I P Q F P} \underline{\text { APRPHP }}{ }^{-289}$

${ }^{295-}$ GYRANAPQAKR ${ }^{-306}$

KPPKTPKK
Cdk1/Cyclin B

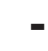

$+$

$+$

$+$

$+$

The S284 and T301 S/T-P motifs of Ana2 can be phosphorylated by recombinant Cdk1/Cyclin B kinase in vitro. (A) The sequence of Ana2 (aa278-306) highlighting the S/T-P motifs at S284 and T301. (B) The indicated biotinylated peptides were synthesised in vitro and incubated with 32P-ATP in the presence of recombinant human Cdk1/Cyclin B, or buffer alone. The reaction mixtures were spotted onto nitrocellulose membranes and autoradiographs were obtained before the membranes were probed with anti-biotin antibodies to confirm the approximately equal loading of the peptides. The peptides including S284 and T301 were phosphorylated specifically in the presence of the kinase to approximately the same extent as the positive control peptide, and this was phosphorylation was essentially abolished if S284 or T301 were mutated to Alanine. We conclude that both of these sites are strongly and specifically phosphorylated by $\mathrm{Cdk} 1 /$ Cyclin B in vitro. A representative blot is shown from three technical repeats. 


\section{Figure $\mathbf{S 7}$}

A
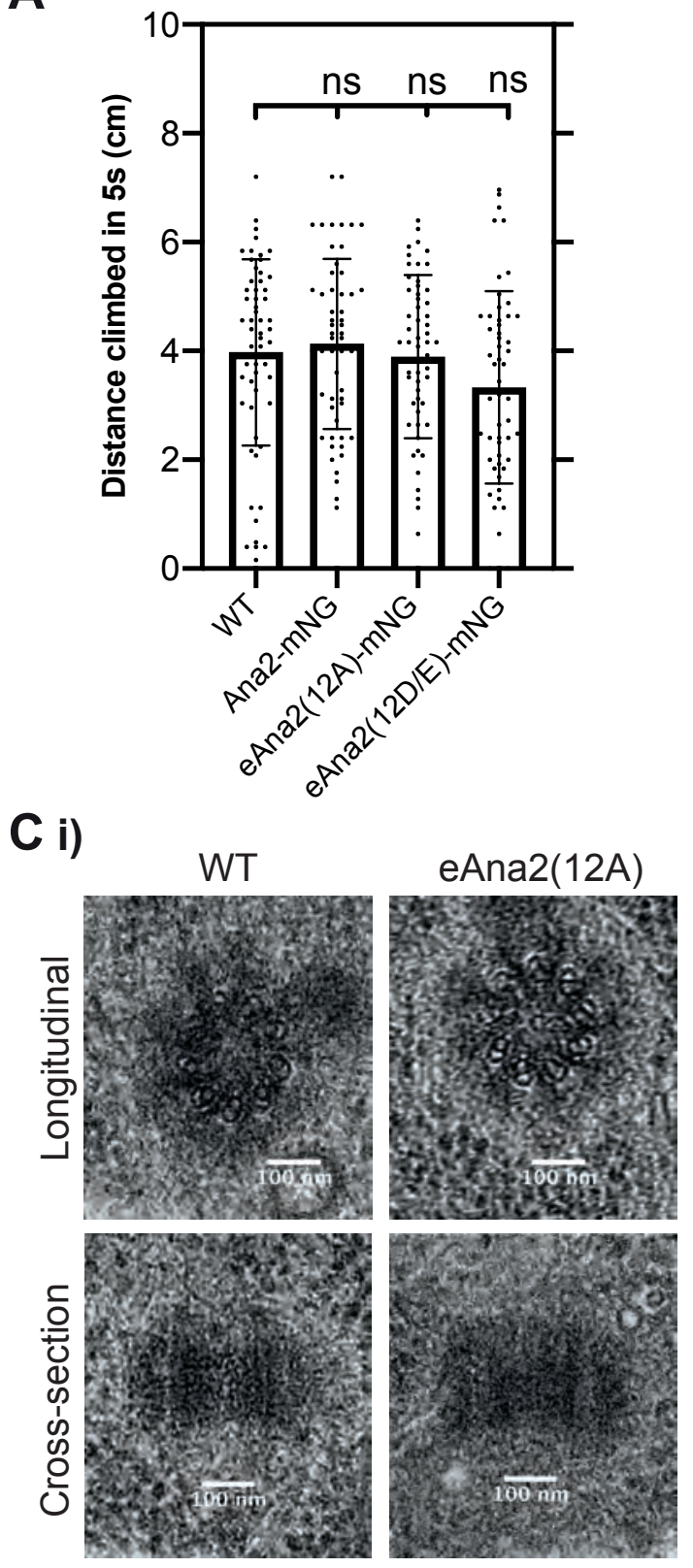

B

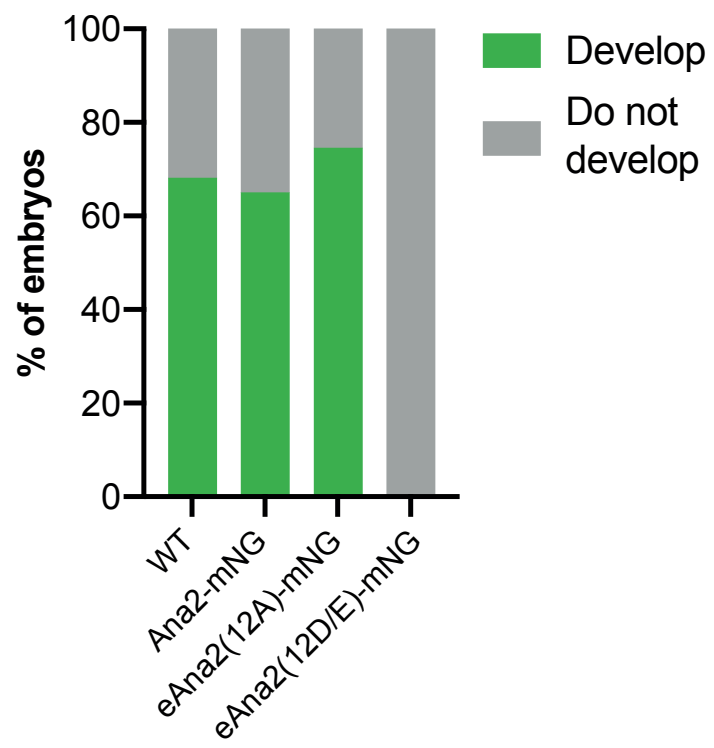

ii)

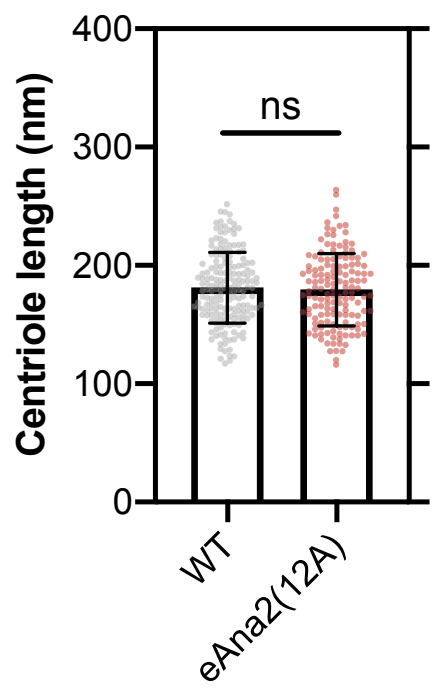

The Ana2(12A) mutant appears to fully rescue the ana2-/- mutant phenotype. (A) Graphs quantify the distance climbed by WT or ana2-/- mutant flies expressing either WT Ana2-mNG, eAna2(12A)-mNG or eAna2(12D/E)-mNG in the $5 \mathrm{sec}$ period after all the flies have been mechanically "banged" to the bottom of a vial. This is a standard assay to measure fly coordination. Note that ana2- mutant flies are completely uncoordinated, so they cannot climb any distance at all. All three alleles, WT, 12A and 12D/E rescue this phenotype, suggesting that centriole duplication and cilia formation are unperturbed in these "rescued" flies. Each individual point on the graph represents the average distance climbed by a single fly in an individual experiment. 10-15 flies were measured in 4-6 technical repeats for each genotype. Statistical significance was assessed using an unpaired t-test with Welch's correction (ns, not significant). (B) Graph quantifies the percentage of embryos that hatch as larvae when laid by either WT females or ana2- mutant females expressing either WT Ana2-mNG, eAna2(12A)-mNG or eAna2(12D/E)-mNG. Note that these experiments were conducted when the laboratory was experiencing a general problem with Fly food, whereby many of our laboratory strains were laying embryos that did not hatch at their normal high frequencies (usually $>85 \%$ for WT controls); $\sim 400$ embryos were counted for each genotype. (C) (i) EM Images show exemplar centrioles in either WT or ana2-- mutant expressing eAna2(12A) 3rd instar larval wing discs. We examined $>200$ centrioles in 5 wing-discs of each genotype and identified no obvious morphological defects. (ii) Graph shows centriole lengthseo red blind in longitudinal EM sections, as depicted in the bottom panels in (Ci)i- $n$ ana2-/- mutant 3rd instar larval wing discs expressing either eAna2(WT) or eAna2(12A). Statistical significance was assessed using an unpaired t-test with Welch's correction (ns, not significant). 


\section{Figure S8}

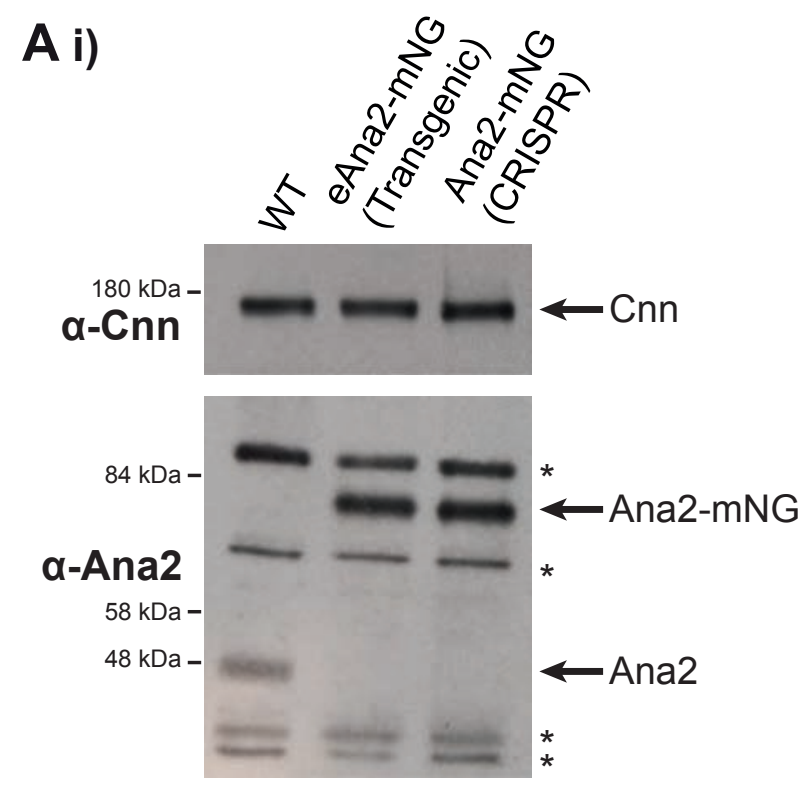

ii)

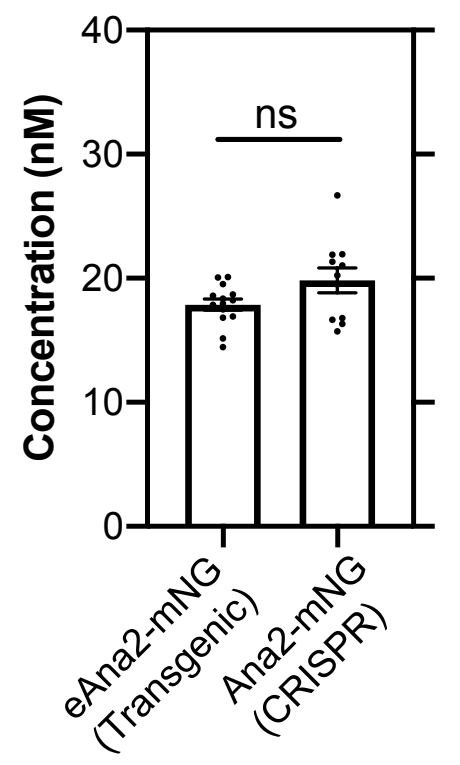

B

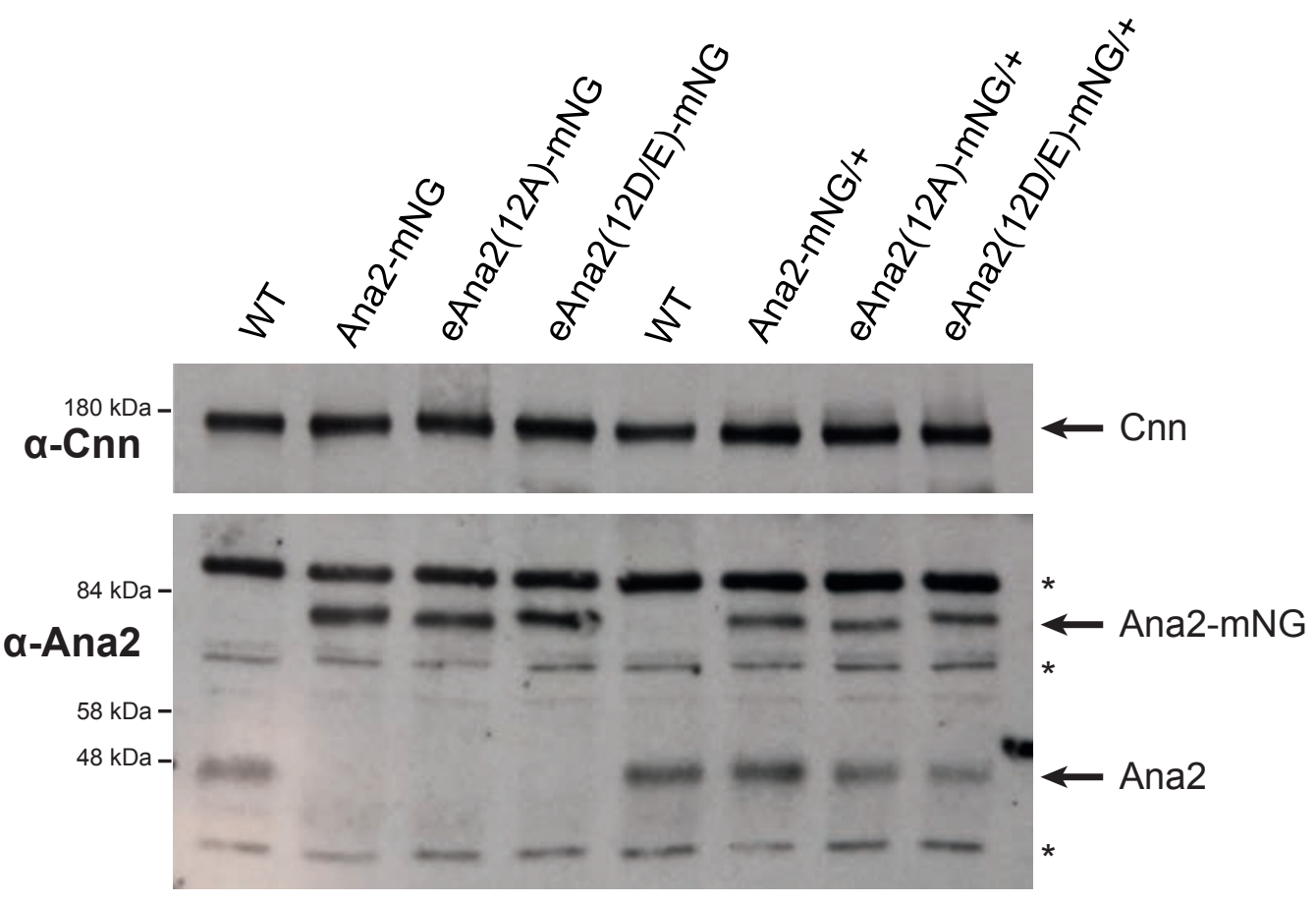

The eAna2-mNG, eAna2(12A) and eAna2(12D/E) proteins are expressed at similar levels. (A) (i) Western blots of $0-2 \mathrm{hr}$ embryos comparing the expression levels of Ana2-mNG in the eAna2-mNG transgenic line generated by P-element mediate transformation (and expressed here in an ana2-/- mutant background) and the Ana2-mNG knock-in line generated by CRISPR/Cas9. The two proteins are expressed at similar levels and are both overexpressed by $\sim 2$-4-fold compared to the endogenous protein. A representative blot is shown from at least two technical repeats. (ii) Graph compares FCS-measured cytoplasmic Ana2-mNG concentrations (Mean \pm SEM) in the transgenic WT eAna2-mNG and CRISPR/Cas9 knock-in Ana2-mNG lines. Measurements were taken at the start of nuclear cycle 12. Statistical significance was assessed using an unpaired t-test with Welch's correction (ns, not significant). (B) Western blots of 0-2hr embryos comparing the expression levels of Ana2-mNG, eAna2(12A)-mNG and eAna2(12D/E)-mNG, which are comparable in all genotypes. In $(A, B)$ prominent non-specific bands recognised by the anti-Ana2 antibodies are highlighted $\left({ }^{*}\right)$, Cnn is shown as a loading control, and a representative blot is shown from at least two technical repeats. 


\section{Materials and Methods}

\section{Drosophila melanogaster stocks}

\section{Fly stocks and husbandry}

A list of all alleles and fly stocks used in this study can be found in Table S1. Flies were maintained at $18{ }^{\circ} \mathrm{C}$ or $25^{\circ} \mathrm{C}$ in plastic vials or bottles on Drosophila culture medium $(0.68 \%$ agar, $2.5 \%$ yeast, $6.25 \%$ cornmeal (maize), $3.75 \%$ molasses, $0.42 \%$ propionic acid, $0.14 \%$ tegosept, and $0.70 \%$ ethanol). For spectroscopy/microscopy, hatching rate and western blotting experiments, flies were placed in egg-laying cages on fruit juice plates $(40 \%$ cranberry-raspberry juice, $2 \%$ sucrose, and $1.8 \%$ agar) with a drop of yeast paste. Fly handling techniques were performed as previously described (Roberts, 1986).

\section{CRISPR/Cas9-mediated fly line generation}

For CRISPR/Cas9-mediated fly line generation of mNG knock-ins, a single guide RNA (gRNA) plasmid and donor plasmid for homology-directed repair (HDR) were injected into embryos expressing Cas9 from the nos promoter (BL54591) as previously described (Port et al., 2015, 2014). The injected founder flies were crossed to balancer lines to isolate the potential knockin allele and screened via PCR for the mNG insertion. All gRNA plasmids (pCFD3: U6:3-gRNA) were generated as described in (Port et al., 2014). The gRNA target sequences were chosen based on a gRNA design algorithm to reduce potential off-target effects. Donor plasmids were assembled from individual PCR-amplified DNA fragments using NEBuilder ${ }^{\circledR} \mathrm{HiFi}$ DNA Assembly-based cloning and consisted of $\sim 1 \mathrm{~kb}$ homology arms up-and downstream of the cutting site, the mNG sequence including a short linker (N-term: TATCAAACAAGTTTGTACAAAAAAGCAGGCTTC; C-term: GACCCAGCTTTCTTGTACAAAGTGGTT CGATATCCAGCACAGTGGCGGCCGCTCGAG), and a plasmid backbone (pBluescript SK-). To 
prevent cleavage of the target sequence within the homology arm of the donor plasmid, point mutations in the gRNA sequence within the coding region-where possible and especially within the NGG protospacer adjacent motif (PAM) sequence-were generated that only affect individual base pairs but not the amino acid sequence of the gene. Further, the gRNA target and PAM sequence were inserted at the outer flanks of both homology arms to induce Cas9-mediated cleavage and thereby linearisation of the donor plasmid in vivo.

For the generation of CRISPR/Cas9-mediated ana2 knock-out alleles ( $a n a 2^{\Delta a}$ and $a n a 2^{\Delta b}$ ), two gRNAs (one for each end of the ana 2 coding region; different 5' and 3' gRNAs were designed to generate the two alleles) were cloned into the pCFD4 (U6:1-gRNA U6:3-gRNA) plasmid (Port et al., 2014, 2015). The resulting plasmids were injected into BL25709 flies (y, v, nos-int; attp40) to generate gRNA-transgenic flies through attP-mediated mutagenesis. These transgenic flies were crossed to the previously described Cas9-expressing fly line BL54591 (Port et al., 2014). The $a n a 2^{\Delta a}$ allele [a $1290 \mathrm{bp}$ deletion that removes the entire genomic sequence between the first $15 \mathrm{bp}$ and the last $9 \mathrm{bp}$ of the Ana2 protein coding sequence] and the $a n a 2^{\Delta b}$ allele [a 1299 bp deletion that removes the entire genomic sequence between the first $2 \mathrm{bp}$ and the last $13 \mathrm{bp}$ of the Ana2 protein coding sequence] were isolated from a single founder each from the second-generation progeny.

The entire gene locus of all final knock-in and knock-out fly lines were afterwards sequenced. All injections for fly line generation were performed by 'The University of Cambridge Department of Genetics Fly Facility'. All gRNA sequences and primers used for the generation of gRNA/donor plasmids and screening of founder flies can be found in Table S2. 


\section{Transgenic fly line generation}

Transgenic fly lines were generated via random P-element insertion (injected, mapped, and balanced by 'The University of Cambridge Department of Genetics Fly Facility'). For transgene selection, the $w^{+}$gene marker was included in the transformation vectors and injected into the $w^{1118}$ genetic background.

To generate Ana2 12A mutants, mutations encoding the following amino acid substitutions were introduced into an eAna2-pDONR vector (encoding the genomic region of ana2 from 2 $\mathrm{kb}$ upstream of the start codon up to, but not including the stop codon; (Aydogan et al., 2018) using NEB Q5 Site Directed Mutagenesis: S63A; S84A; S101A; S172A; S257A; S284A; T301A; S345A; S348A; S365A; S395A; S403A. The resulting constructs were recombined with a destination vector encoding mNG (Aydogan et al., 2020) using Gateway technology (Thermo Fischer Scientific) to create eAna2(12A)-mNG. For untagged eAna2(12A), the endogenous ana2 stop codon was reintroduced at its normal locus into the eAna2(12A) pDONR (described above) using NEB Q5 Site Directed Mutagenesis and the resulting vector was recombined with a destination vector encoding no tag (Aydogan et al., 2018), using Gateway technology.

All other transgenic Ana2 constructs were directly cloned into the appropriate destination vector (with or without $\mathrm{mNG}$ tag as described above) expressed from the ana2 core promoter (2kb) using NEBuilder ${ }^{\circledR}$ HiFi DNA Assembly. The WT Ana2 gene was amplified from genomic BL54591 DNA, and the cDNA of the two truncated Ana2 constructs ( $\Delta C C$ (aa195-229), $\triangle$ STAN(aa316-383)) was amplified from previously generated plasmids (Cottee et al., 2015). For both cDNA-containing destination vectors, Ana2's one intron was afterwards reintroduced using NEBuilder ${ }^{\circledR}$ HiFi DNA Assembly. The 12D/E mutations of Ana2 (S63D; 
S84D; S101D; S172D; S257D; S284D; T301E; S345D; S348D; S365D; S395D; S403D (S -> D and

T -> E to mimic the size of the aa)) was designed in silico and synthesised by GENEWIZ Co. Ltd.

(Suzhou, China). All primers used for the generation of transgenic fly lines can be found in

Table 2.

\section{Behavioral assays}

\section{Hatching experiments}

Embryos were collected for $1 \mathrm{~h}$ and aged for $24 \mathrm{~h}$ at $25^{\circ} \mathrm{C}$. Afterwards the hatching rate was calculated by quantifying the $\%$ of embryos that hatched out of their chorion.

\section{Negative gravitaxis experiments}

A negative gravitaxis assay was performed as previously described in (Aydogan et al., 2018). In short, 10-15 2-day-old adult male flies in 3-5 technical repeats were mechanically tapped to the bottom of a measuring cylinder and the distance that was climbed by each individual fly within the first $5 \mathrm{sec}$ after the tap was measured.

\section{Immunoblotting and in vitro kinase assay}

\section{Immunoblotting}

Embryos for immunoblotting were collected for $0-3$ hours at $25^{\circ} \mathrm{C}$, chemically dechorionated and fixed in methanol as previously described in (Stevens et al., 2010). Afterwards, the embryos were stored at $4{ }^{\circ} \mathrm{C}$ at least overnight and rehydrated with $3 \times \mathrm{PBT}$ (PBS $+0.1 \%$ Triton X-100) washes of 15 min each. Under a dissection microscope, 40 pre-cellularisation stage 
embryos of each genotype were transferred into an Eppendorf tube with $20 \mu \mathrm{L}$ of PBT buffer and mixed with $20 \mu \mathrm{L}$ of $2 x$ SDS loading dye to a final concentration of 1 embryo/ $\mu \mathrm{L}$. The samples were then lysed at $95{ }^{\circ} \mathrm{C}$ for $10 \mathrm{~min}$ on a heat block, gently spun for a few seconds on a small lab bench centrifuge and stored at $-20^{\circ} \mathrm{C} .10 \mu \mathrm{L}$ of sample (which is the equivalent of 10 embryos) was loaded into each lane of a 3-8\% Tris-Acetate pre-cast SDS-PAGE gel (Invitrogen, Thermo Fisher Scientific) and afterwards transferred from the gel onto a nitrocellulose membrane (BIO-RAD, $0.2 \mu \mathrm{m} \# 162-0112)$ using a BIO-RAD Mini Trans-Blot system. For western blotting, membranes were incubated with blocking buffer (1x PBS $+4 \%$ milk powder $+0.1 \%$ Tween 20 ) for 1 hour on an orbital shaker at room temperature, then for 1 hour in blocking buffer with the primary antibody (1:500 dilution). The membranes were washed $3 x$ with TBST (TBS $+0.1 \%$ Tween-20) and then incubated for another $45 \mathrm{~min}$ in blocking buffer with the secondary antibody (1:3000 dilution, horseradish peroxidaseconjugated for chemiluminescence analysis). The membranes were washed $3 x$ for 15 min with TBST buffer, before incubation for $1 \mathrm{~min}$ in HRPO substrate (Thermo Scientific SuperSignal West Femto Maximum Sensitivity Substrate, \#34095) at a concentration that was empirically determined for each different protein and exposed to X-ray film for $\sim 10-600 \mathrm{sec}$. The following antibodies and substrate concentrations were used: anti-Sas-6 (rabbit, (Peel et al., 2007), Substrate 1:1); anti-Ana2 (rabbit, (Stevens et al., 2010), Substrate 1:1); anti-Asl (rabbit, (Novak et al., 2014), Substrate 1:4); anti-Sas-4 (rabbit, (Novak et al., 2014), Substrate 1:3); anti-GFP (mouse, Roche AB_390913, Substrate 1:1); anti-actin (mouse, SigmaAldrich AB_476730, Substrate 1:2); anti-Cnn (rabbit, (Lucas and Raff, 2007), Substrate 1:15); anti-Gaga transcription factor (rabbit, (Raff et al., 1994), Substrate 1:5); anti-rabbit (donkey, VWR International Ltd (NA934)) ; anti-mouse (sheep, VWR International Ltd (NA931-1M)). 


\section{In vitro kinase assay and dot blotting}

Peptides for the in vitro kinase assay were synthesized by GeneScript (The Netherlands). The complete peptide sequences were either biotin-GGAIPQFP-[S/A]-PRPHPAKK (representing the S284 site) or biotin- GGAGYRAN-[T/A]-PQAKRAKK (representing the T301 site), and for the positive control biotin-Ahx-GGAKPPKTPKKAKKL ( $\mathrm{Ahx}=$ aminohexanonic acid). All peptides were resuspended and stored at $-80^{\circ} \mathrm{C}$ in $0.1 \mathrm{M}$ phosphate buffer $\mathrm{pH} 7.4,150 \mathrm{mM} \mathrm{NaCl}$ and 2 mM DTT.

The resuspended peptides, at final concentration of $50 \mu \mathrm{M}$, were combined with $0.36 \mu \mathrm{g}$ of recombinant human protein CDK1/Cyclin B (Thermo Fisher, PV3292), 1x Kinase Buffer (Cell Signaling, \#9802), $100 \mu \mathrm{M}$ cold ATPs (Cell Signaling, \#9804) and $5 \mu \mathrm{Ci} \psi$-[32P] ATP in a reaction volume of $20 \mu \mathrm{l}$. The reaction was incubated at $30{ }^{\circ} \mathrm{C}$ for $15 \mathrm{~min}$, and then terminated with $10 \mu \mathrm{l}$ of $7.5 \mathrm{M} \mathrm{GuHCl}$. $4 \mu \mathrm{l}$ of each reaction was spotted onto a streptavidin-coated SAM2 Biotin Capture Membrane (Promega, \#TB547). The membrane was air-dried, then washed 2x for 30 sec with $2 \mathrm{M} \mathrm{NaCl}, 3 \times 2$ min with $2 \mathrm{M} \mathrm{NaCl}$, 4x 2 min with $2 \mathrm{M} \mathrm{NaCl}+1 \% \mathrm{H} 3 \mathrm{PO} 4$, and then $2 \times 30$ sec with distilled water and air-dried again. The dry membrane was exposed to autoradiograph film (Carestream BioMax MR) for different lengths of time. Overnight exposures were performed at $-80^{\circ} \mathrm{C}$.

A loading control for the kinase assay was performed using a dot blot. $1.2 \mu \mathrm{l}$ of the resuspended peptide was spotted on to a nitrocellulose membrane (BIO-RAD, $0.2 \mu \mathrm{m} \# 162-$ 0112) and left to air-dry. The dry membrane was washed in blocking buffer (PBS $+4 \%$ milk powder $+0.1 \%$ Tween-20) for 20-30 $\mathrm{min}$ and subsequently incubated for $45 \mathrm{~min}$ in Streptavidin-HRP (Thermo Scientific) diluted 1:3000 in blocking buffer. The membrane was 
then washed $3 \times 10-15 \mathrm{~min}$ in wash buffer (TBS $+0.1 \%$ Tween-20) followed by incubation with HRPO-substrate (Thermo Scientific SuperSignal West Femto Maximum Sensitivity Substrate, \#34095) for 1 min and subsequently exposed on film.

\section{Spectroscopy/microscopy experiments}

\section{Embryo collection for fluorescence spectroscopy/microscopy measurements}

Embryos were collected on cranberry-raspberry juice plates for $1 \mathrm{~h}$ at $25^{\circ} \mathrm{C}$ and aged at $25^{\circ} \mathrm{C}$ for another 45 min. Embryos were then dechorionated by hand and mounted on a strip of glue which was positioned on either high precision $35 \mathrm{~mm}$, high Glass Bottom $\mu$-dishes (ibidi) (for FCS/PeCoS experiments) or on MatTek dishes $(1.5 \mathrm{H}$ thick glass bottom, MatTek Corporation, USA). Embryos were covered in Voltalef H1OS PCTFE oil (ARKEMA, France) to avoid desiccation.

\section{Fluorescence correlation spectroscopy (FCS) and Peak Counting Spectroscopy (PeCoS)}

Point FCS and PeCoS measurements were performed and analysed as previously described in (Aydogan et al., 2020). All measurements were conducted on a confocal Zeiss LSM 880 (Argon laser excitation at $488 \mathrm{~nm}$ and GaAsP photon-counting detector (491-544 $\mathrm{nm}$ detector range)) with Zen Black Software. A C-Apochromat 40x/1.2 W objective and a pinhole setting of 1AU were used, spherical aberrations were corrected for on the correction collar of the objective at the beginning of each experimental day by maximizing the FCS-derived CPM value of a fluorescent dye solution. The effective volume $V_{\text {eff }}$ was previously estimated to be $\sim 0.25 \mathrm{fL}$ (determined by two independent methods: (1) comparison of the diffusion coefficient of Alexa Fluor 488 NHS Ester in water with a previously reported one (Petrášek and Schwille, 
2008); (2) imaging of subresolution beads (FluoSpheres Carboxylate-Modified Microspheres, $0.1 \mu \mathrm{m})$. Measurements were conducted with a laser power of $6.31 \mu \mathrm{W}$ for FCS and $10.00 \mu \mathrm{W}$ for PeCoS, and no photobleaching was observed for any protein. The temperature of the microscope was kept between $25.0-26.0^{\circ} \mathrm{C}$ using the Zeiss inbuilt heating unit $\mathrm{XL}$.

For experimental FCS recordings, consecutive cytoplasmic measurements were made $6 x$ for $10 \mathrm{sec}$ each at the centrosomal plane of the embryo. In some cases, the cytoplasmic position of the laser beam was slightly readjusted during the measurement, but the recording, in which the readjustment was made, was discarded. Erratic autocorrelation functions (usually generated when a centrosome or yolk granule moved into the point of measurement) were also discarded before all remaining curves were fitted with eight different diffusion models in the FoCuS-point software (one or two diffusing species with no dark state of the fluorophore, one dark state of the fluorophore (either triplet or blinking state), or two dark states of the fluorophore (triplet and blinking state) (Waithe et al., 2016). The fitting boundaries were restricted to 0.4 ns-200/3000 ms (depending on the diffusion speed of the protein), the triplet state to 1-10 $\mu \mathrm{s}$, and the blinking state to $10-300 \mu \mathrm{s}$. In all models, the structural parameter $A R$, which denotes the ratio of the axial to radial radii $\left(A R=\omega_{z} / \omega_{x y}\right)$ of the measurement volume, was kept constant at 5, and the anomalous subdiffusion parameter $\alpha$ was selected individually for each protein based on the curve's best fit (tested with 0.05 increments). The most suited model and anomalous subdiffusion parameter $\alpha$ were chosen based on the Bayesian information criterion (Schwarz, 1978) and were applied to all measurements of the same protein (see Table S3). After background correction and calculation of the cytoplasmic concentration, diffusion coefficient and CPM, outliers were discarded using a ROUT outlier test (applied to all $10 \mathrm{~s}$ recordings in GraphPad Prism $(\mathrm{Q}=1 \%)$ ). Only measurements 
with at least $4 \times 10$ s recordings were kept for further analysis. For recordings throughout an entire nuclear cycle, only embryos where all measurements fulfilled these criteria were kept. Most embryos developed at a similar speed which resulted in the same number of FCS recordings throughout the cycle, and only these embryos were used for the final analysis.

For PeCoS measurements throughout nuclear cycle 12, one continuous measurement was conducted throughout the first 9 min of S-phase, which was then split into and analysed as individual 60-second-long intervals. If a centriole moved through the observation spot during the measurement and caused a sharp rise in the time-trace of intensity fluctuations, the entire recording was discarded.

\section{Spinning-disk confocal microscopy}

Embryos were imaged at room temperature using an Andor Dragonfly 505 spinning-disk system (40 $\mu \mathrm{m}$ pinholes) which was mounted on a Leica DMi8 stand. A $488 \mathrm{~nm}$ solid state diode laser and a HC PL APO 63x/1.40 oil immersion objective were used. For the image acquisition, stacks consisting of 17 slices with a spacing of $0.5 \mu \mathrm{m}$ in z were taken every 30 sec using an Andor iXon Ultra 888 EMCCD camera.

Post-acquisition, the resulting images were first processed using Fiji (National Institutes of Health), and then further analysed either using GraphPad Prism 8 (for Sas-6-mNG and ePlk4mNG incorporation), methodology described in (Aydogan et al., 2018, 2020) or in a customised Python script (for Ana2-mNG (WT, 12A and 12D/E) incorporation), methodology described in (Wong et al., 2021). In Fiji, the stacks were first reduced to maximum-intensity projections, which were then bleach-corrected using the exponential fit algorithm. The 
background was subtracted using a rolling ball radius of 10 pixels, and the centriolar pairs tracked using the Fiji plug-in TrackMate (Tinevez et al., 2017). The following settings were chosen within TrackMate: spot diameter: $1.1 \mu \mathrm{m}$, no gaps between frames, only centriolar pairs that could be tracked from the beginning of nuclear cycle 12 until nuclear envelope breakdown (NEB) (for Sas-6)/beginning of nuclear cycle 13 (for Ana2)/throughout the entire detection window of the oscillation (for Plk4) were kept for the final analysis.

For the Sas- 6 incorporation dynamics, the regression of all centriolar pairs of each individual embryo was calculated in GraphPad Prism 8 and, in agreement with our previous studies (Aydogan et al., 2018), the 'linear growth+plateau' model was the preferred model to describe centriole growth under WT conditions. Within the experiment, all regression curves were fitted with a 'linear growth+plateau' and a 'linear growth only' model and, depending on the best fit, the incorporation parameters were extracted from either of the two models. For the Plk4 incorporation dynamics, a Lorentzian model was fitted in GraphPad Prism 8 to extract the amplitude and location of the peak as previously described (Aydogan et al., 2020). For the Ana2 incorporation dynamics, the mean intensity curve from all embryos was not modelled but directly displayed from the normalised raw data, and the incorporation parameters for each embryo extracted from the initial timepoint and the datapoint with the maximum intensity. Sas- 6 and Ana2 incorporation data was normalised to NEB, Plk4-mNG to centriole separation (CS) as NEB could not be identified due to the low cytoplasmic signal. The mean signal of the first time point detected under WT conditions was set as a signal of 1 and the data normalised accordingly. 
The averaged centriole images shown in the Figures represent the collective behaviour of all the centrioles in an embryo. They were generated by averaging the individual images of all the centrioles being tracked in an embryo at each timepoint. The images were adjusted and displayed using the same parameters for each experiment, except for Ana2(12D/E) (Figure 7), where the intensity was doubled for optimal presentation.

\section{Electron microscopy}

Wing-discs from 3rd instar larvae were prepared as described previously (Stevens et al., 2010). Briefly, the wing discs were dissected in PBS and then fixed in $2.5 \%$ glutaraldehyde, $4 \%$ paraformaldehyde and $0.1 \%$ tannic acid (from a freshly prepared $10 \%$ stock) in $0.1 \mathrm{M}$ PIPES buffer ( $\mathrm{pH} 7.2$ ) for $1 \mathrm{hr}$ (up to $2 \mathrm{hr}$ ) at RT and left overnight in the fridge at $4{ }^{\circ} \mathrm{C}$. Samples were then washed twice in 0.1M PIPES, followed by one wash in $50 \mathrm{mM}$ glycine in $0.1 \mathrm{M}$ PIPES to quench free aldehydes, and then another wash in 0.1M PIPES. Samples were then post-fixed in $1 \% \mathrm{OsO}_{4}$ for $2 \mathrm{hr}$ at $\mathrm{RT}$, followed by extensive washing in distilled water. Samples were stained with $0.5 \%$ uranyl acetate overnight at $4{ }^{\circ} \mathrm{C}$, washed in distilled water, dehydrated in an ethanol series and embedded in Agar100 (Agar Scientific). Blocks were polymerised at 50 ${ }^{\circ} \mathrm{C}$ for $24-42 \mathrm{hr}$. Semi-thin serial sections $(100 \mathrm{~nm})$ were obtained in a Leica EM UC7 ultramicrotome (Leica Microsystems, Austria) and stained in lead citrate. Images of centrioles in longitudinal orientation were taken on a TECNAI T12 transmission microscope (FEl, Netherlands) at $13,000 \mathrm{X}$ magnification, to measure centriole length from wing-discs. The length of the MT doublets within the electron-dense area was measured using the line tool in Fiji (ImageJ).

\section{Data visualisation and statistical analysis}


bioRxiv preprint doi: https://doi.org/10.1101/2022.02.15.480489; this version posted February 16, 2022 . The copyright holder for this

preprint (which was not certified by peer review) is the author/funder, who has granted bioRxiv a license to display the preprint in perpetuity. It is made available under aCC-BY-NC 4.0 International license.

All data graphs were generated, and all statistical analysis were performed in GraphPad Prism

7 or 8 . The statistical tests applied to individual datasets are described in the corresponding figure legends. In general, a D'Agostino-Pearson omnibus normality test was applied to each data set to assess whether its data values resembled a Gaussian distribution. Statistical significance was defined as $\mathrm{P}<0.05$.

Table S1: Alleles and fly stocks used in this study

\begin{tabular}{|c|c|}
\hline Alleles used in this study & Source \\
\hline$p($ Sas-6)-mNG & (Alvarez-Rodrigo et al., 2019) \\
\hline$p($ Sas-6)-dNG & (Alvarez-Rodrigo et al., 2019) \\
\hline eAsl-mKate2 & (Aydogan et al., 2020) \\
\hline$\left.a s\right|^{B 46}$ & (Baumbach et al., 2015) \\
\hline$m N G-A s l$ & This paper; CRISPR/Cas9 knock-in \\
\hline Asl-mNG & This paper; CRISPR/Cas9 knock-in \\
\hline mNG-Sas-6 & This paper; CRISPR/Cas9 knock-in \\
\hline Sas-6-mNG & This paper; CRISPR/Cas9 knock-in \\
\hline Sas-4-mNG & This paper; CRISPR/Cas9 knock-in \\
\hline$m N G-A n a 2$ & This paper; CRISPR/Cas9 knock-in \\
\hline Ana2-mNG & This paper; CRISPR/Cas9 knock-in \\
\hline$m N G-P I k 4$ & This paper; CRISPR/Cas9 knock-in \\
\hline$e P I k 4-m N G$ & (Aydogan et al., 2020) \\
\hline Plk4Aa74 & (Aydogan et al., 2018) \\
\hline eSas-6-GFP & (Aydogan et al., 2018) \\
\hline Sas-6 602901 & (Peel et al., 2007) \\
\hline$a n a 2^{\Delta a}$ & This paper; CRISPR/Cas9 knock-out \\
\hline
\end{tabular}


bioRxiv preprint doi: https://doi.org/10.1101/2022.02.15.480489; this version posted February 16,2022 . The copyright holder for this

preprint (which was not certified by peer review) is the author/funder, who has granted bioRxiv a license to display the preprint in perpetuity. It is made available under aCC-BY-NC 4.0 International license.

\begin{tabular}{|c|c|}
\hline$a n a 2^{\Delta b}$ & This paper; CRISPR/Cas9 knock-out \\
\hline WT eAna2-mNG & This paper; transgenic allele expressed from core promoter \\
\hline eAna2( $\triangle C C)-m N G \# 4$ & This paper; transgenic allele expressed from core promoter \\
\hline eAna2(ASTAN)-mNG\#2 & This paper; transgenic allele expressed from core promoter \\
\hline$e A n a 2(12 A)-m N G$ & This paper; transgenic allele expressed from core promoter \\
\hline eAna2(12A) & This paper; transgenic allele expressed from core promoter \\
\hline eAna2(12D/E)-mNG & This paper; transgenic allele expressed from core promoter \\
\hline Fly stocks used in this study & Figure \\
\hline Oregon- $R$ (Wild type control) & $5, S 2, S 3, S 5, S 7 C, S 8$ \\
\hline $\begin{array}{l}W^{67} \text { (used as WT control in some } \\
\text { experiments) }\end{array}$ & $S 7 A+B$ \\
\hline $\begin{array}{l}\text { w;;p(Sas-6)-mNG/eAsl-mKate2, } \\
\text { as/B46 }^{\text {But }}\end{array}$ & $1,2,54$ \\
\hline $\begin{array}{l}\text { w;;p(Sas-6)-dNG/eAsl-mKate2, } \\
\text { as/B46 }^{\text {But }}\end{array}$ & $1,2,54$ \\
\hline$w ; ; m N G-A s l /+$ & S1, S2 \\
\hline$w ;$; Asl-mNG/Asl-mNG & $1,2, S 1, S 2,54$ \\
\hline w;; Asl-mNG/+ & $S 2$ \\
\hline w;; mNG-Sas-6/mNG-Sas-6 & $1,2, S 1, S 2,54$ \\
\hline$w ; ; m N G-S a s-6 /+$ & $S 2$ \\
\hline w; Sas-6-mNG/Sas-6-mNG & $1,2, S 1, S 2,54$ \\
\hline w; Sas-6-mNG/+ & $5, S 2$ \\
\hline w; Sas-4-mNG/Sas-4-mNG & $1,2, S 1, S 2,54$ \\
\hline$w ;$; Sas-4-mNG/+ & $S 2$ \\
\hline$w ; m N G-A n a 2 / m N G-A n a 2$ & $1,2, S 1, S 2, S 4$ \\
\hline w; mNG-Ana2/+ & $S 2$ \\
\hline
\end{tabular}


bioRxiv preprint doi: https://doi.org/10.1101/2022.02.15.480489; this version posted February 16,2022 . The copyright holder for this

preprint (which was not certified by peer review) is the author/funder, who has granted bioRxiv a license to display the preprint in perpetuity. It is made available under aCC-BY-NC 4.0 International license.

\begin{tabular}{|c|c|}
\hline w; Ana2-mNG/Ana2-mNG & $1,2,4, S 1, S 2, S 3, S 4, S 5 A, S 7, S 8$ \\
\hline w; Ana2-mNG/+ & $7, S 2, S 5 A, S 8$ \\
\hline$w ; ; m N G-P I k 4 / m N G-P I k 4$ & S1 \\
\hline $\begin{array}{l}\text { W;; ePIk4-mNG, Plk4Aa74/ } \\
\text { ePIk4-mNG, PIk4Aa74 }\end{array}$ & $1,6, S 1$ \\
\hline $\begin{array}{l}\text { w; eSas-6-GFP\#1/+ ; Sas- } \\
\text { 602901/Sas-6c02901 }\end{array}$ & S3 \\
\hline $\begin{array}{l}\text { w; eSas-6-GFP\#1/eSas-6-GFP\#1; } \\
\text { Sas-6 } 0202901 / \text { Sas-6 } 0202901\end{array}$ & S3 \\
\hline $\begin{array}{l}\text { w; eSas-6-GFP\#1/+ ; Sas-6 602901, } \\
\text { eSas-6-GFP\#2/+ }\end{array}$ & S3 \\
\hline $\begin{array}{l}\text { w; eSas-6-GFP\#1/eSas-6-GFP\#1; } \\
\text { Sas-6 602901, eSas-6- } \\
\text { GFP\#2/Sas-6c02901, eSas-6-GFP\#2 }\end{array}$ & S3 \\
\hline $\begin{array}{l}\text { W; ana } 2^{\Delta a} /+; e A n a 2-m N G / \text { eAsl- } \\
\text { mKate2, as/B46 }\end{array}$ & $3, S 5 B$ \\
\hline $\begin{array}{l}\text { w; ana } 2^{\Delta a} /+; \operatorname{eAna2}(\triangle C C)- \\
m N G / e A s I-m K a t e 2,\left.a s\right|^{B 46}\end{array}$ & 3,55 \\
\hline 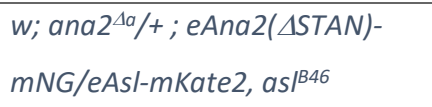 & 3,55 \\
\hline $\begin{array}{l}\text { w; ana2 } 2^{\Delta a} / a n a 2^{\Delta a} ; \text { eAna2- } \\
m N G / e A n a 2-m N G\end{array}$ & 3,58 \\
\hline $\begin{array}{l}\text { w; ana2 }{ }^{\Delta b}, e A n a 2(12 A)- \\
m N G / a n a 2^{\Delta b}, e A n a 2(12 A)-m N G\end{array}$ & $3,4, S 7 A+B, S 8$ \\
\hline$w ; a n a 2^{\Delta b}$, eAna2(12A)-mNG/+ & S8 \\
\hline $\begin{array}{l}\text { w; ana } 2^{\Delta a}, e A n a 2(12 A) / a n a 2^{\Delta a}, \\
e A n a 2(12 A)\end{array}$ & S7C \\
\hline $\begin{array}{l}\text { w; ana } 2^{\Delta a}, \text { eAna2 }(12 A) / a n a 2^{\Delta a}, \\
\text { eAna2(12A); Sas-6-mNG/+ }\end{array}$ & 5 \\
\hline
\end{tabular}


bioRxiv preprint doi: https://doi.org/10.1101/2022.02.15.480489; this version posted February 16, 2022 . The copyright holder for this

preprint (which was not certified by peer review) is the author/funder, who has granted bioRxiv a license to display the preprint in perpetuity. It is made available under aCC-BY-NC 4.0 International license.

\begin{tabular}{|c|c|}
\hline $\begin{array}{l}\text { w; ana2 }{ }^{\text {Aa }} \text {, eAna2 }(12 A) /+ \text {; ePIk4- } \\
\text { mNG, Plk4 } 4^{A a 74} / \text { ePIk4-mNG, } \\
\text { Plk4 } 4^{\text {Aa74 }}\end{array}$ & 6 \\
\hline$w ; a n a 2^{\Delta a}$, eAna2(12D/E)-mNG/+ & 7,58 \\
\hline $\begin{array}{l}\text { w; ana } 2^{\Delta a}, \text { eAna2(12D/E)-mNG/ } \\
a n a 2^{\Delta a}, \text { eAna2(12D/E)-mNG }\end{array}$ & $S 7 A+B, S 8$ \\
\hline w; Ana2-mNG/ana2 ${ }^{\Delta a}$ & S3 \\
\hline
\end{tabular}

Table S2: Primers and gRNA sequences used in this study

\begin{tabular}{|c|c|}
\hline Aim & Primer sequences (5'-) \\
\hline $\begin{array}{l}\text { Insertion of Sas- } 6 \text { N-terminal } \\
\text { gRNA sequence into the pCFD3 } \\
\text { plasmid (KI) }\end{array}$ & $\begin{array}{l}\text { GTCGAGTAGCTATCCTCGCTCCC } \\
\text { AAACGGGAGCGAGGATAGCTACT }\end{array}$ \\
\hline $\begin{array}{l}\text { Insertion of Sas-6 C-terminal } \\
\text { gRNA sequence into the pCFD3 } \\
\text { plasmid (KI) }\end{array}$ & $\begin{array}{l}\text { GTCGAGAACGGCTTGCAATACCCA } \\
\text { AAACTGGGTATTGCAAGCCGTTCT }\end{array}$ \\
\hline $\begin{array}{l}\text { Insertion of Ana2 N-terminal } \\
\text { gRNA sequence into the PCFD3 } \\
\text { plasmid (KI) }\end{array}$ & $\begin{array}{l}\text { GTCGGCAGCATATCCTCCGTTTC } \\
\text { AAACGAAACGGAGGATATGCTGC }\end{array}$ \\
\hline $\begin{array}{l}\text { Insertion of Ana2 C-terminal } \\
\text { gRNA sequence into the pCFD3 } \\
\text { plasmid (KI) }\end{array}$ & $\begin{array}{l}\text { GTCGCTTTCACAACAGCTTCGGC } \\
\text { AAACGCCGAAGCTGTTGTGAAAG }\end{array}$ \\
\hline $\begin{array}{l}\text { Insertion of AsI N-terminal gRNA } \\
\text { sequence into the pCFD3 plasmid } \\
\text { (KI) }\end{array}$ & $\begin{array}{l}\text { GTCGATACCTGGCGTGTTCATATT } \\
\text { AAACAATATGAACACGCCAGGTAT }\end{array}$ \\
\hline $\begin{array}{l}\text { Insertion of Asl C-terminal gRNA } \\
\text { sequence into the pCFD3 plasmid } \\
\text { (KI) }\end{array}$ & $\begin{array}{l}\text { GTCGTTAGCTGTGACCATTGCCTT } \\
\text { AAACAAGGCAATGGTCACAGCTAA }\end{array}$ \\
\hline $\begin{array}{l}\text { Insertion of Sas-4 C-terminal } \\
\text { gRNA sequence into the pCFD3 } \\
\text { plasmid (KI) }\end{array}$ & $\begin{array}{l}\text { GTCGAGAGACCCGACTCTAATACT } \\
\text { AAACAGTATTAGAGTCGGGTCTCT }\end{array}$ \\
\hline
\end{tabular}


bioRxiv preprint doi: https://doi.org/10.1101/2022.02.15.480489; this version posted February 16, 2022 . The copyright holder for this

preprint (which was not certified by peer review) is the author/funder, who has granted bioRxiv a license to display the preprint in perpetuity. It is made available under aCC-BY-NC 4.0 International license.

\begin{tabular}{|c|c|}
\hline $\begin{array}{l}\text { Insertion of PIk4 N-terminal gRNA } \\
\text { sequence into the pCFD3 plasmid } \\
\text { (KI) }\end{array}$ & $\begin{array}{l}\text { GTCGCTAGCTATGTTATCCAATC } \\
\text { AAACGATTGGATAACATAGCTAG }\end{array}$ \\
\hline $\begin{array}{l}\text { Primers for the NEBuilder } \\
\text { assembly of the Sas- } 6 \text { N-terminal } \\
\text { donor plasmid }\end{array}$ & $\begin{array}{l}\text { GGGAGCGAGGATAGCTACTCGAATTCGATATCAAGCTTATCGATA } \\
\text { GGGAGCGAGGATAGCTACTCACTAGTTCTAGAGCGGCCGCCA } \\
\text { GAGTAGCTATCCTCGCTCCCTGGGTGGTCCACTGTTGTCCCGCTG } \\
\text { TGCTCACCATGATAGATCAGGCTCGTGAGAAAC } \\
\text { CTGATCTATCATGGTGAGCAAGGGCGAGGAGG } \\
\text { ACTATACGAGTCTTCTGATCCTGGAGGCCACATGAAGCCTGCTTTTTTGTACAAACT } \\
\text { GATCAGAAGACTCGTATAGTGCCAAAATGGACTATGGCAAGAG } \\
\text { GAGTAGCTATCCTCGCTCCCTGGCAGTGTGCTGCTTGAGGTCCTC }\end{array}$ \\
\hline $\begin{array}{l}\text { Primers for the NEBuilder } \\
\text { assembly of the Sas-6 C-terminal } \\
\text { donor plasmid }\end{array}$ & $\begin{array}{l}\text { TGGGTATTGCAAGCCGTTCTGAATTCGATATCAAGCTTATCGATA } \\
\text { TGGGTATTGCAAGCCGTTCTACTAGTTCTAGAGCGGCCGCCA } \\
\text { AGAACGGCTTGCAATACCCACGGCAACGCACAACGCGCGCATGCG } \\
\text { TAGGGATGGCCAATCTCTCCTTTAGAATGAGGATTTCTGAAAAGAG } \\
\text { GGAGAGATTGGCCATCCCTACTGGCAAAGAAAATCGGCGAGACCCAGCTTCTTGT } \\
\text { ACAAAGTG } \\
\text { ATAAGTAAAATTACTTGTACAGCTCGTCCATGC } \\
\text { GTACAAGTAATTTTACTTATTGTTAATGCATTTTTTC } \\
\text { AGAACGGCTTGCAATACCCACGGCGCTGTGTATCCATCTTGGCCGC }\end{array}$ \\
\hline $\begin{array}{l}\text { Primers for the NEBuilder } \\
\text { assembly of the Ana2 N-terminal } \\
\text { donor plasmid }\end{array}$ & $\begin{array}{l}\text { GAAACGGAGGATATGCTGCCGAATTCGATATCAAGCTTATCGATA } \\
\text { GAAACGGAGGATATGCTGCCACTAGTTCTAGAGCGGCCGCCA } \\
\text { GGCAGCATATCCTCCGTTTCGGGCCGTGAAATGCCCAGCGAGCTG } \\
\text { TGCTCACCATTTGGAGCGTATTTGTTTATATTTGC } \\
\text { TACGCTCCAAATGGTGAGCAAGGGCGAGGAGG } \\
\text { GGTAACATGTCTTCAGTCTCGGGAACAAACATGAAGCCTGCTTTTTGTACAAACT } \\
\text { GAGACTGAAGACATGTTACCCAGACTAGCGCCCAGGCCGAGT }\end{array}$ \\
\hline
\end{tabular}


bioRxiv preprint doi: https://doi.org/10.1101/2022.02.15.480489; this version posted February 16, 2022 . The copyright holder for this

preprint (which was not certified by peer review) is the author/funder, who has granted bioRxiv a license to display the preprint in perpetuity. It is made available under aCC-BY-NC 4.0 International license.

\begin{tabular}{|c|c|}
\hline & GGCAGCATATCCTCCGTTTCGGGGCAAGTATTTCAGCGCCAGCTCG \\
\hline $\begin{array}{l}\text { Primers for the NEBuilder } \\
\text { assembly of the Ana2 C-terminal } \\
\text { donor plasmid }\end{array}$ & $\begin{array}{l}\text { GCCGAAGCTGTTGTGAAAGCGAATTCGATATCAAGCTTATCGATA } \\
\text { GCCGAAGCTGTTGTGAAAGCACTAGTTCTAGAGCGGCCGCCA } \\
\text { GCTTTCACAACAGCTTCGGCTGGGGCCACAGAACTGGGTCCTCGC } \\
\text { TAGTAATTTAGGTTGATTCCTGATATTCTCCAAGTCCAGT } \\
\text { GGAATCAACCTAAATTACTAGACCCAGCTTTCTTGTACAAAGTG } \\
\text { GTACATGCTTTTACTTGTACAGCTCGTCCATGC } \\
\text { GTACAAGTAAAAGCATGTACAATGTTCGTTTTGTT } \\
\text { GCTTTCACAACAGCTTCGGCTGGGGACCCCTCTCAATATCAGGTGG }\end{array}$ \\
\hline $\begin{array}{l}\text { Primers for the NEBuilder } \\
\text { assembly of the AsI N-terminal } \\
\text { donor plasmid }\end{array}$ & $\begin{array}{l}\text { CCGAATATGAACACGCCAGGTATACTAGTTCTAGAGCGGCCGCCA } \\
\text { CCGAATATGAACACGCCAGGTATGAATTCGATATCAAGCTTATCGATA } \\
\text { CCTGGCGTGTTCATATTCGGCCAAGGTTTTCCAAATAGATCCCG } \\
\text { TGCTCACCATATTCAGCTAAGGGGACGCCACAAGCAT } \\
\text { TTAGCTGAATATGGTGAGCAAGGGCGAGGAGG } \\
\text { TTATCCCGGGAGTATTCATGAAGCCTGCTTTTTTGTACAAACT } \\
\text { CATGAATACTCCCGGGATAAGCCTCTTTCAGGGGGCGGA } \\
\text { CCTGGCGTGTTCATATTCGGCAATGCGGGCTTTCAAGTCAACG }\end{array}$ \\
\hline $\begin{array}{l}\text { Primers for the NEBuilder } \\
\text { assembly of the Asl C-terminal } \\
\text { donor plasmid }\end{array}$ & $\begin{array}{l}\text { CCAAAGGCAATGGTCACAGCTAAACTAGTTCTAGAGCGGCCGCCA } \\
\text { CCAAAGGCAATGGTCACAGCTAAGAATTCGATATCAAGCTTATCGATA } \\
\text { GCTGTGACCATTGCCTTTGGGGAAATTCAGTTGTTGAAACTCCA } \\
\text { AGAATGGCCGTTGCCCTTAGGCTTTCTATTTGAGTTGGTGATTG } \\
\text { CTAAGGGCAACGGCCATTCTGACCCAGCTTTCTTGTACAAAGTG } \\
\text { TTCCTAAGTCTTACTTGTACAGCTCGTCCATGC } \\
\text { GTACAAGTAAGACTTAGGAAAATATATATATGTATAT } \\
\text { GCTGTGACCATTGCCTTTGGGAGTGGATAGCATCCTCTGCCTG }\end{array}$ \\
\hline
\end{tabular}


bioRxiv preprint doi: https://doi.org/10.1101/2022.02.15.480489; this version posted February 16, 2022 . The copyright holder for this

preprint (which was not certified by peer review) is the author/funder, who has granted bioRxiv a license to display the preprint in perpetuity. It is made available under aCC-BY-NC 4.0 International license.

\begin{tabular}{|c|c|}
\hline $\begin{array}{l}\text { Primers for the NEBuilder } \\
\text { assembly of the Sas-4 C-terminal } \\
\text { donor plasmid }\end{array}$ & $\begin{array}{l}\text { CCAAGTATTAGAGTCGGGTCTCTACTAGTTCTAGAGCGGCCGCCA } \\
\text { CCAAGTATTAGAGTCGGGTCTCTGAATTCGATATCAAGCTTATCGATA } \\
\text { GACCCGACTCTAATACTTGGCAGTGAGAAGGAGCAGCGAAACT } \\
\text { TGGGTCGTATTTAGCATAGTCTGTGTCCATTATGAGCT } \\
\text { ACTATGCTAAATACGACCCAGCTTTCTTGTACAAAGTG } \\
\text { AGACCCGACTTTACTTGTACAGCTCGTCCATGC } \\
\text { GTACAAGTAAAGTCGGGTCTCTGCTTCCGTTG } \\
\text { GACCCGACTCTAATACTTGGTGTTCGCTGCATTCTTGTTGAGTT }\end{array}$ \\
\hline $\begin{array}{l}\text { Primers for the NEBuilder } \\
\text { assembly of the PIk4 N-terminal } \\
\text { donor plasmid }\end{array}$ & $\begin{array}{l}\text { CCCGATTGGATAACATAGCTAGCACTAGTTCTAGAGCGGCCGCCA } \\
\text { CCCGATTGGATAACATAGCTAGCGAATTCGATATCAAGCTTATCGATA } \\
\text { AGCTATGTTATCCAATCGGGGTGTGAGAGTCCAAGGTTGTCTG } \\
\text { TGCTCACCATAGCTAGCCTTTTTTCTGTAGACTTAC } \\
\text { AAGGCTAGCTATGGTGAGCAAGGGCGAGGAGG } \\
\text { AACGCTCTGTTACTGAGCATGAAGCCTGCTTTTTTGTACAAACTT } \\
\text { ATGCTCAGTAACAGAGCGTTTGGAGAAACAATTGAGGTG } \\
\text { AGCTATGTTATCCAATCGGGTACTGCTAGCAAATGTTATGATTCC }\end{array}$ \\
\hline Screening primers inside $m N G$ & $\begin{array}{l}\text { CCCGTCAGGGTAGGGCAGGTAC } \\
\text { GAAGACCGAGCTGAAGCACTCCA }\end{array}$ \\
\hline Screening primers for $m N G$-Sas- 6 & $\begin{array}{l}\text { CTCCCCTATATCCGCTGGTTGGA } \\
\text { CACATACCTTCTCTTTGTTTCCCT }\end{array}$ \\
\hline Screening primers for Sas-6-mNG & $\begin{array}{l}\text { CAGCATGCTGGAAGCCTCCCAC } \\
\text { CAGCAGATTTCCGATTTCCACCC }\end{array}$ \\
\hline Screening primers for $m N G$-Ana 2 & $\begin{array}{l}\text { CGCCGAGGAAGAGCTGCAGCTG } \\
\text { CGCCCCCAGGCGCATATCCTTC }\end{array}$ \\
\hline Screening primers for Ana2-mNG & $\begin{array}{l}\text { CCTCGTGCTGCACCCACCTTCG } \\
\text { CCATCCCCTGTTCCCAGTCGAC }\end{array}$ \\
\hline
\end{tabular}


bioRxiv preprint doi: https://doi.org/10.1101/2022.02.15.480489; this version posted February 16, 2022 . The copyright holder for this

preprint (which was not certified by peer review) is the author/funder, who has granted bioRxiv a license to display the preprint in perpetuity. It is made available under aCC-BY-NC 4.0 International license.

\begin{tabular}{|c|c|}
\hline Screening primers for $m N G$-Asl & $\begin{array}{l}\text { CTTTGATGCGCAAAGTTGGAAACG } \\
\text { CGAAGCGACTGTTTGCTCCAAATA }\end{array}$ \\
\hline Screening primers for Asl-mNG & $\begin{array}{l}\text { GCGATAACCTTTCAGACATGCTAG } \\
\text { GGAGAGTCCCTGAACACGAACGT }\end{array}$ \\
\hline Screening primers for Sas-4-mNG & $\begin{array}{l}\text { GCAGGCGCATGTCTCGGCACAG } \\
\text { CTCTGATCTGGCAACGCCAGGC }\end{array}$ \\
\hline Screening primers for $\mathrm{mNG}$ NIk4 & $\begin{array}{l}\text { TCATTGACGTGTGTGAGAGTCCAA } \\
\text { CAAATGTACATTGTAAATTCCTGAAT }\end{array}$ \\
\hline $\begin{array}{l}\text { Primers for the insertion of the } \\
\text { ana } 2 \text { gRNA sequence into the } \\
\text { pCFD4 plasmid (KO); for } \\
\text { generation of ana } 2^{\Delta a}\end{array}$ & $\begin{array}{l}\text { TATATAGGAAAGATATCCGGGTGAACTTCGGCAGCATATCCTCCGTTTCGTTTTAGA } \\
\text { GCTAGAAATAGCAAG } \\
\text { ATTTTAACTTGCTATTTCTAGCTCTAAAACAAGCTGTTGTGAAAGCATGTCGACGTTA } \\
\text { AATTGAAAATAGGTC }\end{array}$ \\
\hline $\begin{array}{l}\text { Primers for the insertion of the } \\
\text { ana } 2 \text { gRNA sequence into the } \\
\text { pCFD4 plasmid (KO); for } \\
\text { generation of ana } 2^{\Delta b}\end{array}$ & $\begin{array}{l}\text { TATATAGGAAAGATATCCGGGTGAACTTCGCCGTTTCGGGAACAAACATTGTTTTAG } \\
\text { AGCTAGAAATAGCAAG } \\
\text { ATTTTAACTTGCTATTTCTAGCTCTAAAACGCCGAAGCTGTTGTGAAAGCGACGTTA } \\
\text { AATTGAAAATAGGTC }\end{array}$ \\
\hline $\begin{array}{l}\text { Primers for the screening of the } \\
\text { ana } 2 \text { knock-out deletions }\end{array}$ & $\begin{array}{l}\text { CTGTTCTCAGCTGGAGTCGGAGTCTCTGC } \\
\text { TCGCCTTCGGAACGGACTTTGCGCAGTGC }\end{array}$ \\
\hline $\begin{array}{l}\text { Primers for the amplification of } \\
\text { the DEST vector containing the } \\
\text { ana } 2 \text { promoter and C-terminal } \\
\text { mNG }\end{array}$ & $\begin{array}{l}\text { GAAGCTGTTGGACCCAGCTTTCTTGTACAAAGTG } \\
\text { GAACAAACATTTGGAGCGTATTTGTTTATATTTGCC }\end{array}$ \\
\hline $\begin{array}{l}\text { Primers for the amplification of } \\
\text { the ana } 2 \text { gene and its mutant } \\
\text { forms without Stop codon }\end{array}$ & $\begin{array}{l}\text { TACGCTCCAAATGTTTGTTCCCGAAACGGAGGAT } \\
\text { AAGCTGGGTCCAACAGCTTCGGCTGGTTCCTGA }\end{array}$ \\
\hline $\begin{array}{l}\text { Primers for the amplification of } \\
\text { the DEST vector containing the } \\
\text { ana } 2 \text { promoter }\end{array}$ & $\begin{array}{l}\text { GCTGTTGTGACCGCGGTGGCGGCCGTCTAGAA } \\
\text { GAACAAACATTTGGAGCGTATTTGTTTATATTTGCC }\end{array}$ \\
\hline
\end{tabular}


bioRxiv preprint doi: https://doi.org/10.1101/2022.02.15.480489; this version posted February 16, 2022 . The copyright holder for this

preprint (which was not certified by peer review) is the author/funder, who has granted bioRxiv a license to display the preprint in perpetuity. It is made available under aCC-BY-NC 4.0 International license.

\begin{tabular}{|c|c|}
\hline $\begin{array}{l}\text { Primers for the amplification of } \\
\text { the ana } 2 \text { gene and its mutant } \\
\text { forms with Stop codon }\end{array}$ & $\begin{array}{l}\text { TACGCTCCAAATGTTTGTTCCCGAAACGGAGGAT } \\
\text { GCCACCGCGGTCACAACAGCTTCGGCTGGTTCC }\end{array}$ \\
\hline $\begin{array}{l}\text { Primers for the reintroduction of } \\
\text { ana2's intron }\end{array}$ & $\begin{array}{l}\text { TGTATGAAAAGAATCCAATAAAACATCCTTCCTAGCAGGTAGACGCTTGTCTCCCATT } \\
\text { ATTGGATTCTTTTCATACAGATTCAACGTACGCACCTTGATTGGTGGTCAGAATATCG } \\
\text { C }\end{array}$ \\
\hline
\end{tabular}

Table S3: Selected model and anomalous subdiffusion parameter $\alpha$ for all proteins measured with FCS

\begin{tabular}{|c|c|c|}
\hline Protein & Diffusion model & Anomolous subdiffusion parameter \\
\hline$m N G$ & $\begin{array}{l}1 \text { diffusing species, } 1 \text { dark state of the } \\
\text { fluorophore (triplet state) }\end{array}$ & 0.75 \\
\hline$d N G$ & $\begin{array}{l}1 \text { diffusing species, } 1 \text { dark state of the } \\
\text { fluorophore (triplet state) }\end{array}$ & 0.85 \\
\hline Asl-mNG & $\begin{array}{l}1 \text { diffusing species, } 2 \text { dark states of the } \\
\text { fluorophore }\end{array}$ & 0.75 \\
\hline$m N G-S a s-6$ & $\begin{array}{l}1 \text { diffusing species, } 2 \text { dark states of the } \\
\text { fluorophore }\end{array}$ & 0.80 \\
\hline Sas-6-mNG & $\begin{array}{l}1 \text { diffusing species, } 2 \text { dark states of the } \\
\text { fluorophore }\end{array}$ & 0.80 \\
\hline Sas-4-mNG & $\begin{array}{l}1 \text { diffusing species, } 2 \text { dark states of the } \\
\text { fluorophore }\end{array}$ & 0.80 \\
\hline$m N G-A n a 2$ & $\begin{array}{l}1 \text { diffusing species, } 2 \text { dark states of the } \\
\text { fluorophore }\end{array}$ & 0.80 \\
\hline Ana2-mNG & $\begin{array}{l}1 \text { diffusing species, } 2 \text { dark states of the } \\
\text { fluorophore }\end{array}$ & 0.80 \\
\hline eAna2-mNG/+ & $\begin{array}{l}1 \text { diffusing species, } 2 \text { dark states of the } \\
\text { fluorophore }\end{array}$ & 0.80 \\
\hline eAna2( $\triangle C C)-m N G /+$ & $\begin{array}{l}1 \text { diffusing species, } 2 \text { dark states of the } \\
\text { fluorophore }\end{array}$ & 0.85 \\
\hline
\end{tabular}


bioRxiv preprint doi: https://doi.org/10.1101/2022.02.15.480489; this version posted February 16, 2022. The copyright holder for this preprint (which was not certified by peer review) is the author/funder, who has granted bioRxiv a license to display the preprint in perpetuity. It is made available under aCC-BY-NC 4.0 International license.

\begin{tabular}{|l|l|l|}
\hline eAna2(ASTAN)-mNG/+ & $\begin{array}{l}1 \text { diffusing species, 2 dark states of the } \\
\text { fluorophore }\end{array}$ & 0.85 \\
\hline eAna2-mNG & $\begin{array}{l}1 \text { diffusing species, 2 dark states of the } \\
\text { fluorophore }\end{array}$ & 0.85 \\
\hline eAna2(12A)-mNG & $\begin{array}{l}\text { 1 diffusing species, 2 dark states of the } \\
\text { fluorophore }\end{array}$ & 0.80 \\
\hline eSas-6-GFP & $\begin{array}{l}\text { 1 diffusing species, 2 dark states of the } \\
\text { fluorophore }\end{array}$ & 0.75 \\
\hline
\end{tabular}




\section{Materials and Methods References}

Alvarez-Rodrigo, I., T.L. Steinacker, S. Saurya, P.T. Conduit, J. Baumbach, Z.A. Novak, M.G. Aydogan, A. Wainman, and J.W. Raff. 2019. Evidence that a positive feedback loop drives centrosome maturation in fly embryos. elife. 8:1-31. doi:10.7554/eLife.50130.

Aydogan, M.G., T.L. Steinacker, M. Mofatteh, Z.M. Wilmott, F.Y. Zhou, L. Gartenmann, A. Wainman, S. Saurya, Z.A. Novak, S.-S. Wong, A. Goriely, M.A. Boemo, and J.W. Raff. 2020. An Autonomous Oscillation Times and Executes Centriole Biogenesis. Cell. 181:1566-1581.e27. doi:10.1016/j.cell.2020.05.018.

Aydogan, M.G., A. Wainman, S. Saurya, T.L. Steinacker, A. Caballe, Z.A. Novak, J. Baumbach, N. Muschalik, and J.W. Raff. 2018. A homeostatic clock sets daughter centriole size in flies. Journal of Cell Biology. 217:1233-1248. doi:10.1083/jcb.201801014.

Baumbach, J., Z.A. Novak, J.W. Raff, and A. Wainman. 2015. Dissecting the Function and Assembly of Acentriolar Microtubule Organizing Centers in Drosophila Cells In Vivo. PLoS Genetics. 11:1-22. doi:10.1371/journal.pgen.1005261.

Cottee, M.A., N. Muschalik, S. Johnson, J. Leveson, J.W. Raff, and S.M. Lea. 2015. The homooligomerisation of both Sas- 6 and Ana2 is required for efficient centriole assembly in flies. eLife. 4:1-65. doi:10.7554/eLife.07236.

Gratz, S.J., F.P. Ukken, C.D. Rubinstein, G. Thiede, L.K. Donohue, A.M. Cummings, and K.M. Oconnor-Giles. 2014. Highly specific and efficient CRISPR/Cas9-catalyzed homologydirected repair in Drosophila. Genetics. 196:961-971. doi:10.1534/genetics.113.160713.

Lucas, E.P., and J.W. Raff. 2007. Maintaining the proper connection between the centrioles and the pericentriolar matrix requires Drosophila Centrosomin. Journal of Cell Biology. 178:725-732. doi:10.1083/jcb.200704081.

Novak, Z.A., P.T. Conduit, A. Wainman, and J.W. Raff. 2014. Asterless licenses daughter centrioles to duplicate for the first time in Drosophila embryos. Current Biology. 24:1276-1282. doi:10.1016/j.cub.2014.04.023.

Peel, N., N.R. Stevens, R. Basto, and J.W. Raff. 2007. Overexpressing Centriole-Replication Proteins In Vivo Induces Centriole Overduplication and De Novo Formation. Current Biology. 17:834-843. doi:10.1016/j.cub.2007.04.036.

Petrášek, Z., and P. Schwille. 2008. Precise Measurement of Diffusion Coefficients using Scanning Fluorescence Correlation Spectroscopy. Biophys J. 94:1437-1448. doi:10.1529/biophysj.107.108811.

Port, F., H.M. Chen, T. Lee, and S.L. Bullock. 2014. Optimized CRISPR/Cas tools for efficient germline and somatic genome engineering in Drosophila. Proceedings of the 
National Academy of Sciences of the United States of America. 111. doi:10.1073/pnas.1405500111.

Port, F., N. Muschalik, and S.L. Bullock. 2015. Systematic evaluation of Drosophila CRISPR tools reveals safe and robust alternatives to autonomous gene drives in basic research. G3: Genes, Genomes, Genetics. 5:1493-1502. doi:10.1534/g3.115.019083.

Raff, J.W., R. Kellum, and B. Alberts. 1994. The Drosophila GAGA transcription factor is associated with specific regions of heterochromatin throughout the cell cycle. EMBO Journal. 13:5977-5983. doi:10.1002/j.1460-2075.1994.tb06943.x.

Roberts, D.B. 1986. Drosophila - A Practical Approach. Biochemical Education. 15:162. doi:10.1016/0307-4412(87)90074-4.

Schwarz, G. 1978. Estimating the Dimension of a Model. The Annals of Statistics. 6:461-464. doi:10.1214/aos/1176344136.

Stevens, N.R., H. Roque, and J.W. Raff. 2010. DSas-6 and Ana2 Coassemble into Tubules to Promote Centriole Duplication and Engagement. Developmental Cell. 19:913-919. doi:10.1016/j.devcel.2010.11.010.

Tinevez, J.Y., N. Perry, J. Schindelin, G.M. Hoopes, G.D. Reynolds, E. Laplantine, S.Y. Bednarek, S.L. Shorte, and K.W. Eliceiri. 2017. TrackMate: An open and extensible platform for single-particle tracking. Methods. 115:80-90. doi:10.1016/j.ymeth.2016.09.016.

Waithe, D., M.P. Clausen, E. Sezgin, and C. Eggeling. 2016. FoCuS-point: Software for STED fluorescence correlation and time-gated single photon counting. Bioinformatics. 32:958-960. doi:10.1093/bioinformatics/btv687.

Wong, S.-S., Z.M. Wilmott, S. Saurya, F.Y. Zhou, K.-Y. Chau, A. Goriely, and J.W. Raff. 2021. Mother centrioles generate a local pulse of Polo/PLK1 activity to initiate mitotic centrosome assembly. 2021.10.26.465695. doi:10.1101/2021.10.26.465695. 